\title{
Annotated Bibliography of Scientific Research on Pygmy Rabbits Published from 1990 to 2020
}

Open-File Report 2022-1003 



\section{Annotated Bibliography of Scientific Research on Pygmy Rabbits Published from 1990 to 2020}

By Nathan J. Kleist, Joshua S. Willems, Heidi L. Bencin, Alison C. Foster, Laine E. McCall, Jennifer K. Meineke, Erin E. Poor, and Sarah K. Carter

Open-File Report 2022-1003 


\section{U.S. Geological Survey, Reston, Virginia: 2022}

For more information on the USGS - the Federal source for science about the Earth, its natural and living resources, natural hazards, and the environment—visit https://www.usgs.gov or call 1-888-ASK-USGS.

For an overview of USGS information products, including maps, imagery, and publications, visit https://store.usgs.gov/.

Any use of trade, firm, or product names is for descriptive purposes only and does not imply endorsement by the U.S. Government.

Although this information product, for the most part, is in the public domain, it also may contain copyrighted materials as noted in the text. Permission to reproduce copyrighted items must be secured from the copyright owner.

Suggested citation:

Kleist, N.J., Willems, J.S., Bencin, H.L., Foster, A.C., McCall, L.E., Meineke, J.K., Poor, E.E., and Carter, S.K., 2022, Annotated bibliography of scientific research on pygmy rabbits published from 1990 to 2020: U.S. Geological Survey Open-File Report 2022-1003, 75 p., https://doi.org/10.3133/ofr20221003.

ISSN 2331-1258 (online) 


\section{Acknowledgments}

Funding for this work was provided by the Bureau of Land Management. We are appreciative of the input and guidance of Travis Haby (BLM National Operations Center). We are very grateful to Janet Rachlow (University of Idaho) and Marjorie Matocq (University of Nevada, Reno) for providing independent peer review of the entire report and the summaries it contains. We thank the many authors of publications summarized within this annotated bibliography for providing input on the draft product summaries, including Jennifer Adams (University of Idaho), Janine Brown (Smithsonian Conservation Biology Institute), Meghan Camp (Washington State University), Natasha Carr, Amy Commendador (Idaho State University), Miranda Crowell (University of Nevada, Reno), Stephanie DeMay (Texas A\&M University), Patrick Drohan (Penn State University), Donald Duszynski (The University of New Mexico), Robert Edgel (Brigham Young University), Kristen Ellis (Colorado State University), Wendy Estes-Zumpf (Wyoming Game \& Fish Department), Wilfredo Falcón (University of Puerto Rico), Jennifer Forbey (Boise State University), Steve Germaine, Donald Grayson (University of Washington), Joan Hagar, Kenneth Halanych (Auburn University), Todd Katzner, Brian Kraatz (Western University of Health Sciences), Eveline Larrucea (University of Nevada, Reno), Randy Larsen (Brigham Young University), Timothy Lawes (Oregon State University), Richard Lyman (University of Missouri), Meghan Martin (San Diego Zoo Global), Charlotte Milling (University of Idaho), Lyndon Murray (California State Parks), Peter Olsoy (Boise State University), Xinzhu Pu (Boise State University), W. Douglas Robinson (Oregon State University), Mary Rowland (U.S. Forest Service), Dana Sanchez (Oregon State University), Lisa Shipley (Washington State University), Michele Skopec (Weber State University), Amanda Thimmayya (Wyoming Military Department), Amy Ulappa (Boise State University), Lisette Waits (University of Idaho), Tammy Wilson, and Bonnie Woods (University of Idaho). 



\section{Contents}

Acknowledgments ……...................................................................................................................

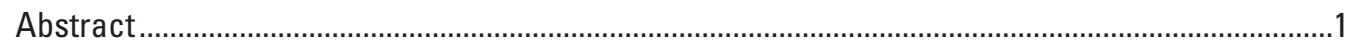

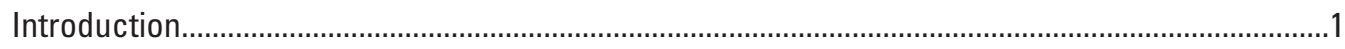

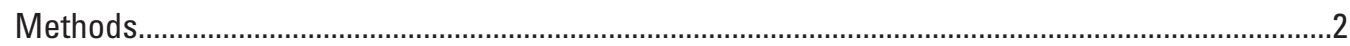

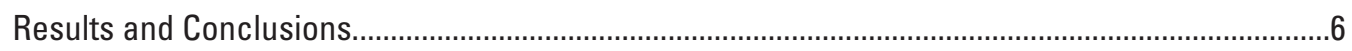

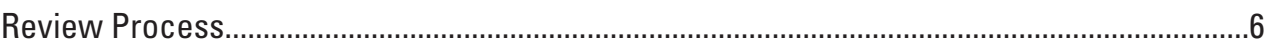

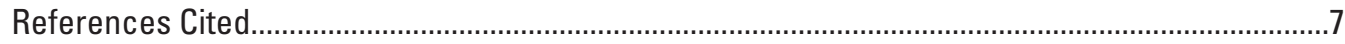

\section{Table}

1. Management categories and topics assessed for each product included in the

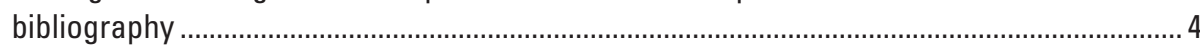

\section{Conversion Factors}

International System of Units to U.S. customary units

\begin{tabular}{|c|c|c|}
\hline Multiply & By & To obtain \\
\hline \multicolumn{3}{|c|}{ Length } \\
\hline meter $(\mathrm{m})$ & 3.281 & foot $(\mathrm{ft})$ \\
\hline kilometer $(\mathrm{km})$ & 0.6214 & mile (mi) \\
\hline meter (m) & 1.094 & yard (yd) \\
\hline \multicolumn{3}{|c|}{ Area } \\
\hline hectare (ha) & 2.471 & acre \\
\hline square kilometer $\left(\mathrm{km}^{2}\right)$ & 247.1 & acre \\
\hline hectare (ha) & 0.003861 & square mile $\left(\mathrm{mi}^{2}\right)$ \\
\hline square kilometer $\left(\mathrm{km}^{2}\right)$ & 0.3861 & square mile $\left(\mathrm{mi}^{2}\right)$ \\
\hline
\end{tabular}

Temperature in degrees Celsius $\left({ }^{\circ} \mathrm{C}\right)$ may be converted to degrees Fahrenheit $\left({ }^{\circ} \mathrm{F}\right)$ as follows: ${ }^{\circ} \mathrm{F}=\left(1.8 \times{ }^{\circ} \mathrm{C}\right)+32$. 


\title{
Abbreviations
}

\author{
BLM Bureau of Land Management \\ B.P. before present (years before 1950, in thousands of years) \\ DNA deoxyribonucleic acid (genetic code) \\ GPS Global Positioning System \\ HMAs Habitat Management Areas \\ USGS U.S. Geological Survey \\ PCR polymerase chain reaction \\ REA Rapid Ecoregional Assessments \\ ROW right of way \\ URL uniform resource locator
}




\section{Species Names}

\begin{tabular}{|c|c|}
\hline Common Name & Scientific Name \\
\hline American pika & Ochotona princeps Richardson \\
\hline $\begin{array}{l}\text { Appalachian cottontail } \\
\text { and Robinson }\end{array}$ & Sylvilagus obscurus Chapman, Cramer, Deppenaar, \\
\hline big sagebrush & Artemisia tridentate Nutt. \\
\hline black-tailed jackrabbit & Lepus californicus Gray \\
\hline bluebunch wheatgrass & Pseudoroegneria spicata (Pursh) A. Love \\
\hline brush rabbit & Sylvilagus bachmani Waterhouse \\
\hline bushy-tailed woodrat & Neotoma cinerea Ord \\
\hline chisel-toothed kangaroo rat & Dipodomys microps Merriam \\
\hline cottontail rabbit & Sylvilagus species Gray \\
\hline coyote & Canis latrans Say \\
\hline dark kangaroo mouse & Microdipodops megacephalus Merriam \\
\hline desert cottontail & Sylvilagus audubonii Baird \\
\hline eastern cottontail & Sylvilagus floridanus J. A. Allen \\
\hline European brown hare & Lepus europaeus Pallas \\
\hline European rabbit & Oryctolagus cuniculus Linnaeus \\
\hline European rabbit & Oryctolagus cuniculus algirus Loche \\
\hline European rabbit & Oryctolagus cuniculus cuniculus Linnaeus \\
\hline flat-headed peccary & Platygonus compressus Leconte \\
\hline fleabane & Erigeron species L. \\
\hline greater red rock rabbit & Pronolagus crassicaudatus I. Geoffroy \\
\hline greater sage-grouse & Centrocercus urophasianus Bonaparte \\
\hline great basin pocket mouse & Perognathus parvus Peale \\
\hline kangaroo rat & Dipodomys species Gray \\
\hline little sagebrush & Artemisia arbuscula Nutt. \\
\hline marsh rabbit & Sylvilagus palustris Bachman \\
\hline mole salamander & Ambystoma species Tschudi \\
\hline mountain cottontail & Sylvilagus nuttallii Bachman \\
\hline northern pocket gopher & Thomomys talpoides Richardson \\
\hline riparian brush rabbit & Sylvilagus bachmani riparius Orr \\
\hline sagebrush vole & Lemmiscus curtatus Cope \\
\hline saltbush & Atriplex species L. \\
\hline snowshoe hare & Lepus americanus Erxleben \\
\hline
\end{tabular}


swamp rabbit

Townsend's ground squirrel volcano rabbit

weasel

western harvest mouse

white-tailed jackrabbit

Wyoming big sagebrush yarrow

yellow-bellied marmot
Sylvilagus aquaticus Bachman

Spermophilus townsendii Bachman

Romerolagus diazi Ferrari-Perez

Mustela species Linnaeus

Reithrodontomys megalotis Baird

Lepus townsendii Bachman

Artemisia tridentata Nutt. spp. wyomingensis Beetle and Young Achillea millefolium $\mathrm{L}$.

Marmota flaviventris Audubon and Bachman

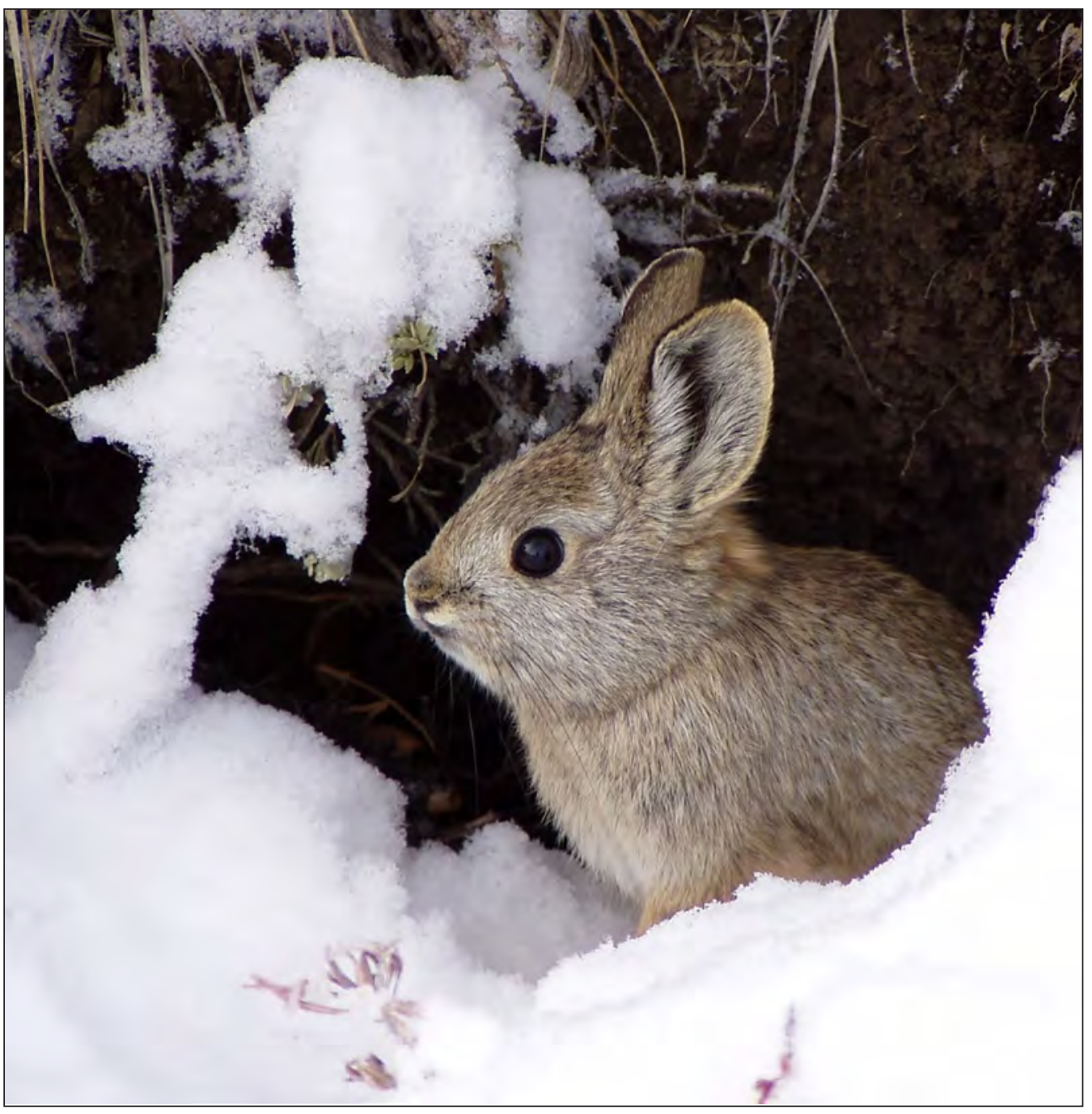

Photograph. H. Ulmschneider and R. Dixon, CC BY-NC 2.0, https://creativecommons.org/licenses/ by-nc/2.0/, this photograph was cropped from the original version. 


\title{
Annotated Bibliography of Scientific Research on Pygmy Rabbits Published from 1990 to 2020
}

\author{
By Nathan J. Kleist, ${ }^{1}$ Joshua S. Willems, ${ }^{1,2}$ Heidi L. Bencin, ${ }^{1}$ Alison C. Foster, ${ }^{1}$ Laine E. McCall, ${ }^{1}$ Jennifer K. \\ Meineke, ${ }^{1}$ Erin E. Poor, ${ }^{1,3}$ and Sarah K. Carter ${ }^{1}$
}

Abstract

Integrating recent scientific knowledge into management decisions supports effective natural resource management and can lead to better resource outcomes. However, finding and accessing scientific knowledge can be time consuming and costly. To assist in this process, the U.S. Geological Survey (USGS) is creating a series of annotated bibliographies on topics of management concern for western lands. Previously published reports introduced a methodology for preparing annotated bibliographies to facilitate the integration of recent, peer-reviewed science into resource management decisions. Therefore, relevant text from those efforts is reproduced here to frame the presentation. Sagebrush ecosystems throughout North America face management challenges including habitat loss and fragmentation. Brachylagus idahoensis (pygmy rabbits) are a sagebrush-obligate species that has experienced population declines and range contraction in recent decades. A disjunct population of pygmy rabbits in the Columbia Basin in Washington was listed as federally endangered in 2003. Due to their specialized habitat requirements and low dispersal ability, pygmy rabbits are a high priority for managers throughout their range. We compiled and summarized peerreviewed journal articles, data products, and formal technical reports (such as U.S. Forest Service General Technical Reports and U.S. Geological Survey Open-File Reports) on pygmy rabbits published between January 1, 1990 and December 31, 2020. We first conducted a structured search of three reference databases and three government databases using the phrase "pygmy rabbit" or "Brachylagus idahoensis." We refined the initial list of products by removing (1) duplicates, (2) products not written in English, (3) publications that were not focused on North America, (4) publications that were not published as research, data products, or scientific review articles in peer-reviewed journals or as formal technical reports, and (5) products for which pygmy rabbits were not a research focus or for which the study did not present new data or findings about pygmy rabbits. We summarized each product using a consistent structure (background, objectives, methods, location, findings, and implications) and identified the management topics (for example, captive breeding, habitat characteristics, and population estimates) addressed by each product. We also noted which publications included new publicly available geospatial data. The review process for this annotated bibliography included an initial internal colleague review of each summary, requesting input on each summary from an author of the original publication, and a formal peer review. Our initial searches resulted in 2,285 total products, of which 105 met our criteria for inclusion. Sensitive/rare wildlife, behavior or demographics, site-scale habitat characteristics, habitat selection, and effects distances or spatial scale were the management topics most commonly addressed. The online version of this bibliography, Science for Resource Managers, will be searchable by topic, location, and year; it will include links to each original publication, where available. The studies compiled and summarized here may inform planning and management actions that seek to maintain and restore sagebrush landscapes and associated native species across the western United States.

\section{Introduction}

Reviewing the best available science relevant to potential land management decisions and resource planning efforts is an important part of decision-making processes, helping to ensure that proposed actions and decisions are as effective as possible in meeting their stated goals. However, the number of scientific publications, the restrictive access to many publications and publication databases, and the time needed to perform a comprehensive search for the best available science on any given species or topic

\footnotetext{
${ }^{1}$ U.S. Geological Survey

${ }^{2}$ University of New Hampshire, Durham, N.H.

${ }^{3}$ The Nature Conservancy, Arlington, Va.
} 
can hinder resource managers' ability to access and consider this science in their decisions. To facilitate the integration of science into decision-making on western lands, the U.S. Geological Survey (USGS) has initiated a program of work to compile and summarize recent, peer-reviewed scientific literature on a series of resources and topics of management concern. These bibliographies are also available through the Science for Resource Managers web application (https://apps.usgs.gov/science-for-resource-managers). This tool provides easy access to hundreds of summaries of published science and data products on priority topics for western land managers. Users can search literature citations by management topic, location, and year and export a citable document including citations, summaries, and search parameters that can be appended to decision analyses.

Sagebrush steppe habitats across western North America have been declining due to a variety of stressors, including increases in fire frequency and intensity, invasive grasses, conifer expansions, grazing, fragmentation, and development (Thines and others, 2004; Larrucea and Brussard, 2008; Germaine and others, 2017b). Brachylagus idahoensis (Merriam and Stejneger, 1891) (pygmy rabbits) are the smallest rabbit species in North America and are considered sagebrush obligates - relying on relatively undisturbed patches of tall, dense sagebrush with deep soils that allow for the creation of burrows (Gabler and others, 2001; Purcell, 2006). In 2003, a distinct population segment of pygmy rabbits in the Columbia Basin in Washington was listed as endangered under the U.S. Endangered Species Act of 1973 (U.S. Fish and Wildlife Service, 2003). However, the U.S. Fish and Wildlife Service determined that listing the species as threatened or endangered throughout its range was not warranted due, in part, to a lack of documentation of direct impacts to current and historic pygmy rabbit populations (U.S. Fish and Wildlife Service, 2010). Regardless, ongoing threats to sagebrush ecosystems have continued to raise concerns that pygmy rabbit populations may be at risk (Pocewicz and others, 2014), and they remain a Species of Greatest Conservation Need throughout every state in their range (Germaine and others, 2020). To aid managers in using and synthesizing existing research to inform conservation and management efforts related to pygmy rabbits, we have compiled and summarized peer-reviewed literature and data products about pygmy rabbits published between January 1, 1990, and December 31, 2020.

Although this annotated bibliography does not replace the need to read the primary literature, we hope that this document will serve as a valuable reference for planners and managers responsible for making decisions about management of pygmy rabbits in the United States. Conservation and management of pygmy rabbits and their habitat are topics of ongoing scientific interest and management concern. As such, information in this document could be maintained and periodically updated to serve as a readily accessible, up-to-date resource for managers, planners, and policy makers who need a quick reference to recent peerreviewed science and data about pygmy rabbits.

\section{Methods}

Previous reports (Carter and others, 2018, 2020) introduced a methodology for conducting annotated bibliographies to facilitate the integration of recent, peer-reviewed science into resource management decisions. This and other annotated bibliography reports (for example, Poor and others, 2021) build on that method and apply it to new species and topics of management concern on western lands. Therefore, relevant text from Carter and others $(2018,2020)$ is reproduced herein to frame the presentation.

We conducted a systematic search of three citation indices (Web of Science, Scopus [accessed through the USGS Library], and Google Scholar [accessed through Publish or Perish (Harzing, 2007)]) and three federal government publication databases (USGS ScienceBase, USGS Publications Warehouse, and U.S. Department of Agriculture Forest Service [USFS] TreeSearch), using the search phrase "pygmy rabbit" or "Brachylagus idahoensis." We limited our search to products published from January 1, 1990 to December 31, 2020 to reflect the period of research focus on this species. We conducted our final search of all databases on January 27, 2021.

We refined the initial list of products returned from our searches in five ways. First, we removed duplicate items. Second, we removed products that were not written in English. Third, we removed publications that were not focused on North America because our aim was to provide managers with published products relevant to management of pygmy rabbits in the United States. Fourth, we excluded products that were not published as research, scientific review articles, or data products in peerreviewed journals or as formal technical reports; this exclusion helped ensure that all products presented final work that had gone through a structured peer-review process. Accordingly, we excluded editorial content (such as policy perspectives and commentaries), reports without evidence of a formal peer-review process (such as project and annual reports without a technical series or volume number and a permanent digital object identifier), conference abstracts, article preprints, articles in magazines (for which there was no reference to a peer-review process), articles in journals for which we could not find evidence of a comprehensive peer-review process, theses, dissertations, manuscripts not yet in press, and books, regardless of peer-review status. We also excluded reports that provided short summaries of research projects (often published when those projects were still in progress) that were intended for sharing with a broad public audience, as those research results would be published elsewhere once the studies were complete. Fifth, we retained only those publications for which pygmy rabbit was a main focus and 
for which the publication provided new data or findings about pygmy rabbits (for original research articles) or summarized or synthesized existing data about pygmy rabbits (for review papers). This was primarily accomplished by requiring that "pygmy rabbit" or "Brachylagus idahoensis" be present in the publication title, abstract, or author-supplied keywords (when available), and be present in the main text of the article. Publications removed using this step often only mentioned pygmy rabbit as a comparison species in the introduction or discussion. For very large publications (for example, hundreds of pages) covering multiple topics and species, we explicitly confined our summaries to pygmy rabbits and stated this in the summary itself. Similarly, for products such as paleontological publications or review papers that covered a broad range of species, some of which may not be extant in North America, summaries noted the full range of taxa covered in the publication but focused on those species that are of present-day management concern in North America. In a very small number of cases, a product did present new data or findings about pygmy rabbit but did not contain "pygmy rabbit" or "Brachylagus idahoensis" in the publication title, abstract, or author-supplied keywords. When such articles were identified we included them in the bibliography. We cannot guarantee that our search process identified all of these products, particularly for journals which do not have keywords or for which keywords are not indexed by Web of Science or Scopus. However, we made every effort to identify these articles through Google Scholar.

Google Scholar indexes a wider range of products than the other search engines and thus required slightly different methods. Many of the Google Scholar search results were not published products, were not written in English, or did not focus on systems in North America. Thus, for the Google Scholar search, we used R (R Core Team, 2020) to iteratively filter search results based on metadata provided by Google Scholar. We first removed products of type "citation" and then used identifiers in the uniform resource locator (URL) to remove products that were books, book chapters, patents, theses, or dissertations. We flagged products that included text in the abstract or title that was identified as a language other than English by either of two methods of language detection (Ooms, 2018, 2020). To ensure accurate results, we screened the abstracts and titles of flagged non-English products (Westgate, 2019) and reintegrated those that could not be reliably excluded by language recognition. We then excluded products from URLs that did not have a top-level domain of .com, .edu, .org, .us, .gov, .net, .ca, .uk, .mil, .au, or info. Finally, we removed articles from any journals known to not meet our standards for peer review. We manually filtered the remaining articles so that our final list of products to be included in the annotated bibliography met all criteria described above.

We parsed the final list of publications among our group of scientists to develop summaries of each product. The scientist to which the publication had been assigned then read each publication, summarized its contents using a consistent structure (background, objectives, methods, location, findings, implications), and identified the management topics it addressed (table 1). Location information included the State(s) where the study took place. If a study was based primarily in a captive facility, the location information was the State(s) of origin of the captive individuals. The site of the captive facility was not included as part of the location information in our product summaries but can be found in the original published product. If a study focused on individuals that were held, studied, or bred in captive facilities that were translocated and released as part of the study, the location information refers to the State(s) of the release location. Considerable information was distilled from each publication in developing the summary, and where some products may address data and findings of several species, these summaries may focus on the species of interest to the annotated bibliography. Thus, though we accurately represent each publication, there may be additional information in the original product that is not included in each summary. The target length for summaries was short (350 words or less); as a result, the source documents should always be consulted directly for more specific information (links to the original publication are provided for each summary whenever available). Each initial summary, and the associated original publication, was then reviewed by another scientist in the group to promote consistency between summaries and to provide an additional check on the accuracy of summaries in capturing key findings from the original publication. 
Table 1. Management categories and topics assessed for each product included in the bibliography.

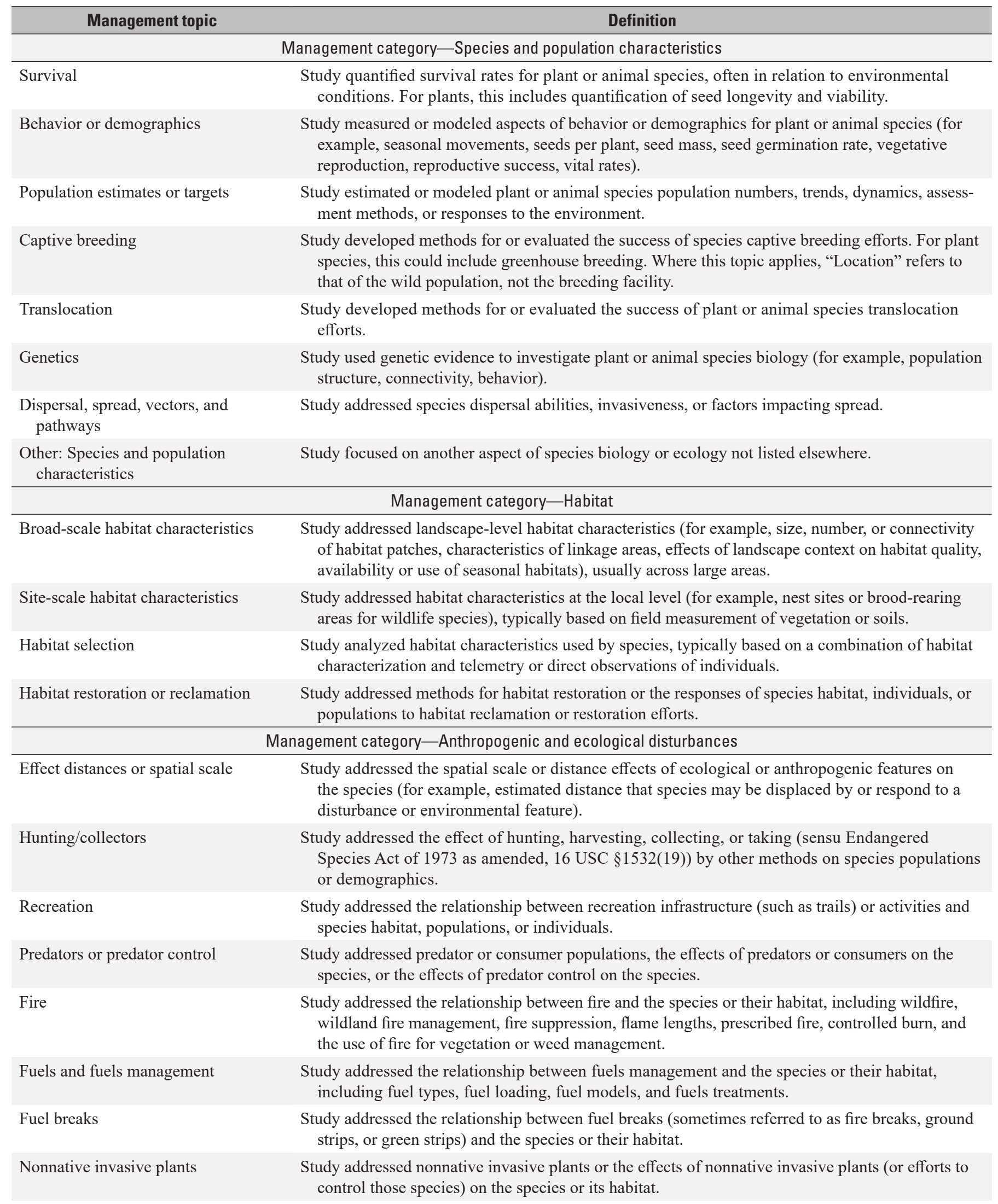


Table 1. Management categories and topics assessed for each product included in the bibliography.-Continued

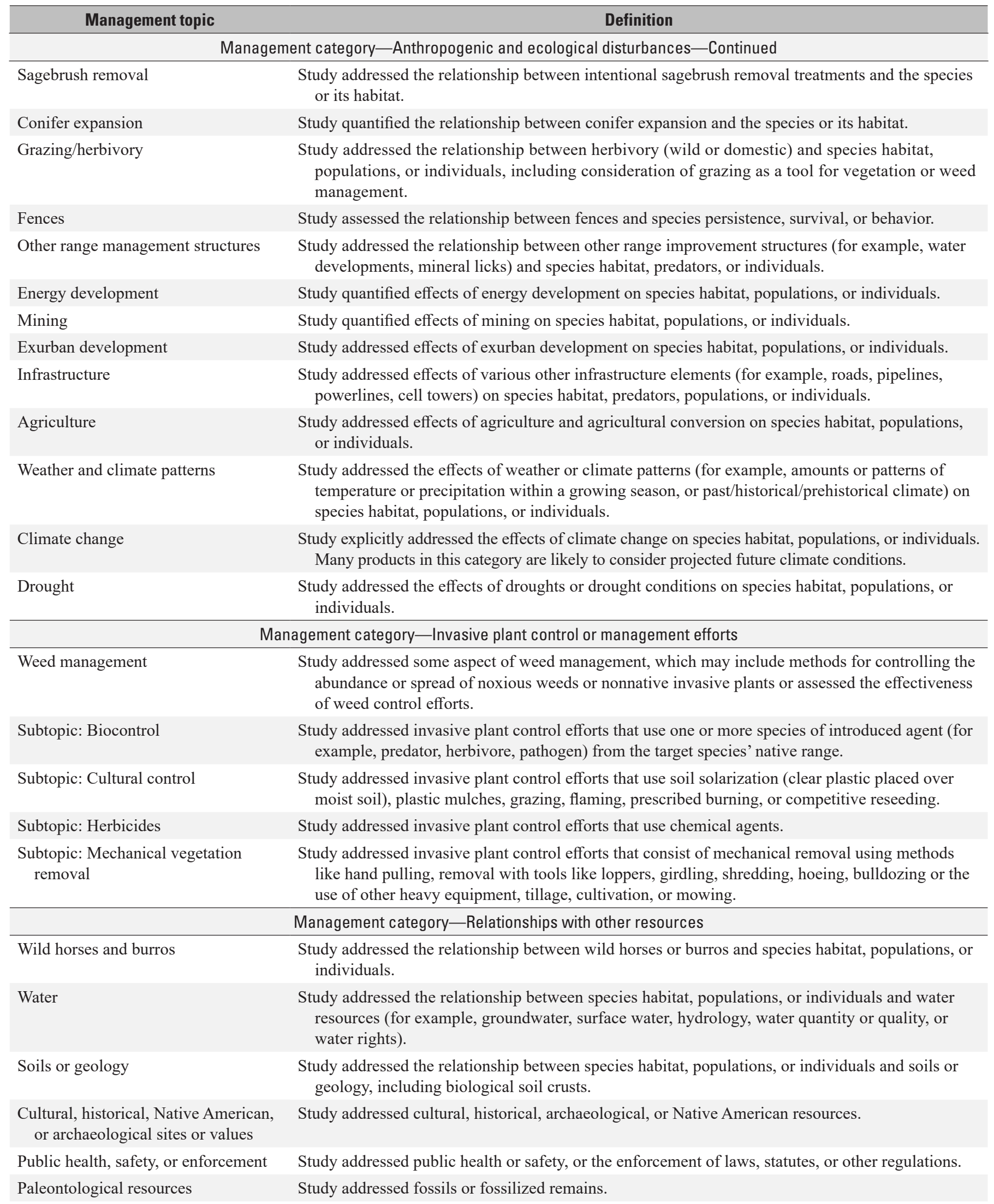


Table 1. Management categories and topics assessed for each product included in the bibliography.-Continued

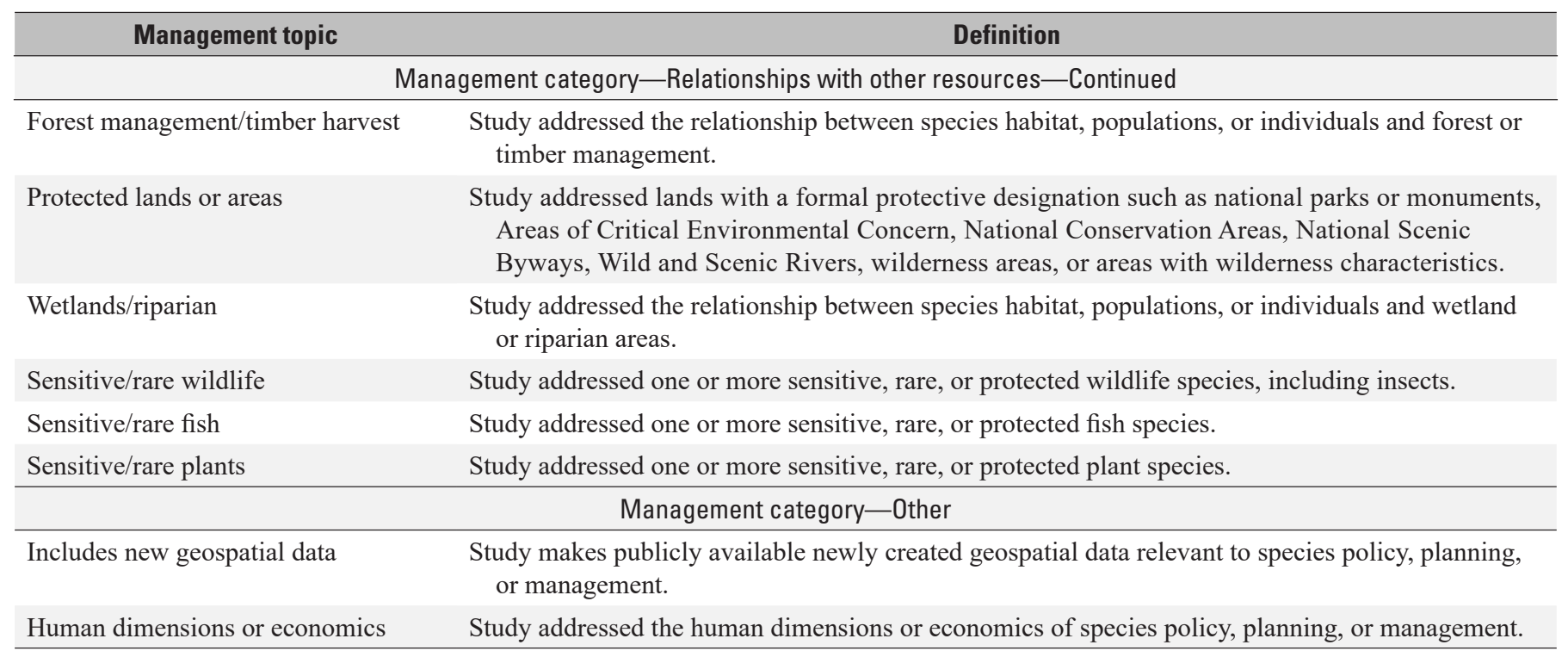

\section{Results and Conclusions}

In our initial searches, we identified a total of 2,285 products: 109 products from Web of Science, 106 from Scopus, 17 from the USGS Publications Warehouse, 112 from ScienceBase, 6 from the USFS TreeSearch, and 1,935 from Google Scholar (published products and unpublished products). For Google Scholar, using the automated filtering methods described in the Methods section above, we removed unpublished products and manually filtered 1,385 products based on the same inclusion criteria. After removing duplicates, publications not written in English, publications that were not peer reviewed, publications focused outside of North America, publications which did not present new data or focus on pygmy rabbit, we retained 105 peerreviewed published science and data products.

These 105 products addressed 30 of the 52 management topics. Every product addressed sensitive/rare wildlife. Forty-three products (41 percent) addressed behavior or demographics, 42 products ( 40 percent) addressed site-scale habitat characteristics, 37 products ( 35 percent) addressed habitat selection, 21 products ( 20 percent) addressed effects distances or spatial scale, 19 products (18 percent) addressed broad-scale habitat characteristics, 18 products (17 percent) addressed population estimates or targets, and 16 products (15 percent) addressed genetics. Two products included new, publicly available geospatial data. Of the addressed management topics, three products ( 3 percent) addressed conifer expansion and two products ( 2 percent $)$ addressed translocation. Nonnative invasive plants, water, wetlands, and sensitive/rare wildlife were addressed by one product (less than 1 percent) each.

These studies are the body of published (1990-2020), peer-reviewed articles, reports, and data products that are written in English and focus on pygmy rabbits in North America. We present this annotated bibliography as a resource for managers to more easily access and integrate this information into their decisions.

\section{Review Process}

In addition to our internal author-team review of each summary, we also requested input on each summary from one or more authors of the original peer-reviewed publication. Two independent reviewers conducted a formal review of the entire document, and the document was subsequently reviewed and approved by the USGS Bureau Approving Official. This process is consistent with USGS Fundamental Science Practices (Fundamental Science Practices Advisory Committee, 2011). 


\section{References Cited}

Carr, N.B., Garman, S.L., Walters, A., Ray, A., Melcher, C.P., Wesner, J.S., O’Donnell, M.S., Sherrill, K.R., Babel, N.C., and Bowen, Z.H., 2013, Wyoming Basin Rapid Ecoregional Assessment work plan: U.S. Geological Survey Open-File-Report 2013-1223, 58 p., accessed July 01, 2021, at https://doi.org/10.3133/ofr20131223.

Carter, S.K., Manier, D.J., Arkle, R.S., Johnston, A.N., Phillips, S.L., Hanser, S.E., and Bowen, Z.H., 2018, Annotated bibliography of scientific research on greater sage-grouse published since January 2015: U.S. Geological Survey Open-File Report 2018-1008, 183 p., accessed February 11, 2021, at https://doi.org/10.3133/ofr20181008.

Carter, S.K., Arkle, R.S., Bencin, H.L., Harms, B.R., Manier, D.J., Johnston, A.N., Phillips, S.L., Hanser, S.E., and Bowen, Z.H., 2020, Annotated bibliography of scientific research on greater sage-grouse published from 2015 to 2019: U.S. Geological Survey Open-File Report 2020-1103, 264 p., accessed February 11, 2021, at https://doi.org/10.3133/ofr20201103.

Fundamental Science Practices Advisory Committee, 2011, U.S. Geological Survey Circular 1367, 8 p.

Gabler, K.I., Heady, L.T., and Laundré, J.W., 2001, A habitat suitability model for pygmy rabbits (Brachylagus idahoensis) in southeastern Idaho: Western North American Naturalist, v. 61, no. 4, p. 480-489. [Also available at https://doi.org/10.1002/ecs2.1817.]

Germaine, S.S., Carter, S.K., Ignizio, D.A., and Freeman, A.T., 2017a, Analysis of land disturbance and pygmy rabbit occupancy values associated with oil and gas extraction in southwestern Wyoming, 2012: U.S. Geological Survey data release, accessed on February 11, 2021, at https://doi.org/10.5066/F7BR8QDD.

Germaine, S.S., Carter, S.K., Ignizio, D.A., and Freeman, A.T., 2017b, Relationship between gas field development and the presence and abundance of pygmy rabbits in southwestern Wyoming: Ecosphere, v. 8, no. 5, article e01817, 19 p. [Also available at https://doi.org/10.1002/ecs2.1817.]

Germaine, S.S., Assal, T., Freeman, A., and Carter, S.K., 2020, Distance effects of gas field infrastructure on pygmy rabbits in southwestern Wyoming: Ecosphere, v. 11, no. 8, article e03230, 16 p. [Also available at https://doi.org/10.1002/ecs2.3230.]

Harzing, A.W., 2007, Publish or Perish, version 7: Harzing, Research in International Management software release, accessed February 11, 2021, at https://harzing.com/resources/publish-or-perish.

Larrucea, E.S., and Brussard, P.F., 2008, Shift in location of pygmy rabbit (Brachylagus idahoensis) habitat in response to changing environments: Journal of Arid Environments, v. 72, no. 9, p. 1636-1643. [Also available at https://doi.org/10.1016/j.jaridenv.2008.04.002.]

Merriam, C.H., and Stejneger, L., 1891, Results of a biological reconnoissance of south-central Idaho: North American Fauna, no. 5, p. 1-133. [Also available at https://doi.org/10.5962/bhl.title.87015.]

Ooms, J., 2018, cld2 - Google's Compact Language Detector 2, R package version 1.2: R Project for Statistical Computing software release, accessed February 11, 2021, at https://CRAN.R-project.org/package=cld2.

Ooms, J., 2020, cld3: Google's Compact Language Detector 3, R package version 1.3: R Project for Statistical Computing software release, accessed February 11, 2021, at https://CRAN.R-project.org/package=cld3.

Pocewicz, A., Copeland, H.E., Grenier, M.B., Keinath, D.A., and Waskoviak, L.M., 2014, Assessing the future vulnerability of Wyoming's terrestrial wildlife species and habitats: Report prepared by The Nature Conservancy, Wyoming Game and Fish Department and Wyoming Natural Diversity Database, accessed February 11, 2021, at http://www.nature.org/media/wyoming/ wyoming-wildlife-vulnerability-assessment-June-2014.pdf.

Poor, E.E., Kleist, N.J., Bencin, A.C., Foster, A.C., and Carter, S.K., 2021, Annotated bibliography of scientific research on Ventenata dubia published from 2010 to 2020: U.S. Geological Survey Open-File Report 2021-1031, 26 p., accessed July 01, 2021, at https://doi.org/10.3133/ofr20211031.

Purcell, M.J., 2006, Pygmy rabbit (Brachylgus idahoensis) distribution and habitat selection in Wyoming: Laramie, Wyoming, University of Wyoming, Master's thesis, 161 p., 14 figs.

R Core Team, 2020, R: A language and environment for statistical computing, version 4.0.3: Vienna, Austria, R Foundation for Statistical Computing software release, accessed February 11, 2021, at https://www.R-project.org/. 
Thines, N.J.S., Shipley, L.A., and Sayler, R.D., 2004, Effects of cattle grazing on ecology and habitat of Columbia Basin pygmy rabbits (Brachylagus idahoensis): Biological Conservation, v. 119, no. 4, p. 525-534. [Also available at https://doi.org/10.1016/j.biocon.2004.01.014.]

U.S. Fish and Wildlife Service, 2003, Endangered and threatened wildlife and plants-Final rule to list the Columbia Basin distinct population segment of the pygmy rabbit (Brachylagus idahoensis): Federal Register, v. 68, no. 43, p. 10388-10409, accessed February 11, 2021, at https://www.federalregister.gov/articles/2003/03/05/03-5076/endangered-and-threatenedwildlife-and-plants-final-rule-to-list-the-columbia-basin-distinct.

U.S. Fish and Wildlife Service, 2010, Endangered and threatened wildlife and plants-12-month finding on a petition to list the pygmy rabbit as endangered or threatened, Proposed rule: 767: Federal Register, v. 75, no. 189, p. 60516-60561, accessed February 11, 2021, at https://www.govinfo.gov/content/pkg/FR-2010-09-30/pdf/2010-24349.pdf.

Westgate, M.J., 2019, revtools-An R package to support article screening for evidence synthesis: Research Synthesis Methods, v. 10, no. 4, p. 606-614, accessed February 11, 2021, at https://doi.org/10.1002/jrsm.1374. 


\title{
Annotated Bibliography of Scientific Research on Pygmy Rabbits Published from 1990 to 2020
}

\author{
Adams, J.R., Goldberg, C.S., Bosworth, W.R., Rachlow, J.L., and Waits, L.P., 2011, Rapid \\ species identification of pygmy rabbits (Brachylagus idahoensis) from faecal pellet \\ DNA: Molecular Ecology Resources, v. 11, no. 5, p. 808-812.
}

DOI: https://doi.org/10.1111/j.1755-0998.2011.03020.x

Background: Survey efforts for pygmy rabbits are difficult due to this species' cryptic behavior, and detection rates are often low within occupied habitats. Fecal pellet collection improves detection rate but complicates species identification due to habitat overlap with other lagomorphs. A new polymerase chain reaction (PCR) method provides an efficient and reliable method for species-specific identification of pygmy rabbits from pellet deoxyribonucleic acid (DNA), or the genetic code.

Objectives: The authors sought to (1) apply a fragment analysis test to distinguish among six sympatric leporid species and (2) evaluate the effect of sample collection season on DNA amplification success rates.

Methods: The authors extracted DNA from 142 fecal pellet samples of variable age collected in the field during July 2006 to February 2008 and 141 samples collected during November 2009 to February 2010. They used tissue samples to determine unique DNA fragments for each of the six leporid species (pygmy rabbit, mountain cottontail, desert cottontail, black-tailed jackrabbit, white-tailed jackrabbit, and eastern cottontail).

Location: Idaho, Montana

Findings: The authors correctly identified the species of origin for all pellet samples that were successfully amplified, and 80 percent of all samples were pygmy rabbit. They also identified eastern cottontail presence in Idaho and western Montana, and this species had not been previously known in this region. Fecal pellets collected during the winter were amplified more successfully than pellets collected at other times of the year.

Implications: The authors suggest that this multispecies PCR approach represents an accurate and efficient method to analyze fecal pellet DNA in lagomorphs. They state that accuracy of the species identification combined with the increased detection rate of fecal pellets could improve survey efforts for cryptic species, like pygmy rabbits. Finally, they claim this analysis technique is particularly useful when conducting noninvasive population surveys for pygmy rabbits in areas where closely related species are sympatric.

Topics: genetics; population estimates or targets; sensitive/rare wildlife

\section{Alldredge, J.R., and Dasgupta, N., 2003, Multiple comparisons in resource selection using logistic regression: Journal of Agricultural, Biological, and Environmental Statistics, v. 8, no. 3, p. 356-366.}

DOI: https://doi.org/10.1198/1085711032219

Background: Several methods have been proposed by biologists to assess habitat selection by animals among discrete habitat types. Here, the authors use data on pygmy rabbits to present a statistical method to determine the difference between resource use and continuous habitat attributes across discrete categories.

Objectives: The authors sought to develop a method to test the effects of continuous habitat characteristics across grazing treatments. 
Methods: In 1996, the authors surveyed for pygmy rabbit burrows at 102 plots across four different grazing treatments: ungrazed since 1957, grazed until 1997, grazed on a three-year rotation, and grazed during the vegetative dormant period. At each site, the presence or absence of pygmy rabbit burrows was recorded, and vegetation characteristics were measured. The authors used statistical methods and input from wildlife biologists to select percent canopy cover of fleabane and sagebrush as the continuous habitat characteristics to include in their model.

Location: Washington

Findings: The authors' results suggest that, compared to the ungrazed site, the probability of finding a burrow in the unit grazed until 1997 depended on sagebrush cover, the probability of finding a burrow in the unit grazed on a three-year rotation depended on sagebrush and fleabane cover, and the probability of finding a burrow grazed during the vegetative dormant period depended on fleabane cover. All treatments were different than the control, ungrazed unit.

Implications: Pygmy rabbit occurrence might be related to grazing management approaches, which, the authors suggest, might interact with site-level vegetation characteristics. They state that their results, showing a different relationship between fleabane and pygmy rabbit occurrence between grazed and control sites, suggest further investigation of the complex relationships between pygmy rabbits, habitat characteristics, and grazing.

Topics: site-scale habitat characteristics; habitat selection; grazing/herbivory; sensitive/rare wildlife

\section{Camp, M.J., Rachlow, J.L., Woods, B.A., Johnson, T.R., and Shipley, L.A., 2012, When to run and when to hide-The influence of concealment, visibility, and proximity to refugia on perceptions of risk: Ethology, v. 118, no. 10, p. 1010-1017.}

DOI: https://doi.org/10.1111/eth.12000

Background: Concealment (hiding cover) and visibility (what animals can see from their location) as provided by vegetation are important components of a prey species' ability to avoid predation and can impact the distance at which animals flee approaching predators. As predation is a leading cause of mortality for pygmy rabbits, understanding the role vegetation plays in avoiding predation and their perceptions of risk can help inform habitat management.

Objectives: The authors sought to examine the effects of (1) vegetation cover and (2) distance to burrows on pygmy rabbits' perceptions of predation risk.

Methods: The authors trapped and collared 49 pygmy rabbits at three study sites. During May to August 2010, they used radio-transmitter collars to relocate each animal. They measured the flight initiation distance (the distance at which pygmy rabbits fled from researchers), and the concealment and visibility conferred by vegetation at these sites. The authors used models to determine whether visibility, concealment, and other site-specific factors influenced the distance at which pygmy rabbits perceived a risk and fled researchers.

Location: Idaho, Montana

Findings: Pygmy rabbits demonstrated shorter flushing distances (perceived greater safety) when they were heavily concealed by vegetation and when they were near a burrow. There was no significant effect of visibility on perceived risk. There was a significant interaction between concealment and visibility, where increasing visibility reduced the effect of concealment.

Implications: The authors suggest that the influence of visibility on perceived risk may depend on types of threats and pygmy rabbit behavior at the time of a threat. The authors observed pygmy rabbits relying on sagebrush to avoid detection, and they suggest that fine-scale assessment of vegetation structure could help determine habitat suitability for pygmy rabbits. They state that thinning of vegetation could increase pygmy rabbit perception of predation risk or make them more susceptible to actual predation events. Finally, the authors suggest that both perceived and real predation risk can decrease habitat quality for pygmy rabbits.

Topics: behavior or demographics; site-scale habitat characteristics; habitat selection; effect distances or spatial scale; sagebrush removal; sensitive/rare wildlife 


\section{Camp, M.J., Rachlow, J.L., Woods, B.A., Johnson, T.R., and Shipley, L.A., 2013, Examining functional components of cover-The relationship between concealment and visibility in shrub-steppe habitat: Ecosphere, v. 4, no. 2, p. 1-14.}

DOI: https://doi.org/10.1890/ES12-00114.1

Background: Habitat features that provide concealment from predators may come at the cost of reduced visibility, limiting detection of approaching threats. Tradeoffs between concealment and visibility could play a role in habitat selection and predation risk but have not been well examined.

Objectives: The authors sought to (1) quantify cover on a continuous scale in sagebrush-steppe and grassland habitats and (2) investigate how properties of cover influenced habitat selection of pygmy rabbits.

Methods: The authors captured 49 pygmy rabbits across three sites during May to July 2010. They equipped each individual with a radio transmitter and tracked their location every two to three days through August 2010 for a total of five tracking occasions. They quantified terrestrial concealment and visibility at 4, 8, and 12 meters for each site where a rabbit was located plus two randomly selected, nearby points. They also measured aerial concealment and visibility at each location a rabbit was found and at the same two random points. They repeated these measurements at 60 randomly selected points at a grassland site where pygmy rabbits were not located. Finally, they measured shrub cover at each sagebrush site and used linear mixed-effects models to analyze the data.

Location: Idaho, Montana

Findings: The authors found that concealment increased and visibility decreased as distance from the survey point increased. They found an inverse relationship between concealment and visibility at all sites and distances for both aerial and terrestrial measurements. Finally, they found that pygmy rabbits selected for overall increased terrestrial and aerial concealment and reduced terrestrial and aerial visibility compared to random points but that these results varied between sites and across distances measured.

Implications: The authors suggest their results show a tradeoff is present between concealment and visibility, but this tradeoff does not exist in a 1:1 ratio. They note their study design replicated presence of a terrestrial predator and therefore their assessment of pygmy rabbits' response to aerial predators was limited. Finally, they state that better understanding of how pygmy rabbits are selecting habitat for concealment and visibility characteristics will help better assess habitat quality for management and restoration decisions.

Topics: behavior or demographics; site-scale habitat characteristics; habitat selection; predators or predator control; sensitive/ rare wildlife

\section{Camp, M.J., Rachlow, J.L., Shipley, L.A., Johnson, T.R., and Bockting, K.D., 2014, Grazing in sagebrush rangelands in western North America-Implications for habitat quality for a sagebrush specialist, the pygmy rabbit: The Rangeland Journal, v. 36, no. 2, p. 151-159.}

\section{DOI: https://doi.org/10.1071/RJ13065}

Background: Livestock grazing is an extensive human-use of western lands that managers must balance with specialized habitat requirements for species of conservation concern, like pygmy rabbits. Understanding the effects of grazing on pygmy rabbits is needed for successful management, because grazing is a pervasive use of their habitat that they did not evolve with.

Objectives: The authors sought to investigate how grazing by domestic cattle during spring and summer could alter (1) forage availability, (2) security cover, and (3) the rate of collapse of burrow entrances.

Methods: The authors measured habitat characteristics during spring and summer 2011 across 8 pasture areas with different grazing treatments: 4 pastures were grazed in summer, 2 were grazed in spring, and two had not been grazed for 10 years. The stocking density of cattle across the grazed pastures (10.37 Animal Units per hectare) was near the average for all regional Bureau of Land Management (BLM) allotments. The authors measured forage mass, estimated concealment and visibility, and mapped activity status and proximity of cattle hoof prints for all burrow entrances. They performed statistical analyses to test for an effect of grazing on habitat. 


\title{
Location: Montana
}

Findings: Forage mass of perennial grasses was affected by grazing, season, and the interaction between grazing and season, while the forage mass of perennial forbs was affected by grazing and season. Sagebrush forage mass was not influenced by grazing. There was no effect of grazing on concealment or visibility. Although cattle hoof prints were found near most burrow entrances, there was no significant impact on burrow entrance integrity. The authors note that long-term grazing exclosures trended towards increased forage mass, but the effect was not significant, and there was no effect of long-term grazing exclosure on sagebrush forage mass.

Implications: The authors suggest that current grazing management practices in this region might be compatible with pygmy rabbit persistence, if pygmy rabbits are not limited by forage mass of perennial grasses and forbs. They note that exclosures exceeding ten years may be needed to determine long-term effects of grazing.

Topics: site-scale habitat characteristics; habitat restoration or reclamation; grazing/herbivory; sensitive/rare wildlife

\section{Camp, M.J., Shipley, L.A., Johnson, T.R., Forbey, J.S., Rachlow, J.L., and Crowell, M.M., 2015, Modeling trade-offs between plant fiber and toxins-A framework for quantifying risks perceived by foraging herbivores: Ecology, v. 96, no. 12, p. 3292-3302.}

\author{
DOI: https://doi.org/10.1890/14-2412.1
}

Background: Animals select habitat patches for foraging by weighing costs and benefits associated with each patch. The probability that an animal selects a patch increases as costs, like predation risk, decrease, and benefits, like food quality, increase. The same framework can be applied to quantify trade-offs between the toxicity and nutritional value of plants within a food patch to inform predictions about habitat selection across scales.

Objectives: The authors sought to evaluate how two herbivores with different dietary tolerances for plant toxins and fiber content make decisions about habitat use when presented with foraging choices along a gradient of costs and benefits.

Methods: The authors captured wild pygmy rabbits and mountain cottontail rabbits and housed them in individual pens. They measured consumption to established food preferences in May to June 2013 by offering five to seven animals of each species food choices along a gradient of toxicity and fiber content. The authors then presented nine rabbits of each species the choice between a high fiber food or an herbivore pellet-based food with a toxic plant compound added. They gradually altered the fiber content and toxicity levels of each food choice to find the toxin concentration that led to equal consumption of food type and analyzed the results with a multi-step statistical approach.

Location: Idaho, Montana, Washington

Findings: Both species perceived fiber and toxicity as costly. However, pygmy rabbits selected high-toxin food more readily than mountain cottontail rabbits, and mountain cottontail rabbits selected high-fiber foods more readily than pygmy rabbits. The authors predicted that consumption of high-toxin, high-nutrient value sagebrush leaves, relative to consumption of low-toxin, low-nutrient value sagebrush stems or mature grass, was less risky for pygmy rabbits than mountain cottontail rabbits.

Implications: The authors suggest that differences in toxin versus nutrient trade-offs likely reflect the higher metabolic needs and more efficient detoxification of pygmy rabbits. They state that their results may be evidence of a mechanism that drives foraging differences and promotes coexistence of these two species within sagebrush habitats. The authors suggest that their model could be extrapolated to map a spatially explicit "landscape of risk" across potential habitats.

Topics: behavior or demographics; other: species and population characteristics; habitat selection; sensitive/rare wildlife 


\section{Camp, M.J., Shipley, L.A., Johnson, T.R., Olsoy, P.J., Forbey, J.S., Rachlow, J.L., and Thornton, D.H., 2017, The balancing act of foraging-Mammalian herbivores trade-off multiple risks when selecting food patches: Oecologia, v. 185, no. 4, p. 537-549.}

DOI: https://doi.org/10.1007/s00442-017-3957-6

Background: Animals make decisions about foraging patch use by weighing the competing risks associated with the patch, including predation risk and forage quality. Pygmy rabbits are obligate burrowers with a high tolerance for plant toxins, while mountain cottontails do not require burrows and are more tolerant of forage with high fiber content. The development of a model that includes multiple competing risks may improve predictions of food patch use in heterogenous and fragmented landscapes.

Objectives: The authors objectives were to (1) develop a model to predict risk and analyze tradeoffs between four competing risks (plant fiber, plant toxins, predator exposure, and refuge distance) associated with a food patch, and (2) use the model to make spatially explicit predictions of foraging-patch use by free-ranging herbivores.

Methods: The authors captured pygmy and mountain cottontail rabbits and performed paired choice trials from May 2013 to September 2015. Each rabbit was presented with two forage patches with differing levels of food toxins and fiber, security cover, and distance to burrow. They used 3 to 9 individuals of each species for every trial, with 913 total trials for pygmy rabbits and 675 total trials for mountain cottontails. They developed a statistical model of risk and applied it to a simulated landscape.

Location: Idaho, Montana, Washington

Findings: Both species had increased perceived risk when the food at a patch had higher toxin levels or lower nutritional value, but pygmy rabbits were more tolerant of toxins than mountain cottontails. Pygmy rabbits had increased perceived risk when burrows were further and predator exposure was higher, but mountain cottontails did not. For pygmy rabbits, the model predicted that large patches of Wyoming big sagebrush were the least risky and that the riskiness of all sagebrush patches decreased with size and increased with distance to burrow. The less toxic bluebunch wheatgrass was predicted as least risky for mountain cottontails regardless of exposure to predators or distance to burrow.

Implications: The authors suggest that these two species make different decisions about foraging based on perceived risk and the model they developed can help predict consequences of environmental change across fragmented landscapes.

Topics: behavior or demographics; broad-scale habitat characteristics; site-scale habitat characteristics; habitat selection; effect distances or spatial scale; grazing/herbivory; sensitive/rare wildlife

\section{Camp, M.J., Shipley, L.A., Milling, C.R., Rachlow, J.L., and Forbey, J.S., 2018, Interacting effects of ambient temperature and food quality on the foraging ecology of small mammalian herbivores: Journal of Thermal Biology, v. 71, p. 83-90.}

DOI: https://doi.org/10.1016/j.jtherbio.2017.10.021

Background: Forage quality and thermal conditions are important environmental factors for small mammalian herbivores. However, the interaction between food quality and temperature and the potential for these interactions to influence behavior and metabolic processes in small mammalian herbivores, like pygmy rabbits and mountain cottontails, has not been well studied.

Objectives: The authors sought to examine (1) the effect of temperature on selection of food with variable fiber and chemical defenses, (2) the effect of temperature on intake, digestion, and passage of food relative to fiber content, and (3) the effect of plant fiber and chemical defenses on resting metabolic rate.

Methods: The authors captured wild pygmy and mountain cottontail rabbits and performed a series of three experiments from December 2015 to April 2016. The authors provided six individuals of each species food with different fiber and chemical content across a range of temperatures. They then tested four combinations of fiber content and temperature on four individuals of each species. Finally, the authors tested the effects of plant fiber and chemical content on resting metabolic rate in four pygmy and six mountain cottontail rabbits. They performed statistical analyses and assessed species-specific differences.

Location: Idaho, Montana, Washington 
Findings: Both species increased overall consumption of food and selected higher fiber diets with colder temperatures. Pygmy rabbits ate more food with a higher proportion of chemical defenses regardless of temperature compared to cottontails, indicating that pygmy rabbits have a higher tolerance of plant chemical defenses than do cottontails. Digestibility was not impacted by temperature, but pygmy rabbits passed food more quickly in colder temperatures. High-fiber food was less digestible than the control. Ingestion of food with more chemical defenses did not affect either species' resting metabolic rate.

Implications: The authors suggest that high-fiber food could increase metabolic rate and provide body heat. In contrast to the authors' predictions and related work on small mammals, neither species selected food with higher chemical defenses with colder temperatures, which has been found in other small mammal species. The authors state that this study is evidence of the important interactions between temperature and diet selection and that a better understanding of these interactions will benefit conservation.

Topics: behavior or demographics; weather and climate patterns; sensitive/rare wildlife

\title{
Carr, N.B., and Melcher, C.P., eds., 2017, Wyoming Basin Rapid Ecoregional Assessment: (ver. 1.1, April 2017) U.S. Geological Survey Open-File Report 2015-1155, 896 p.
}

\author{
DOI: https://doi.org/10.3133/ofr20151155
}

Background: The Rapid Ecoregional Assessments (REAs) are broad-scale assessments that evaluate the potential effects of change agents on key ecological attributes of priority ecological communities and species. The REAs assess current risk, which provides a baseline for evaluating current status and future risks. Establishing priority management issues across multiple agencies helps foster stronger collaboration and cooperation in regional resource management. The Wyoming Basin REA evaluated 7 ecological communities and 14 species including pygmy rabbits. We have confined our summary to pygmy rabbits. A document outlining the goals and objectives for this paper was also published (Carr and others, 2013)

Objectives: The authors sought to assess and characterize (1) key ecological attributes and (2) the potential effects of a standard set of indicators on pygmy rabbit habitat within the Wyoming Basin.

Methods: The authors identified pygmy rabbits as a species of regional management concern and created a habitat model using known pygmy rabbit locations and a suite of vegetation and environmental variables. They assessed development levels and evaluated connectivity between habitat patches at local, landscape, and regional levels. Finally, they mapped the perimeters of all fires in pygmy rabbit habitat since 1980 .

Location: Colorado, Idaho, Montana, Utah, Wyoming

Findings: The model predicted 23,950 square kilometers $\left(\mathrm{km}^{2}\right)$ (13.4 percent) of the study area was suitable habitat for pygmy rabbits. They found $\sim 20$ percent of potential habitat was relatively undeveloped and 35 percent was highly developed, which coincided with results for sagebrush shrub habitat. Development resulted in fragmentation of pygmy rabbit habitat with only 7.8 percent of undeveloped areas occurring in patches greater than $100 \mathrm{~km}^{2}$ and no undeveloped patches greater than $1,000 \mathrm{~km}^{2}$. They found that baseline pygmy rabbit habitat was highly connected, but that development reduced structural connectivity at local, landscape, and regional scales. The amount of habitat burned each year was highly variable but typically small. Finally, they found that most pygmy rabbit habitat was managed by BLM and that habitat on BLM land was less developed than habitat on private land.

Implications: The authors suggest that because pygmy rabbit dispersal can be hindered by roads high levels of development could limit pygmy rabbit movement between relatively undeveloped areas. The authors also conclude that many of the areas of highest conservation potential for pygmy rabbits are in areas of projected sagebrush persistence under some climate change scenarios.

Topics: dispersal, spread, vectors, and pathways; broad-scale habitat characteristics; site-scale habitat characteristics; effects distances or spatial scale; fire; infrastructure; weather and climate patterns; climate change; sensitive/rare wildlife 


\title{
Commendador, A.S., and Finney, B.P., 2016, Holocene environmental change in the eastern Snake River Plain of Idaho, USA, as inferred from stable isotope analyses of small mammals: Quaternary Research, v. 85, no. 3, p. 358-370.
}

\author{
DOI: https://doi.org/10.1016/j.yqres.2016.03.008
}

Background: Analysis of stable carbon and nitrogen isotopes from animal bones can provide insights into past environments and previous climate change events. Small mammal remains are particularly valuable for obtaining information on past local climate and vegetation change due to their small size and restricted home ranges. Most prior studies have focused on examining the remains of large mammals with relatively little work being done using small mammal remains.

Objectives: The authors sought to examine stable carbon and nitrogen isotopes from the remains of three small mammal species with differing diets and life-history traits to make inferences about climatic conditions and changes over the Holocene period.

Methods: The authors examined the remains of three species (pygmy rabbit, northern pocket gopher, Townsend's ground squirrel) collected from the Wasden site in Idaho between 1965 and 1977. They examined a total of 159 mandibles from 78 pocket gopher and 81 pygmy rabbits, and 23 tibiae from ground squirrel individuals. They obtained the composition of stable nitrogen and carbon isotopes from each sample as well as collagen samples for radiocarbon dating. The authors then compared differences in carbon/nitrogen ratios between species and across depths from which the samples were excavated.

Location: Idaho

Findings: Pygmy rabbit samples were found to have significantly higher stable nitrogen and lower stable carbon values than ground squirrels. There was no difference between pocket gophers and pygmy rabbits. Pygmy rabbits also showed a significant relationship between both carbon and nitrogen and the depth at which the sample was excavated.

Implications: The authors state their results show differences in the feeding habits of the three species examined as well as changes in diet over time. They state that pygmy rabbit carbon and nitrogen values show tighter clustering than the other species and similar values to sagebrush, indicative of a dietary specialist. They claim that increases in stable nitrogen and carbon in pygmy rabbit samples during the Holocene likely reflect changes in isotopic compositions of their dominant food source, sagebrush, as a result of increasing aridity and (or) temperature in the region at that time. The authors also state that they are better able to track changes in plant diversity through the remains of generalist species than through specialist species.

Topics: broad-scale habitat characteristics; weather and climate patterns; paleontological resources; sensitive/rare wildlife

\section{Crawford, J.A., Anthony, R.G., Forbes, J.T., and Lorton, G.A., 2010, Survival and causes of mortality for pygmy rabbits (Brachylagus idahoensis) in Oregon and Nevada: Journal of Mammalogy, v. 91, no. 4, p. 838-847.}

DOI: https://doi.org/10.1644/09-MAMM-A-068.1

Background: Pygmy rabbits are a species of conservation concern, and it is believed that populations are declining throughout their range. Understanding factors that impact their survival is a critical step towards identifying conservation needs. Little is known, however, about monthly or annual survival of pygmy rabbits.

Objectives: The authors sought to (1) determine causes of pygmy rabbit mortality, and (2) investigate factors influencing their survival rates.

Methods: From June to September 2005, the authors captured 121 adult and juvenile pygmy rabbits from four study sites and fitted them with radio transmitters. They determined sex, age, reproductive condition, and weight of all rabbits. The authors tracked rabbits four to five times a week until April 2007 and examined dead rabbits to determine cause of death. As rabbits died, the authors trapped and radio-collared new individuals to maintain minimum sample sizes (15-20) for each site. Finally, they calculated survival rates for a 12-month interval and determined the influence of several variables on survival.

Location: Nevada, Oregon 
Findings: Throughout the course of the study, the authors radio-collared a total of 298 pygmy rabbits. They estimated an annual survival rate of $0.003-0.173$, and determined that survival rates varied between sexes, study sites, and month. Males had lower survival rates than females, and body condition did not influence survival. They also found that predation was the greatest cause of pygmy rabbit mortality, and that coyotes, birds of prey, and weasels were the most common identifiable predators. Patterns of predation varied by species and time of year.

Implications: The authors suggest that variation in survival among study sites may be due to differences in predator abundance, grazing management, and vegetation. They also suggest that a low overall survival rate may be due to declining populations, and that males may have had even lower survival rates because of their increased movement activities. They note that seasonal patterns for predator species, such as migration or overwintering, may impact pygmy rabbit survival patterns. Because pygmy rabbit populations can experience a large amount of variation annually, monitoring populations over time may provide more accurate estimates of survival.

Topics: survival; population estimates or targets; site-scale habitat characteristics; predators or predator control; grazing/ herbivory; sensitive/rare wildlife

\section{Crowell, M.M., Shipley, L.A., Camp, M.J., Rachlow, J.L., Forbey, J.S., and Johnson, T.R., 2016, Selection of food patches by sympatric herbivores in response to concealment and distance from a refuge: Ecology and Evolution, v. 6, no. 9, p. 2865-2876.}

DOI: https://doi.org/10.1002/ece3.1940

Background: When foraging, animals face a tradeoff between acquiring food and choosing resource patches that minimize predation risk. Characteristics of both prey and predator species could influence when, where, and how animals choose to forage while minimizing risk. Tradeoffs also exist with regards to habitat structure such as increased concealment versus increased visibility for predator detection.

Objectives: The authors sought to investigate differences in foraging site preference in pygmy rabbits and mountain cottontails by comparing (1) cover amount, (2) cover orientation, and (3) burrow distance.

Methods: Feeding trials were conducted May to November 2013 and January to July 2014 with 5 to 11 pygmy rabbits and six to nine mountain cottontails. The authors conducted three separate feeding experiments with food patches varying in percent cover or terrestrial and aerial concealment as well as distance from burrow or hutch. The authors then used models to investigate the effect that amount of cover, orientation of cover, and distance from burrow had on the proportion of food consumed at patches for both species.

Location: Idaho, Montana, Washington

Findings: Both species were found to prefer patches with greater overall cover. Pygmy rabbits showed preference for patches with more terrestrial cover while mountain cottontails preferred patches with more aerial cover. Pygmy rabbits showed a strong preference for patches closer to burrows while distance from burrow had no effect on mountain cottontail patch use.

Implications: The authors state that different life history traits influence the ways in which species utilize their habitat to limit predation risk. The authors suggest that pygmy rabbits' smaller size could lead to increased reliance on burrows for predator avoidance while larger mountain cottontails rely more on running away. Pygmy rabbits could be more vulnerable to terrestrial predators that are able to excavate burrows, explaining their preference for terrestrial cover, whereas mountain cottontails could be more vulnerable to aerial predation. The authors state that this difference helps promote niche separation between the two species in sagebrush habitats. They also state that species which use habitats differently could be affected by habitat alterations in contrasting ways.

Topics: behavior or demographics; site-scale habitat characteristics; habitat selection; sensitive/rare wildlife 


\section{Crowell, M.M., Shipley, L.A., Forbey, J.S., Rachlow, J.L., and Ketsey, R.G., 2018, Dietary partitioning of toxic leaves and fibrous stems differs between sympatric specialist and generalist mammalian herbivores: Journal of Mammalogy, v. 99, no. 3, p. 565-577.}

DOI: https://doi.org/10.1093/jmammal/gyy018

Background: Pygmy rabbits are dietary specialists that utilize sagebrush, a plant that is difficult or costly for other species to consume but highly abundant year-round. However, little is known about how generalist herbivores, such as the mountain cottontail, within the same environment rely on sagebrush for food, and whether they utilize the same parts of the plant as pygmy rabbits.

Objectives: The authors sought to examine how dietary tradeoffs between plant secondary metabolites and plant fiber might lead to dietary partitioning between pygmy rabbits and mountain cottontail rabbits.

Methods: In the winter of 2014, the authors surveyed three field sites to sample browsed sagebrush plants and collect fecal pellets from both species. From these samples, they determined the preferred stem diameter, diet composition, and proportion of plant parts consumed for both species. They also collected Wyoming big sagebrush and analyzed leaves and stems for plant secondary metabolites and fiber content. The authors measured dietary tradeoffs by conducting feeding trials to determine the proportion of leaves to stems consumed, and the stem diameter cropped by each species.

Location: Idaho, Montana

Findings: The authors found that sagebrush leaves and stems contained the same plant secondary metabolites, but leaves contained higher overall quantities. Both free-ranging and captive pygmy rabbits consumed more sagebrush overall, cropped smaller stem diameters, and consumed a greater proportion of leaves than cottontail rabbits. Using results from chemical analysis, the authors determined that pygmy rabbits consumed less fiber, but more protein and plant secondary metabolites than cottontail rabbits.

Implications: The authors suggest that cottontail rabbits are more tolerant to fiber while pygmy rabbits are more tolerant to plant secondary metabolites and that this difference creates dietary partitioning, allowing the two species to coexist in the same landscape. However, they note that they observed more overlap than expected and this may lead to resource competition during the winter when resources are scarce. The authors also suggest that the different foraging strategies of these species may influence sagebrush community dynamics over time.

Topics: behavior or demographics; grazing/herbivory; sensitive/rare wildlife

\section{Crowell, M.M., Shoemaker, K.T., and Matocq, M.D., 2020, Ideal conditions for increased trapping success of pygmy rabbits (Brachylagus idahoensis) across the Great Basin: Journal of Mammalogy, v. 101, no. 6, p. 1736-1749.}

DOI: https://doi.org/10.1093/jmammal/gyaa114

Background: Sagebrush ecosystems are some of the most at-risk areas in North America, and their continuing decline puts sagebrush-dependent wildlife at risk. Pygmy rabbits are especially suffering from loss of sagebrush ecosystems, but they are understudied, and accurate population monitoring is challenging. Live trapping pygmy rabbits is important for monitoring; however, an effective method for trapping pygmy rabbits with minimal bias remains unknown.

Objectives: The authors sought to determine how (1) trap orientation, (2) weather, and (3) individual age and (or) sex influences trap success in pygmy rabbits.

Methods: The authors trapped pygmy rabbits at 16 active sites during March to August in 2016 to 2018 . They placed traps wrapped in burlap at burrow systems in different orientations, including in active burrow entrances facing inward and outward, in inactive burrow entrances (at active burrow systems) facing outward, near burrow entrances facing inward, and freely placed traps in rabbit runways or in areas with large deposits of fecal pellets. The authors tagged, aged, and sexed captured rabbits and collected weather information during trapping periods. They used models to determine what abiotic factors led to ideal trapping conditions and configurations and if rabbit age or sex influenced trappability. 
Location: Nevada, Oregon

Findings: Throughout the study the authors trapped 711 individual pygmy rabbits. Trap orientation significantly affected trap success, with rabbits most likely to be captured in traps placed in active burrow entrances facing outwards. Freely placed traps in runways were the second most successful. Cloud cover and month also significantly affected trap success, with rabbits more likely to be captured on days with clear skies during June, July, and August. Neither rabbit age nor sex influenced trappability.

Implications: The authors recommend researchers monitoring pygmy rabbit populations place traps in burrow entrances and active runways as they found this can increase trap success. The authors suggest testing the use of double-door traps placed within active burrows, as this may lead to increased trap success. To increase efficiency, the authors recommend trapping pygmy rabbits from June to August and increasing trapping effort on overcast days.

Topics: behavior or demographics; population estimates or targets; weather and climate patterns; sensitive/rare wildlife

\title{
DeMay, S.M., Becker, P.A., Eidson, C.A., Rachlow, J.L., Johnson, T.R., and Waits, L.P., 2013, Evaluating DNA degradation rates in faecal pellets of the endangered pygmy rabbit: Molecular Ecology Resources, v. 13, no. 4, p. 654-662.
}

\author{
DOI: https://doi.org/10.1111/1755-0998.12104
}

Background: Fecal DNA can be a valuable tool for noninvasively sampling and monitoring rare wildlife populations, though DNA persistence can be a limiting factor. Degradation of DNA samples can be influenced by a variety of factors and can differ both between and within species depending on environmental conditions. Development of fecal DNA methods and analyses will benefit the monitoring of ongoing reintroductions of pygmy rabbits in Washington.

Objectives: The authors sought to determine how DNA degradation in pygmy rabbit fecal pellets was affected by (1) DNA type (mitochondrial or nuclear), (2) sample age, (3) amplified product length, (4) sex, and (5) weather.

Methods: The authors collected a total of 275 fresh fecal pellet samples from 14 pygmy rabbits ( 9 male, 5 female) from June 20 to August 17, 2011. They placed samples at the base of a sagebrush shrub for between 1 and 60 days. The authors then amplified mitochondrial DNA and nuclear DNA. They also measured weather data at the field site and collected tissue samples from each rabbit to assess fecal DNA accuracy. Finally, they also assessed genotyping errors using two methods.

Location: Washington

Findings: The authors found that analysis with mitochondrial DNA was successful more often than with nuclear DNA. The authors found that fresher samples had higher rates of success, but that mitochondrial DNA remained viable in pellets up to 21 days old and that there was no deleterious effect of storage length. They also found that DNA analyses run with shorter loci were more successful than those run with longer loci. Finally, the authors found that overall DNA analysis was more successful in females than males and less successful from pellets exposed to higher temperature days.

Implications: The authors state that their results provide critical information for developing passive monitoring methods for reintroducing pygmy rabbits. The authors claim passive genetic monitoring of pygmy rabbits is possible during summer months when samples are relatively fresh. They also state individual identification from fecal pellets is possible but more susceptible to DNA degradation from high temperatures. Finally, they recommend future work focus on examining DNA degradation during winter months.

Topics: genetics; sensitive/rare wildlife 


\title{
DeMay, S.M., Rachlow, J.L., Waits, L.P., and Becker, P.A., 2015, Comparing telemetry and fecal DNA sampling methods to quantify survival and dispersal of juvenile pygmy rabbits: Wildlife Society Bulletin, v. 39, no. 2, p. 413-421.
}

\author{
DOI: https://doi.org/10.1002/wsb.521
}

\begin{abstract}
Background: Efforts to recover the federally endangered population of Columbia Basin pygmy rabbits focus on captive breeding and the reintroduction of juvenile rabbits, but juveniles are difficult to study. Information about dispersal, survival and parentage of the reintroduced juveniles is used for evaluating recovery efforts. Two methods for monitoring survival and dispersal are tracking using telemetry and noninvasive genetic sampling of fecal samples.
\end{abstract}

Objectives: The authors sought to (1) compare the benefits, limitations, and costs of using telemetry versus noninvasive genetic sampling, and (2) measure survival and dispersal patterns of juvenile pygmy rabbits.

\begin{abstract}
Methods: The authors trapped 104 captive-bred juvenile pygmy rabbits between May and July 2012 from protected enclosures. They weighed, sexed, and took DNA samples from the rabbits to create a genetic database. They attached radio transmitters to 85 of the rabbits, released them, and located them 2 to 4 times a week using telemetry. The authors also collected fecal samples near pygmy rabbit burrows around the initial release area after fresh snowfall from December 2012 to January 2013, which they used to genetically identify individuals. Finally, the authors calculated dispersal distance, post-release mortality, and the costs per rabbit for both survey methods.
\end{abstract}

Location: Washington

Findings: Telemetry data provided the best detail for the dispersal patterns of juvenile pygmy rabbits during the first 2 weeks, but the transmitters fell off an average of 15 days after release. The authors found that the noninvasive genetic sampling technique was better for long-term studies on survival and dispersal than the telemetry data but did not provide detailed temporal information. They also found that noninvasive genetic sampling was more cost effective per rabbit than telemetry. The survival rate was at least 37 percent. They reported that the average dispersal distance was $204 \mathrm{~m}$ using telemetry and $445 \mathrm{~m}$ using noninvasive genetic sampling

Implications: The authors suggest that future studies on pygmy rabbit reintroduction select a monitoring technique based on the need for fine-scale temporal data or long-term data. They also suggest that the dispersal distances were larger in the noninvasive genetic sampling because the reintroduced pygmy rabbits continued to move and settle into the winter.

Topics: survival; behavior or demographics; population estimates or targets; genetics; dispersal, spread, vectors, and pathways; sensitive/rare wildlife

\section{DeMay, S.M., Becker, P.A., Waits, L.P., Johnson, T.R., and Rachlow, J.L., 2016, Consequences for conservation-Population density and genetic effects on reproduction of an endangered lagomorph: Ecological Applications, v. 26, no. 3, p. 784-795.}

DOI: https://doi.org/10.1890/15-0931

Background: Understanding the life history, including mating and reproduction, of rare and cryptic species like the federally endangered population of Columbia Basin pygmy rabbits can help improve conservation and management efforts. Challenges to understanding mating and reproduction in pygmy rabbits include variation caused by population density, effects of genetic drift, ancestry, and other factors.

Objectives: The authors sought to (1) measure reproductive output, (2) evaluate potential influences for reproductive output, and (3) increase knowledge of pygmy rabbit mating systems.

Methods: In 2012, researchers moved Columbia Basin pygmy rabbits from captive breeding facilities to natural breeding enclosures with wild translocated pygmy rabbits. There were 17 to 49 adult rabbits in each of the four enclosures during the study. Tissue samples for genetic analysis were collected from all adult rabbits. From 2012 to 2014, researchers caught kits produced in the breeding enclosures to take body measurements and tissue samples. The authors either moved kits into different enclosures to promote gene flow or released them into the wild. Through genetic testing, they assigned parentage to the kits and assigned kits to litters to test for multiple paternity. They used models to estimate the number of annual kits per male and female rabbit. 
Location: Washington

Findings: The authors observed that nearly all adult rabbits produced kits during the study. Female rabbits produced an average of 7.5 kits per year, and males produced an average of 7 kits per year. Both females and males bred with an average of three to four different mates per year. The authors found that litter size increased with multiple paternity, which was common and evident in 81 percent of litters. Reproductive output increased with genetic diversity, and males with Washington ancestry had higher reproductive output than males from other states. Reproductive output decreased with increases in population density for all rabbits. The authors also documented the first evidence of successful breeding by juvenile female pygmy rabbits.

Implications: The authors suggest that supplementing pygmy rabbit populations with translocated rabbits from other populations could increase genetic diversity and population size. The authors also hypothesize that males with Washington ancestry possibly had higher fitness due to locally adapted genes. They state the data indicate that individual genetic diversity, ancestry, and population density influence reproductive output in pygmy rabbits.

Topics: survival; behavior or demographics; captive breeding; translocation; genetics; sensitive/rare wildlife

\section{DeMay, S.M., Becker, P.A., Rachlow, J.L., and Waits, L.P., 2017, Genetic monitoring of an endangered species recovery-Demographic and genetic trends for reintroduced pygmy rabbits (Brachylagus idahoensis): Journal of Mammalogy, v. 98, no. 2, p. 350-364.}

DOI: https://doi.org/10.1093/jmammal/gyw197

Background: Fragmentation and loss of habitat led to the extirpation of genetically distinct pygmy rabbit populations from the Columbia Basin. Pygmy rabbits were reintroduced and contain ancestry from both the original Columbia Basin population and populations in other states, which were added to the breeding program to increase both the numbers and genetic diversity of reintroduced individuals. Genetic monitoring provides managers a tool to track both the demographic recovery and genetic diversity of these reintroduced populations.

Objectives: The authors sought to (1) monitor pygmy rabbit dispersal from release sites, (2) investigate relationships between survival and genetics following release into the wild, and (3) monitor ancestry of the Columbia Basin population within the reintroduced population.

Methods: The authors released 1,206 juvenile and adult pygmy rabbits onto 37 release sites within one study area on the Columbia Basin between late spring and summer from 2012 to 2014. The authors then surveyed release sites in the winter for active burrows and collected fecal pellets, which were used in genetic analysis. From these data, individuals were identified, and dispersal and survival rates were modeled.

Location: Washington

Findings: Neither age class nor juvenile weight were associated with dispersal distance. However, juveniles released later in the year had shorter dispersal distances. Post-release apparent survival to winter ranged from 10 to 39 percent each year. Larger, more genetically diverse juveniles that were released later in the year were more likely to survive. Models suggested that adults released later in the year also had higher rates of survival. The percentage of Columbia Basin ancestry was not related to survival. Fourteen wild-born pygmy rabbits (offspring of released rabbits) were detected during winter surveys.

Implications: The authors suggest overall increased genetic diversity, rather than ancestry, may positively influence survival of reintroduced pygmy rabbits. They state that survival benefits of releasing older juveniles must be weighed against the logistical challenges of holding them in crowded enclosures for a longer period of time. The authors suggest that extraction of DNA from fecal pellets is a useful tool for monitoring of pygmy rabbit population genetics, and that using genetic analyses in reintroduction efforts may provide important data to assess fitness of populations prior to release.

Topics: survival; behavior or demographics; population estimates or targets; captive breeding; translocation; genetics; sensitive/ rare wildlife 


\title{
Duszynski, D.W., Harrenstien, L. Couch, L., and Garner, M.M., 2005, A pathogenic new species of Eimeria from the pygmy rabbit, Brachylagus idahoensis, in Washington and Oregon, with description of the sporulated oocyst and intestinal endogenous stages: Journal of Parasitology, v. 91, no. 3, p. 618-623.
}

\author{
DOI: https://doi.org/10.1645/GE-435R
}

Background: The Columbia Basin population of pygmy rabbits is listed as federally endangered and is threatened with habitat loss throughout its range. Efforts to restore the population through captive breeding have had limited success, and some unexpected mortalities of juveniles from a parasitic disease were caused by a newly discovered parasite. Documenting and understanding this pathogen may make the captive breeding efforts more successful.

Objectives: The authors wanted to (1) determine how prevalent this parasite was at the captive breeding facility, (2) describe the life history and structure of its transmission stage, and (3) examine infected intestinal tissue to determine whether this new species might cause pathology in infected pygmy rabbits.

Methods: The authors collected 13 pygmy rabbit fecal samples in January 2003 and 14 pygmy rabbit fecal samples in July 2004 from a captive breeding facility. They tested the fecal samples for the presence of parasites, and they also collected tissue samples from three recently deceased rabbits, including two juveniles, to look for development stages of the parasite.

Location: Idaho, Washington

Findings Evidence of the newly described parasite, Eimeria brachylagia, was widespread among rabbits tested at the captive breeding facility. All three of the deceased rabbits also tested positive for the pathogen. The authors described and documented the new pathogen species and determined that it was found in the intestines.

Implications: The authors state that their data provide the first evidence of this pathogen in pygmy rabbits and link infection by this pathogen to the deaths of several captive individuals. The authors suggest that young pygmy rabbits may be particularly susceptible to this pathogen, which may negatively impact the Columbia Basin population. They noted that other leporid species become infected by similar parasites, but many do not develop symptoms. They recommend that future studies evaluate whether the pathology is exacerbated by captivity stressors or other aspects of pygmy rabbit natural history.

Topics: captive breeding; other: species and population characteristics; sensitive/rare wildlife

\section{Edgel, R.J., Larsen, R.T., Whiting, J.C, and McMillan, B.R., 2018, Space use, movements, and survival of pygmy rabbits in response to construction of a large pipeline: Wildlife Society Bulletin, v. 42, no. 3, p.488-497.}

DOI: https://doi.org/10.1002/wsb.908

Background: Sagebrush habitat in the western United States is declining due to habitat loss and fragmentation from energy development. Pygmy rabbits are sagebrush obligates and impacts from energy development, such as pipeline construction that fragments sagebrush habitat, are not well understood.

Objectives: The authors aimed to measure the effects of oil pipeline right-of-way (ROW) construction on pygmy rabbit (1) space use, (2) movement, and (3) survival.

Methods: Using active and passive trapping techniques the authors captured and radiomarked a total of 108 pygmy rabbits to maintain adequate sample sizes at a pipeline ROW and a control site between July and December 2011. They recorded sex and body condition of the rabbits, then documented their location multiple times a day for a month before and after pipeline construction. The authors collected location data for the rabbits three to four times a week in the summer and at least biweekly from September to April. The authors estimated home ranges and core areas for each rabbit, which they used to model space use and movements. The authors used several models to estimate survival in relation to construction disturbance and seasons.

Location: Utah 
Findings: The authors found that home ranges and core areas were over three times larger before construction than after and remained smaller for the duration of the study. Pygmy rabbits shifted their core areas away from the pipeline and had smaller core areas than those at the control site. Only 3 of 22 rabbits crossed the ROW for over 2 years post construction. The authors reported that survival rates were lowest in the winter and spring. The authors documented similar survival rates between the ROW construction site and the control site.

Implications: The authors suggest that energy development reduces habitat and decreases space use by pygmy rabbits, which can reduce their presence and abundance. The authors believe that the shift in space use is caused by avoidance behavior and more habitat edges, which may increase competition and reduce gene flow. To reduce construction impacts, the authors recommend avoiding destruction of active pygmy rabbit burrows, minimizing removal of mature sagebrush, and focusing restoration on connecting contiguous areas of sagebrush.

Topics: survival; behavior and demographics; effect distances or spatial scale; energy development; sensitive/rare wildlife

\section{Edgel, R.J., Pierce, J.L., and Larsen, R.T., 2014, Pygmy rabbit (Brachylagus idahoensis) habitat selection-Does sagebrush (Artemisia spp.) age influence selection?: Western North American Naturalist, v. 74, no. 2, p. 145-154.}

DOI: https://doi.org/10.3398/064.074.0201

Background: Habitat selection studies can inform managers about what management actions may be the most appropriate when managing areas for specific species. When managing habitat-obligate species, like the sagebrush-obligate pygmy rabbit, information about preferred habitat and habitat selection can be used to manage habitats for these species more effectively. Similar studies have been conducted throughout most of the pygmy rabbit range, but little is known about the habitat needs of pygmy rabbit populations in Utah.

Objectives: The authors sought to describe features of preferred pygmy rabbit habitat in Utah, specifically noting associations with sagebrush age.

Methods: The authors walked transects in known and potential pygmy rabbit habitat from May 2005 to August 2010 and determined pygmy rabbit presence by identifying active burrows and fresh pellets. The authors conducted habitat surveys, which included measurements of vegetative and horizonal cover, understory makeup, shrub density, and sagebrush features at pygmy rabbit burrows and compared them with randomly selected non-occupied points within pygmy rabbit habitat. The authors also measured distance to sagebrush edge, distance to human or predator-built structures (such as raptor nests), collected soil samples, and determined the status of sagebrush at each site. In addition, the authors performed spatial analysis of site characteristics such as aspect, elevation, and slope.

Location: Utah

Findings: The authors sampled 133 sites of which 72 had pygmy rabbits present. Horizontal cover, elevation, and the percent of the understory made up of shrubs and sagebrush were significantly higher at sites with pygmy rabbits, while the percent of dead sagebrush was significantly higher at sites without pygmy rabbits. The authors did not find a significant relationship between sagebrush age and pygmy rabbit presence.

Implications: The authors suggest that managers should protect and maintain healthy areas of sagebrush habitat to promote pygmy rabbit conservation. The authors also recommend more research into pygmy rabbit associations with temperature and climate to determine why they were associated with higher elevation areas.

Topics: site-scale habitat characteristics; habitat selection; effect distances or spatial scale; weather and climate patterns; sensitive/rare wildlife 


\section{Elias, B.A., Shipley, L.A., Sayler, R.D., and Lamson, R.S., 2006, Mating and parental care in captive pygmy rabbits: Journal of Mammalogy, v. 87, no. 5, p. 921-928.}

DOI: https://doi.org/10.1644/05-MAMM-A-335R1.1

Background: Mating and parental care are important parts of an animal's biology and are important to understand when managing wildlife populations. However, in secretive or rare species, like the pygmy rabbit, it can be challenging to collect information about reproductive behaviors. Captive populations can be used to study reproduction to better understand reproductive behaviors.

Objectives: The authors objectives were to study reproduction in a captive population of pygmy rabbits to better understand (1) mating behaviors and (2) parental care.

Methods: The authors used 94 captive pygmy rabbits for breeding between 2001 to 2005. The authors provided housing and husbandry to the rabbits that mimicked natural conditions. They began breeding attempts in mid-February to mid-March each year, introducing females to males until females became pregnant, and again after birth. The authors used cameras in rabbit pens to record and monitor breeding and mating behaviors on 24 occasions, from 2003 to 2004 . When females were pregnant and after birth, the authors monitored and recorded information about gestation, parturition, lactation, parental care, and milestones for the young.

Location: Idaho, Washington

Findings: The breeding season for pygmy rabbits started in mid-February and lasted until June. Across all years, 37 percent of mating sessions resulted in pregnancy. Captive female pygmy rabbits had low pregnancy rates, averaging 1.3 litters per year and 4.3 young per year. Unlike other rabbit species, pygmy rabbits dug separate natal burrows in which to give birth and house young. Once the young were inside, female pygmy rabbits backfilled the burrows and young remained inside for about two weeks. Young began eating solid food within two days of emergence, with parental care ending within two weeks.

Implications: The authors suggest natal burrows are essential for pygmy rabbit reproductive success and therefore land management practices, such as livestock grazing, could negatively impact pygmy rabbit reproduction by reducing vegetation and trampling burrows. They suggest future studies look specifically at the effects of livestock on pygmy rabbits. The authors also state that the need for burrows to successfully reproduce creates challenges for pygmy rabbit captive breeding projects.

Topics: survival; behavior or demographics; captive breeding; sensitive/rare wildlife

\section{Elias, B.A., Shipley, L.A., McCusker, S., Sayler, R.D., and Johnson, T.R., 2013, Effects of genetic management on reproduction, growth, and survival in captive endangered pygmy rabbits (Brachylagus idahoensis): Journal of Mammalogy, v. 96, no. 6, p. 1282-1292.}

DOI: https://doi.org/10.1644/12-MAMM-A-224.1

Background: Captive breeding has had low success rates for augmenting wild rabbit populations, and inbreeding depression may be a contributing factor. In some cases, such as the Columbia Basin pygmy rabbit, researchers may be forced to make trade-offs between preserving unique genetic lineages and avoiding inbreeding depression by incorporating new genetic variants into the population.

Objectives: The authors sought to determine how the Columbia Basin genome, in relation to environmental and demographic variables, contributes to (1) pregnancy, (2) litter size, (3) juvenile growth, and (4) survival in pygmy rabbits.

Methods: During 2001 to 2002, the authors captured 16 wild Columbia Basin pygmy rabbits for captive breeding. In 2003, they added four Idahoan pygmy rabbits to the breeding program to increase genetic diversity. Researchers bred rabbits from February to June each year and recorded data on pregnancy, body mass, health, and survival of adult and juvenile rabbits. Finally, they used models to determine the role of genetic, demographic, and environmental factors on pairing success, litter size, juvenile growth, and juvenile and adult survival.

Location: Idaho, Washington 
Findings: Over 10 years the authors bred 81 females and 70 males, producing 887 young. Pairing success decreased as Columbia Basin genetics in the male and female increased. Litter sizes were larger when females were older and had not had a litter the previous year. Juvenile growth was lower when parents had higher proportions of Columbia Basin genetics. Half of all juveniles survived to 15 days (to emergence from the natal burrows), and 43 percent of juveniles that survived past emergence lived to adulthood. Juvenile survival decreased in later years, with increased Columbia Basin genetics, and when birth occurred in colder temperatures earlier in the season. Disease was the primary cause of death for adults and juveniles.

Implications: The authors believe delaying breeding until later in the season may increase juvenile survival and that low genetic diversity may have played a role in high disease mortality. The authors found that even low levels of intercrossing Columbia Basin pygmy rabbits with Idahoan pygmy rabbits increased pregnancy, growth rate, and survival, and recommended that comparable captive breeding projects consider similar measures to increase species fitness.

Topics: survival; behavior or demographics; captive breeding; genetics; weather and climate patterns; sensitive/rare wildlife

\section{Ellis, K.S., Larsen, R.T., Whiting, J.C., Wilson, T.L., McMillan, B.R., 2017, Assessing indirect measures of abundance and distribution with remote cameras-Simplifying indices of activity at pygmy rabbit burrows: Ecological Indicators, v. 77, p. 23-30.}

DOI: https://doi.org/10.1016/j.ecolind.2017.01.041

Background: Pygmy rabbits are difficult to detect, and researchers often rely on indirect methods to quantify their activity at a site. Using remote cameras can improve survey methods that determine burrow activity based on the condition of fecal pellets and entrance holes and provide more accurate data for population monitoring programs.

Objectives: The authors' objectives were to (1) explore how environmental factors influenced photo rates, (2) use remote cameras to investigate how photo rates of pygmy rabbits related to commonly used burrow-activity classification schemes, and (3) investigate how long a camera needed to be set before detecting a pygmy rabbit.

Methods: Between March 2006 and August 2010, the authors located 405 pygmy rabbit burrow complexes across six sites within sagebrush-steppe habitat. They ranked activity at each burrow using two established ranking systems. They deployed a camera at a burrow entrance on each burrow complex for an average of 30 days to measure pygmy rabbit activity. They modeled the relationship between pygmy rabbit photo rates and ecological factors and assessed the relationship between burrow ranking systems and photo rates.

Location: Utah

Findings: Pygmy rabbit photo detection rates were positively associated with summer season, increasing distance to edge, and the presence of cottontail rabbits. Photo rates were lower when predators were detected at a site. The models suggested a two-rank (active versus inactive) system for classifying burrow activity was the most accurate ranking system. The number of days it took to detect pygmy rabbits varied by burrow activity level.

Implications: The authors state that pygmy rabbits require contiguous sagebrush habitat and using cameras can improve survey methods. The authors suggest that using a two-rank burrow classification system that classifies burrows as active or inactive can optimize field survey methods. They also recommend that cameras be used to confirm the presence of pygmy rabbits, as pygmy rabbits were detected at approximately 40 percent of the burrows ranked as inactive and were not detected at 11 percent of burrows ranked as active, based on the condition of burrow entrances and fecal pellets. When possible, the authors suggest deploying cameras for a minimum of two weeks.

Topics: behavior or demographics; site-scale habitat characteristics; habitat selection; sensitive/rare wildlife 


\title{
Estes-Zumpf, W.A., and Rachlow, J.L., 2007, Evaluation of radio-transmitters on juvenile rabbits-Application to the semifossorial pygmy rabbit (Brachylagus idahoensis): Western North American Naturalist, v. 67, no. 1, p. 133-136.
}

\author{
DOI: https://doi.org/10.3398/1527-0904(2007)67[133:EOROJR]2.0.CO;2
}

Background: Glue-on radio transmitters have been used with other mammal species and may serve as an alternative option to more frequently used expandable or breakaway collars, which may negatively influence juvenile pygmy rabbit survival. However, glue-on transmitters also have a potential risk of injury or may be lost.

Objectives: The authors sought to assess (1) retention time and (2) risk of injury of a glue-on radio-transmitter for juvenile pygmy rabbits.

Methods: The authors trapped 26 juvenile pygmy rabbits outside their natal burrows and tagged them with glue-on radio transmitters during May to July 2004. Rabbits were monitored twice-weekly for radio-transmitter status and recaptured 5 to 14 days post-transmitter attachment to re-glue the transmitter if needed. Rabbits were captured 1 to 4 times over the course of the experiment, for a total of 58 glue or glue-reinforcement events.

Location: Idaho

Results: Upon recapture, the majority of transmitters were found to be firmly attached, while a small fraction were knocked off or fell off. Only a few rabbits experienced minor injuries and there were no observations of mortality. Injuries included a small skin tear or minor loss of hair.

Implications: The authors suggest that glue-on radio-transmitters have the potential to serve as an effective and safe method for juvenile pygmy rabbits until growth rate slows and individuals can safely be fitted with radio collars. The authors state that radio-transmitters may be improved by using a faster-curing or more flexible glue. They state that retention was longer than previously observed in other studies and notable given the thin skin of pygmy rabbits and the type of habitat where they occur. The authors suggest that use of glue-on transmitters may support study of juvenile pygmy rabbit movement, survival, and natal dispersal.

Topics: other: species and population characteristics; sensitive/rare wildlife

\section{Estes-Zumpf, W.A., Rachlow, J.L., and Waits, L.P., 2008, Permanent genetic resources-Ten polymorphic microsatellite markers for the pygmy rabbit (Brachylagus idahoensis): Molecular Ecology Resources, v. 8, no. 2, p. 360-362.}

DOI: https://doi.org/10.1111/j.1471-8286.2007.01956.x

Background: Interest in pygmy rabbit population structure and genetic diversity is increasing, which is at least partially related to the listing of the Columbia Basin population as a Federally Endangered distinct population. Microsatellite markers help measure genetic diversity and are considered an important tool for effective conservation and management, yet markers specific to pygmy rabbits have not been identified.

Objectives: The authors sought to develop specific microsatellite markers for pygmy rabbits.

Methods: The authors isolated and developed ten microsatellite markers in pygmy rabbits. They extracted DNA from ear samples of 94 pygmy rabbits to assess variability of the 10 polymorphic loci. The authors measured heterozygosity and the number of alleles at each locus and assessed the utility of each marker for determination of population genetic structure.

Location: Idaho

Findings: The authors successfully developed primers of 10 microsatellite markers for pygmy rabbits. They observed sufficient polymorphism to determine genetic structure in pygmy rabbit populations at all but one locus.

Implications: The authors suggest that newly developed loci will increase the ability to identify genetic structure and gene flow in pygmy rabbits, which will have specific implications for the endangered Columbia Basin population.

Topics: genetics; sensitive/rare wildlife 


\section{Estes-Zumpf, W.A., and Rachlow, J.L., 2009, Natal dispersal by pygmy rabbits (Brachylagus idahoensis): Journal of Mammalogy, v. 90, no. 2, p. 363-372.}

DOI: https://doi.org/10.1644/08-MAMM-A-078.1

Background: Dispersal impacts population dynamics and gene flow. Natal dispersal, or dispersal following birth, is common and believed to occur over longer distances than other types of dispersal. Movement and dispersal of pygmy rabbits is not fully known, and no data exists for juvenile rabbits. However, it is expected that the pygmy rabbit's small size and reliance on sagebrush may result in shorter natal dispersal distances.

Objectives: The authors sought to determine the effects of sex, study year, age, date of emergence, body condition, and population density on dispersal frequency and distance of pygmy rabbits.

Methods: The authors attached glue-on radio transmitters, weighed, and recorded the sex of 61 juvenile pygmy rabbits immediately following emergence from burrows during May to July 2004 and 2005 at three study sites. Radio-tagged rabbits were initially located twice weekly and then every two weeks from mid-August onward. Using these data, they then used spatial analyses to create the following models: the effect of sex, study year, date of emergence, and body condition on dispersal frequency and distance; and the effect of rabbit burrow density and saturation on dispersal frequency and distance. Additionally, the authors monitored timing and cause of mortality.

Location: Idaho

Findings: Pygmy rabbits dispersed at a young age and females dispersed nearly three times as far as males. Rabbits dispersed rapidly as one-way movements through unfamiliar areas, rarely making exploratory movements around the natal area before dispersing. Most juvenile pygmy rabbits (85 percent) dispersed, however, none of the variables measured were strong predictors of dispersal frequency and presence of other rabbits did not appear to influence dispersal behavior. Mortality was high for both sexes and greatest during the first two months of dispersal; predation was the highest cause of mortality. No other factors measured by the authors were found to effect dispersal frequency or distance and dispersal did not affect survival.

Implications: The authors state that their results show rabbits dispersed farther than previously reported, meaning research may be needed on the fitness consequences of long-distance dispersal and managers may need to consider rabbit conservation at broader spatial extents. They claim creeks and rural highways may affect pygmy rabbit gene flow given that rabbits initially dispersed away from these features and no rabbits crossed rural highways. Additionally, the authors suggest that burrow density and saturation may be poor indicators of local population density. More research is needed to determine what triggers dispersal and settlement in juvenile pygmy rabbits.

Topics: survival; behavior or demographics; dispersal, spread, vectors, and pathways; habitat selection; sensitive/rare wildlife

\section{Estes-Zumpf, W.A., Rachlow, J.L., Waits, L.P., and Warheit, K.I., 2010, Dispersal, gene flow, and population genetic structure in the pygmy rabbit (Brachylagus idahoensis): Journal of Mammalogy, v. 91, no. 1, p. 208-219.}

DOI: https://www.doi.org/10.1644/09-MAMM-A-032R.1

Background: Pygmy rabbits are capable of dispersing long distances, but factors influencing connectivity among populations are not fully known. Genetic diversity is important to ensure population fitness, but fragmented landscapes can negatively influence gene flow. Genetic tools show promise as a method to understand dispersal behavior in mammals and how they may move through fragmented landscapes.

Objectives: The authors sought to study pygmy rabbits using genetic methods to assess (1) population genetic structure and gene flow across study sites separated by different distances and physical barriers and (2) natal dispersal by sex. 
Methods: The authors took genetic samples from 209 wild pygmy rabbits at the first site with 5 sample locations up to $13 \mathrm{~km}$ apart in 2002 to 2006, and from 40 rabbits at a second site with three sample locations 9 to $32 \mathrm{~km}$ apart in 2004 to 2005 . They removed individuals likely to be littermates and used laboratory techniques to amplify DNA and assess differences in genetic code at specific markers. They used statistical analyses to group individual pygmy rabbits into clusters with similar genetic structure. They also analyzed samples from 75 rabbits from the first site and 33 from the second site to assess population substructure. Finally, the authors used several different genetic analyses to determine if dispersal differed by sex.

Location: Idaho

Findings: The authors found relatively high levels of genetic diversity across at both sites; they observed moderate levels of heterozygosity within sites and multiple haplotypes at both sites. Genetic structure based on microsatellite data was low. Although genetic differentiation occurred among some sample locations within sites, levels were relatively low and sample locations within approximately $13 \mathrm{~km}$ had sufficient gene flow to constitute a single population based on genetic clustering. The authors found no evidence of sex-based dispersal or isolation by distance among individuals at either site.

Implications: The authors suggest that levels of gene flow among populations of pygmy rabbits is relatively high and occurs across greater spatial extents than previously thought. The authors state that low volume roads and streams did not appear to prevent gene flow, but that agriculture may have increased isolation, and acted as a complete barrier to gene flow between populations. Furthermore, the authors suggest that land-use change can affect movement and gene flow but that movement by breeding males may mediate gene flow.

Topics: behavior or demographics; genetics; dispersal, spread, vectors, and pathways; broad-scale habitat characteristics; effect distances or spatial scale; infrastructure; agriculture; sensitive/rare wildlife

\title{
Estes-Zumpf, W.A., Zumpf, S.E., Rachlow, J.L., Adams, J.R., and Waits, L.P., 2014, Genetic evidence confirms the presence of pygmy rabbits in Colorado: Journal of Fish and Wildlife Management, v. 5, no. 1, p. 118-123.
}

\author{
DOI: https://doi.org/10.3996/012013-JFWM-005R
}

Background: Pygmy rabbits are a species of concern in the western United States, and one of only two rabbit species in North America that dig their own burrows. Habitat for the species is fragmented and limited as pygmy rabbits rely on tall, dense sagebrush with deep soils for burrowing. Pygmy rabbits have not previously been documented in Colorado despite the presence of potential habitat and existing populations in nearby Wyoming.

Objectives: The authors sought to present the first known evidence of pygmy rabbits in Colorado.

Methods: The authors searched for burrows and fecal pellets potentially belonging to pygmy rabbits in areas of dense sagebrush and mounded microtopography at three sites in northwestern Colorado during July 2010. The authors marked global positioning system (GPS) locations of pellets and noted if pellets were found near burrows and whether pellets of other rabbit species were found nearby. Pellets thought to be from pygmy rabbits were sampled and submitted to a lab for species identification via genetic analyses.

Location: Colorado

Results: The authors collected 16 pellet samples thought to be from pygmy rabbits, and were able to extract DNA from 7 of the samples. The authors confirmed that all seven samples were from pygmy rabbits using two types of genetic markers, thus confirming occurrence of pygmy rabbits in Colorado. The identified pellet samples were from both juvenile and adult rabbits.

Implications: The authors state that this study serves as an example of the value in using noninvasive genetic sampling with field observations to identify species presence in an area. They claim the range of pygmy rabbits is larger than previously recognized or documented, leading to the possibility that other undocumented populations may exist. The authors suggest that pygmy rabbits likely occur in low densities in Colorado, and that their status may need to be assessed more thoroughly in the state to inform management and conservation efforts.

Topics: genetics; population estimates or targets; sensitive/rare wildlife 


\title{
Falcón, W., Goldberg, C.S., Waits, L.P., Estes-Zumpf, W.A., and Rachlow, J.L., 2011, First record of multiple paternity in the pygmy rabbit (Brachylagus idahoensis)-Evidence from analysis of 16 microsatellite loci: Western North American Naturalist, v. 71, no. 2, p. 271-275.
}

\author{
DOI: https://doi.org/10.3398/064.071.0214
}

Background: Rabbits and hares are generally considered to have polygamous (males breed with many females) and promiscuous (both males and females breed with multiple partners) mating systems. Several species have exhibited genetic evidence that more than one male can father offspring within a single litter (multiple paternity). Behavioral and ecological characteristics of male and female pygmy rabbits, such as overlapping home ranges and switching between burrow systems, provides opportunities for multiple paternity in pygmy rabbits, yet it has not been studied.

Objectives: The authors sought to (1) assess potential multiple paternity in pygmy rabbits using genetic markers and (2) determine the mother of each litter.

Methods: The authors extracted DNA from ear tissue from ten wild pygmy rabbits in two litters at two sites. To analyze extracted DNA, the authors amplified 16 genetic markers from pygmy rabbits ( 9 microsatellites) and European rabbits ( 7 microsatellites). The mother of one litter was unknown, so the authors assessed genotypes of seven adult females found near the burrow containing the litter to determine which one was the mother.

Location: Idaho

Findings: The authors found evidence of multiple paternity in both litters at multiple gene locations. The authors were better able to detect multiple paternity when they knew the maternal genotype.

Implications: The authors state that this study is the first documentation of multiple paternity in pygmy rabbits and the first evidence of potential promiscuity in pygmy rabbits. They suggest that multiple paternity may have served to maintain genetic diversity in historically fragmented free-ranging populations and that this trait may also support captive breeding programs.

Topics: genetics; sensitive/rare wildlife

\section{Gabler, K.I., Laundré, J.W., and Heady, L.T., 2000, Predicting the suitability of habitat in southeast Idaho for pygmy rabbits: The Journal of Wildlife Management, v. 64, no. 3, p. 759-764.}

\section{DOI: https://doi.org/10.2307/3802746}

Background: Unlike other leporids, pygmy rabbits rely heavily on big sagebrush for food. Pygmy rabbits have experienced a recent reduction in range, largely driven by habitat loss to agriculture, such that only 60 percent of shrub-steppe habitat remains in Washington. It is unknown how much habitat remains in other parts of pygmy rabbits' range.

Objectives: The authors sought to develop a predictive model to calculate how much suitable pygmy rabbit habitat remains in southeastern Idaho to identify areas of possible conservation focus.

Methods: The authors used GIS to create a map of potentially suitable pygmy rabbit habitat based on known locations of burrows located during surveys in winter 1994-95 and spring of 1996. They overlaid known burrow locations onto four different map layers: vegetation, surface geology, slope, and aspect. From this, they developed a map showing areas of suitable habitat within the study area. They tested the accuracy of their model by conducting surveys for pygmy rabbit sign during the summer of 1996 at 60 randomly selected locations, 30 in predicted habitat and 30 in predicted non-habitat.

Location: Idaho

Findings: A total of 101 burrows were located during the initial surveys. The model found that 23.4 percent of the study area was predicted to be suitable habitat for pygmy rabbits based on vegetation, geology, slope, and aspect characteristics. No sign of pygmy rabbits was detected at any of the non-habitat sites surveyed, whereas rabbits were detected at 17 of the 30 sites predicted to be habitat. 
Implications: The authors state that their results closely match those of previous small-scale studies and could allow mangers to concentrate survey efforts on areas of habitat most suitable for pygmy rabbits. They state that uncertainties in the model, such as the inability to differentiate different densities of sagebrush, could explain the lower success in predicting suitable habitat areas. Finally, the authors suggest that once seemingly suitable habitat has been identified, smaller scale analysis may be needed to identify areas that truly meet the habitat needs of pygmy rabbits.

Topics: broad-scale habitat characteristics; site-scale habitat characteristics; habitat selection; sensitive/rare wildlife

\section{Gabler, K.I., Heady, L.T., and Laundré, J.W., 2001, A habitat suitability model for pygmy rabbits (Brachylagus idahoensis) in southeastern Idaho: Western North American Naturalist, v. 61, no. 4, p. 480-489.}

\section{Persistent URL: https://jstor.org/stable/41717145}

Background: Pygmy rabbits are habitat specialists that prefer tall, dense stands of big sagebrush and soils that allow the construction of burrows. However, little is known about other preferred habitat variables. Understanding pygmy rabbit habitat requirements could help identify suitable habitat areas and inform management planning.

Objectives: The authors sought to (1) compare habitat characteristics between areas of use and non-use, (2) compare characteristics of burrow locations and surrounding areas to examine the scale at which pygmy rabbits are selecting habitat, and (3) compare habitats of occupied and unoccupied burrows.

Methods: The authors surveyed habitat characteristics on five different categories of plots: occupied burrow sites, unoccupied burrow sites, active areas, inactive areas, and nonuse areas. They took measurements on vegetative composition variables at 10 sites for each category except active areas for which they measured 3 sites. They also collected soil samples from points both near and away from burrows for particle size analysis.

Location: Idaho

Findings: The authors found that use and nonuse areas tended to differ the most. They found that nonuse areas had more canopy cover, taller shrubs, and more litter than active areas. They found that occupied burrows, inactive areas, and unoccupied burrows had greater sagebrush density, greater overall shrub coverage, and greater density of tall shrubs. They also found nonuse areas had less sandy soils with more silt and clay.

Implications: The authors suggest that pygmy rabbits have unique and identifiable habitat requirements. They also state that rabbits appear to be selecting for specific burrow sites within active areas, though they note that rabbits may be altering the environment around their burrows. The authors suggest that if pygmy rabbits are selecting burrow locations on a fine scale, there may be less suitable habitat than previously thought and even minor changes to these habitats could make areas unsuitable. Finally, the authors state that their proposed model could be used to identify areas of use and non-use and aid in preventing the loss of pygmy rabbit habitat when developing land use plans.

Topics: broad-scale habitat characteristics; site-scale habitat characteristics; habitat selection; soils or geology; sensitive/ rare wildlife

\section{Germaine, S.S., Assal, T., Freeman, A., and Carter, S.K., 2020, Distance effects of gas field infrastructure on pygmy rabbits in southwestern Wyoming: Ecosphere, v. 11, no. 8, article e03230, $16 \mathrm{p}$.}

DOI: https://doi.org/10.1002/ecs2.3230

Background: Sagebrush ecosystems have been and continue to be substantially altered by development. Oil and gas extraction has been shown to negatively impact sagebrush habitat and pygmy rabbit abundance. Current methods of gas field planning may inadvertently position infrastructure in suitable pygmy rabbit habitat. 
Objectives: The authors sought to assess (1) if well pads were more likely to be located within pygmy rabbit habitat, (2) if distance to gas field infrastructure affected rabbit presence and abundance, (3) the area within a gas field that was unaffected by development, and (4) the relationship between well pad locations and density and height of sagebrush.

Methods: The authors performed a series of spatial analyses using field surveys of pygmy rabbit abundance and presence in 120 plots across 4 gas fields in sagebrush habitat during May to September 2011, July to November 2012, and June to September 2013. First, they compared frequency of suitable rabbit habitat for 200 well pads and 200 random points within non-developed shrublands. Second, they modeled rabbit abundance and presence with distance to infrastructure. Third, they assessed areas unaffected by development based on rabbit decline relative to existing infrastructure within the lowest density gas field. Finally, they compared big sagebrush height and density between well pads and a random set of points.

Location: Wyoming

Findings: The authors found habitat suitability was higher at well pads in most gas fields and well pads in one gas field were more likely to be distributed within suitable rabbit habitat. Presence and abundance of rabbits was lower closer to roads, well pads, and utility lines. Most undeveloped areas within the gas field were close to well pads or roads. Well pads did not occur more frequently in areas with taller or denser sagebrush.

Implications: The authors suggest the negative effects related to proximity to well pads may be lessened in areas with overall lower well pad density. The authors found that very little land surrounding gas fields remained unimpaired for pygmy rabbits and state that future planning should use drilling technologies that reduce well pad area and associated infrastructure impacts.

Topics: broad-scale habitat characteristics; site-scale habitat characteristics; habitat selection; effect distances or spatial scales; energy development; infrastructure; sensitive/rare wildlife

\section{Germaine, S.S., Carter, S.K., Ignizio, D.A., and Freeman, A.T., 2017, Analysis of land disturbance and pygmy rabbit occupancy values associated with oil and gas extraction in southwestern Wyoming (June 7, 2012): U.S. Geological Survey data release.}

DOI: https://doi.org/10.5066/F7BR8QDD

Background: Pygmy rabbits are a priority for management in Wyoming and rely on sagebrush habitat for survival. Southwest Wyoming has experienced a large amount of disturbance from oil and gas exploration which has resulted in loss and fragmentation of sagebrush habitat. Past work has found negative impacts from oil and gas development on sagebrush obligate species, but no studies have focused on the response of pygmy rabbits to these stressors.

Objectives: The authors sought to provide (1) pygmy rabbit occupancy and location data, (2) shrub and sagebrush cover values, and (3) the area covered by gas field infrastructure in support of the research article by Germaine and others (2017b; https://doi.org/10.1002/ecs2.1817).

Methods: The authors compiled data on pygmy rabbit occupancy, amount of fresh sign per plot, vegetation data from remote sensing, and amount of area covered by 10 different types of gas field infrastructure. These data were mapped at a $0.5 \mathrm{~km}$ and $1 \mathrm{~km}$ radius of each plot center.

Location: Wyoming

Findings: The authors found that there was a relationship between gas field development and pygmy rabbits within their study area. They also state that their results can be generalized to other areas.

Implications: The authors state that these data represent a benchmark dataset for comparison of future studies investigating the effects of oil and gas development on pygmy rabbits.

Topics: population estimates or targets; site-scale habitat characteristics; habitat selection; effect distances or spatial scale; energy development; infrastructure; sensitive/rare wildlife; creates new geospatial data 


\title{
Germaine, S.S., Carter, S.K., Ignizio, D.A., and Freeman, A.T., 2017, Relationship between gas field development and the presence and abundance of pygmy rabbits in southwestern Wyoming: Ecosphere, v. 8, no. 5, article e01817, 19 p.
}

\author{
DOI: https://doi.org/10.1002/ecs2.1817
}

Background: Energy development disturbs large areas of sagebrush habitat and is continuing to expand. Pygmy rabbits are true sagebrush obligates and are sensitive to disturbance, though little is known about the impact that gas field infrastructure may have on their presence and abundance. Protections against development have already been put in place for greater sage-grouse, but it is unknown whether such protections are sufficient to also protect pygmy rabbits.

Objectives: The authors sought to (1) examine the effects of gas field development and infrastructure on pygmy rabbit presence and identify levels of disturbance above which pygmy rabbit presence may decline significantly, (2) investigate how development affects abundance at occupied sites, and (3) assess whether protection measures for greater sage-grouse provide adequate protection for pygmy rabbits.

Methods: During spring and summer of 2011, 2012, and 2013, the authors sampled 120 plots across 4 gas fields. They used digital well pad data to choose plots across a range of well pad densities. The authors then surveyed for signs of pygmy rabbits twice a year for two consecutive years, and measured sagebrush and other shrub cover using digital imagery. Finally, they mapped, classified, and quantified surface disturbance, and used these variables to model presence and abundance of pygmy rabbits.

\section{Location: Wyoming}

Findings: The authors found a strong, negative association between pygmy rabbit presence and abundance and gas field infrastructure and that these declines began after about 2 percent of the surveyed area was developed. Abundance was most strongly associated with buried utilities, two-track trails, and well pad complexes. Presence of two-track trails was associated with increased abundance while buried utilities and well pad complex variables were associated with decreased abundance. Data are provided in a data release by Germaine and others (2017a; https://doi.org/10.5066/F7BR8QDD).

Implications: The authors suggest that even low levels of gas development can adversely affect pygmy rabbits, specifically that development of gas fields could have direct and indirect effects on pygmy rabbit survival due to habitat loss and degradation, and the use of heavy equipment. The authors conclude by stating that pygmy rabbits show similar sensitivities to gas development as greater sage-grouse but may experience population declines at lower development levels than are currently permitted.

Topics: population estimates or targets; site-scale habitat characteristics; habitat selection; effect distances or spatial scale; energy development; infrastructure; sensitive/rare wildlife

\section{Germaine, S., Ignizio, D., Keinath, D., and Copeland, H., 2014, Predicting occupancy for pygmy rabbits in Wyoming - An independent evaluation of two species distribution models: Journal of Fish and Wildlife Management, v. 5, no. 2, p. 298-314.}

\section{DOI: https://doi.org/10.3996/022014-JFWM-016}

Background: Species distribution models are important tools when making management and conservation decisions. Two distribution models exist for pygmy rabbits in Wyoming and evaluating the accuracy of these models could help managers know which model best addresses their needs. Anthropogenic disturbances have affected many ecosystems, yet few species distribution models include such disturbances.

Objectives: The authors sought to (1) assess the accuracy of two different species distribution models and (2) investigate the influence of gas field road density on the efficacy of both models. 
Methods: The authors compared performance of two previously created models. The authors conducted pygmy rabbit occupancy surveys at 187 plots within the modeled areas in 2008 and 2009. They selected plots that were at least two kilometers apart and away from oil and gas development. In addition, they surveyed 120 plots from July to November 2012 in gas fields across a range of road densities (low, medium, high). The authors summarized each model's classification success by comparing results between each model and the sampled occupancy data. They then compared results from both models to assess model concordance. To assess the effects of anthropogenic disturbance, the authors compared occupancy rates within predicted habitat across all three road density classifications.

Location: Wyoming

Findings: Both models did not differ significantly in overall classification success when using the collected occupancy data and were better at predicting suitable habitat than non-habitat. The authors found that the two models differed in how they classified areas as suitable habitat, partly due to differences in vegetation classification between models. Lastly, the authors found that the accuracy of both models decreased significantly and steadily as the density of roads increased.

Implications: The authors suggest that the most suitable model could depend on the management objective (for example, determining suitable habitat versus predicting areas of non-habitat). The authors recommend that managers should consider using both models together when evaluating pygmy rabbit presence and when trying to avoid suitable habitat during gas extraction activities. Finally, the authors state that anthropogenic disturbances should be incorporated into future habitat models to ensure accurate representation of existing landscape conditions.

Topics: population estimates or targets; broad-scale habitat characteristics; habitat selection; effect distances or spatial scale; energy development; infrastructure; sensitive/rare wildlife

\title{
Grayson, D.K., 2006, The Late Quaternary biogeographic histories of some Great Basin mammals (western USA): Quaternary Science Reviews, v. 25, no. 21-22, p. 2964-2991.
}

\author{
DOI: https://doi.org/10.1016/j.quascirev.2006.03.004
}

Background: Research throughout the Great Basin has provided highly detailed information on prehistoric small mammal distributions in the region. Changes in pygmy rabbit distribution and relative abundance during the Pleistocene and Holocene can provide insights into the potential effects of future climate change on pygmy rabbits and other Great Basin small mammals.

Objectives: The author sought to provide the most current information of the biogeographical history of Great Basin mammals including pygmy rabbits.

Methods: The author reviewed existing studies of the prehistoric range and biogeography of several mammalian species in the Great Basin area. They provided in-depth summaries of historical distributions based on paleontological records for six species: pygmy rabbits, yellow-bellied marmots, bushy-tailed woodrats, northern pocket-gophers, dark kangaroo mice, and American pikas.

Location: California, Colorado, Nevada, New Mexico, Oregon, Utah

Findings: Prehistoric evidence shows that pygmy rabbit distribution and abundance declined in the Great Basin region following the end of the Pleistocene. This decline was accompanied by warmer temperatures and lower precipitation across the region as well as a transition from sagebrush to more saltbush-dominated habitat. The author suggests that the expansion of pinyon-juniper woodlands further reduced preferred pygmy rabbit habitat.

Implications: The author states that the prehistoric distribution and abundance of pygmy rabbits and other species help explain current species distributions and can inform predictions for distributional shifts under climate change. The author claims that the parallel prehistoric declines of pygmy rabbits and sagebrush habitat confirms their reliance on sagebrush habitat. Finally, the author highlights the importance of considering species-specific responses to climate change when considering the effects of climate change at the community level.

Topics: dispersal, spread, vectors, and pathways; broad-scale habitat characteristics; weather and climate patterns; climate change; paleontological resources; sensitive/rare wildlife 


\title{
Grayson, D.K., 2000, Mammalian responses to Middle Holocene climatic change in the Great Basin of the western United States: Journal of Biogeography, v. 27, no. 1, p. 181-192.
}

\author{
DOI: https://doi.org/10.1046/j.1365-2699.2000.00383.x
}

Background: The Great Basin region experienced dramatic climate change during the middle Holocene, becoming drier and warmer. Despite previous work examining the response of vegetation and humans to these changes, the response of non-human mammals is not well understood.

Objectives: The author sought to report on species assemblage changes from a recently excavated middle Holocene site.

Methods: The author examined remains collected from the Homestead Cave in 1993. The author only analyzed lagomorph and rodent remains as these represented most specimens collected. The author then analyzed the abundance of each species and the evenness (relative abundance of all species) of the species assemblage in various strata representing different time points during the middle Holocene.

\section{Location: Utah}

Findings: The author found that there was substantial variation in species' trends during the middle Holocene. Overall, the author found a reduction in both species richness and evenness during this time period, with evenness increasing again as the climate began to cool at the end of the middle Holocene. The author found that the response of individual species was highly variable with some species, such as pygmy rabbits and yellow-bellied marmots, becoming locally extinct. Other species, such as bushy-tailed woodrats, were not extirpated much later in the Holocene. Finally, the author found that dry-adapted species, such as chisel-toothed kangaroo rats, increased in abundance during the middle Holocene.

Implications: The author states that climatic conditions of the middle Holocene could be analogous for future conditions under climate change predictions and if climate predictions hold, it will likely mean the loss of or reduction in species that are less adapted to warm, dry conditions throughout the Great Basin, including pygmy rabbits. The author also states that it is unclear whether the middle Holocene provides an accurate comparison for future conditions due to the presence of invasive species that were absent in the Holocene and the potential for increased future precipitation from monsoons.

Topics: weather and climate patterns; climate change; paleontological resources; sensitive/rare wildlife

\section{Hagar, J., and Lienkaemper, G., 2007, Pygmy rabbit surveys on state lands in Oregon: U.S. Geological Survey Open-File Report 2007-1015, 23 p.}

\author{
DOI: https://doi.org/10.3133/ofr20071015
}

Background: Pygmy rabbits are a sensitive species due to specialized habitat requirements and declining populations. The current geographic range of pygmy rabbits in Oregon is not well known. Identifying areas where pygmy rabbits currently occur, and areas of suitable habitat, is important for management efforts in the state.

Objectives: The authors sought to (1) determine pygmy rabbit presence or absence at four counties in Oregon and (2) examine vegetation and soil factors influencing pygmy rabbit occupancy.

Methods: The authors created a habitat model using soil and vegetation characteristics to predict the potential habitat suitability of state lands within four counties in Oregon. The authors prioritized field surveys in areas found to be very high or high potential for pygmy rabbit habitat. They conducted surveys from September 2004 to November 2005 and classified all sites as active, inactive, or unoccupied. Finally, the authors conducted vegetation surveys at 9 active and 3 inactive sites and took soil samples from 10 active sites, 3 inactive sites, and 5 unoccupied sites.

Location: Oregon

Findings: Of all state lands in eastern Oregon, 76,890 hectares (29 percent of total area) were predicted as having high or medium habitat potential. Of the 157 sites that were ground surveyed, 11 percent were active, and 9 percent were inactive but showed evidence of prior activity. All active sites were within Harney and Lake counties. Active sites were found to have more shrub cover and taller shrubs than unoccupied sites. There was no difference found in soil texture between occupied and unoccupied sites. 
Implications: The authors state that shrub cover and shrub height most strongly influenced occupancy in this study. They also state that they observed evidence of cattle grazing at all surveyed sites and that unoccupied sites could potentially have provided habitat for pygmy rabbits prior to disturbance by cattle. Finally, the authors state that further research is needed to assess the effects of larger-scale factors, like habitat fragmentation, on pygmy rabbits. They note that fragmentation may limit successful dispersal, which could leave populations isolated and potentially lead to local extinctions and unused patches of high-potential habitat.

Topics: site-scale habitat characteristics; habitat selection; sensitive/rare wildlife

\title{
Halanych, K.M., and Robinson, T.J., 1997, Phylogenetic relationships of cottontails (Sylvilagus, Lagomorpha) - Congruence of 12S rDNA and cytogenetic data: Molecular Phylogenetics and Evolution, v. 7, no. 3, p. 294-302.
}

\author{
DOI: https://doi.org/10.1006/mpev.1996.0403
}

Background: The New World cottontail rabbit genus, Sylvilagus, contains commercially important species as well as several that are rare and endangered. Important questions regarding the phylogenetic relationships of Sylvilagus remain in question, including current estimates of the number of species within the genus and the phylogenetic position of pygmy rabbits. Understanding the evolution of cottontail rabbits will aid in the management of these species.

Objectives: The authors sought to explore the evolutionary history of cottontail rabbits using genetic techniques.

Methods: The authors collected ear clippings from pygmy rabbits, snowshoe hares, greater red rock rabbits, and several species of cottontail rabbits. They used standard genetic techniques to compare DNA sequences, and statistical analyses to estimate a phylogenetic tree.

\section{Location: Not specified}

Findings: The results of the analysis suggest that pygmy rabbits and cottontail rabbits are sister genera, swamp rabbits and marsh rabbits are sister species, eastern cottontail rabbits and Appalachian cottontail rabbits are sister species, and desert cottontail rabbits and mountain cottontail rabbits are sister species.

Implications: The authors claim there is strong support for pygmy rabbits as the sister genus to cottontail rabbits. They state that the genetic proximity of swamp rabbits and marsh rabbits suggests that the preference for aquatic habitats arose in a common ancestor. The authors suggest that construction of evolutionary relationships can provide important data for managers.

Topics: genetics; sensitive/rare wildlife

\section{Harrenstien, L.A., Finnegan, M.V., Woodford, N.L., Mansfield, K.G., Waters, W.R., Bannantine, J.P., Paustian, M.L., Garner, M.M., Bakke, A.C., Peloquin, C.A., and Phillips, T.M., 2006, Mycobacterium avium in pygmy rabbits (Brachylagus idahoensis) - 28 cases: Journal of Zoo and Wildlife Medicine, v. 37, no. 4, p. 498-512.}

DOI: https://doi.org/10.1638/05-002.1

Background: In response to fears of extinction, scientists initiated captive breeding programs for pygmy rabbits. Infection with Mycobacterium avium is typically only fatal to immunocompromised mammals. However, it is the top cause of mortality in captive breeding programs and is not well understood.

Objectives: The authors sought to (1) describe how M. avium progresses in pygmy rabbits, (2) determine how to diagnose infected rabbits, (3) identify and describe treatment methods, and (4) determine risk factors for mortality from the disease. 
Methods: The authors studied reports of 28 pygmy rabbits who died from mycobacteriosis due to $M$. avium infection and 18 rabbits that died from other causes in captive facilities between June 2002 and September 2004. Individuals originated from Idaho, the Columbia Basin in Washington, or were an intercross of these two populations. They analyzed biological samples from infected rabbits for the presence of mycobacterium. Caretakers gave 16 of 28 infected rabbits antibiotics and recorded the dosage. The authors studied mycobacterial antibodies produced by healthy and infected rabbits and measured the immunocompetence of 51 captive pygmy rabbits, 4 domesticated rabbits, and 1 California riparian brush rabbit.

Location: Idaho, Washington

Findings: The authors found mycobacteriosis in captive-born and wild-caught rabbits, with infections occurring more often in females. They identified weight loss, lethargy, soiling, and anorexia as symptoms of an infection and described the appearance of lesions. Some rabbits had mycobacterium present in blood, urine, and fecal samples prior to death, and most of the infected rabbits showed abnormal blood count values. Natural pygmy rabbit immune responses could not control the disease, but the authors documented evidence of effective antibiotic treatments. Rabbits from Idaho and intercrossed pygmy rabbits exhibited higher immune response than the Columbia Basin population.

Implications: The authors theorize that unsterilized soil in rabbit pens or birds may expose rabbits to M. avium. They suggest intercrossing populations of pygmy rabbits to improve immune response, immediately considering mycobacterial infection in sick rabbits, and using PCR to shorten diagnosis time. Additionally, they suggest that two of the antibiotics studied (azithromycin and rifabutin) may serve as effective treatments.

Topics: captive breeding; other: species and population characteristics; sensitive/rare wildlife

\section{Heady, L.T., and Laundré, J.W., 2005, Habitat use patterns within the home range of pygmy rabbits (Brachylagus idahoensis) in southeastern Idaho: Western North American Naturalist, v. 65, no. 4, p. 490-500.}

\section{Persistent URL: https://jstor.org/stable/41717484}

Background: Modern conservation biology is focused on protecting entire ecosystems rather than individual species, however, the habitat needs of extreme specialist species, such as pygmy rabbits, should be individually considered. Previous studies on pygmy rabbits have focused on winter ecology and habitat characteristics around burrows, however, no studies have examined multiple components of pygmy rabbit habitat during the summer.

Objectives: The authors examined pygmy rabbit home ranges to (1) determine if pygmy rabbits use the spatial area of their home range equally, and (2) evaluate which habitat characteristics within home ranges may cause usage variation.

Methods: The authors trapped and radio-collared pygmy rabbits at two sites in 1995 and 1996. They performed radio telemetry at two stations, recording the locations of five pygmy rabbits through triangulation every 15 minutes in 24-hour blocks in 1995, and 8 to 12-hour blocks in 1996. The authors used grids to estimate home ranges, and categorized areas as either high or low use. They conducted sampling of various habitat characteristics in the three area types and used statistics to link habitat characteristics to usage categories.

Location: Idaho

Findings: The authors found females had smaller home ranges than males. Rabbits used their home range unequally, spending more time closer to their burrows. Habitat characteristics at burrow sites were significantly different when compared to high and low use sites within their home range. Burrow sites had sparser ground cover, taller short shrubs, and denser tall shrubs than at high and low use sites. Within burrow sites, height and density of tall shrubs were higher closer to burrows. Burrow sites had two different soil classes, while high and low use areas had three.

Implications: The authors state their research shows pygmy rabbits are highly dependent on their burrows and that burrows have specific habitat characteristics differing from other areas within their home range. Rather than just being obligates of big sagebrush, the authors suggest pygmy rabbits require specific vegetation structure within big sagebrush landscapes, further limiting the amount of suitable pygmy rabbit habitat.

Topics: behavior or demographics; site-scale habitat characteristics; habitat selection; effect distances or spatial scale; soils or geology; sensitive/rare wildlife 


\section{Himes, J.G., and Drohan, P.J., 2007, Distribution and habitat selection of the pygmy rabbit, Brachylagus idahoensis, in Nevada (USA): Journal of Arid Environments, v. 68, no. 3, p. 371-382.}

DOI: https://doi.org/10.1016/j.jaridenv.2006.07.003

Background: Pygmy rabbits are native to the Great Basin region of the United States. While pygmy rabbit presence and habitat associations are well documented in the northern portions of their range, there have been few studies addressing these topics in the southern portions of their range.

Objectives: The authors sought to (1) create a model to predict habitat variables associated with pygmy rabbit presence, and (2) better understand the southern range limit of pygmy rabbits in Nevada.

Methods: From May to August 2003, the researchers performed road surveys to identify mature sagebrush stands. When they identified stands, the authors walked transects within them and used visual sightings of pygmy rabbits, occurrence of pygmy rabbit pellets, and discovery of burrows to determine pygmy rabbit presence or absence. The authors also considered the age of the pellets and burrows when determining presence. The authors then used existing spatial data of different habitat features and conducted modeling to predict what habitat variables predicted pygmy rabbit presence.

Location: Nevada

Findings: The authors detected pygmy rabbits on 261 of 642 surveyed transects. They found that pygmy rabbits were more likely to be present in areas close to perennial streams, with greater soil depth, and northerly aspects. All types of pygmy rabbit sign were more likely to be found in areas where soil was deeper. Fresh sign, which is indicative of current inhabitance, was more likely to be found in areas with greater soil depth. The authors detected pygmy rabbits in areas that extended their southern range past where it had previously been recorded.

Implications: The authors suggest that pygmy rabbit associations with streams and north facing aspects is associated with their preference for soil depth, as these two variables can be connected to the creation of deep soil. The authors recommend future studies be longer in length to observe if multi-year fluctuations in pygmy rabbit populations are occurring. When managing sagebrush, the authors recommend supporting stands diverse in size and age class to accommodate the needs of entire sagebrush communities.

Topics: population estimates or targets; site-scale habitat characteristics; habitat selection; effect distances or spatial scale; water; soils or geology; sensitive/rare wildlife

\section{Jimenez, A., Schmalz, J., Wright, M.N. and Skopec, M.M., 2020, Sagebrush characteristics influencing foraging patterns of pygmy rabbits: The Journal of Wildlife Management, v. 84, no. 7, p. 1306-1314.}

DOI: https://doi.org/10.1002/jwmg.21923

Background: Wildlife must balance their nutritional requirements with the risk of predation. Pygmy rabbits are adapted to metabolize sagebrush toxins allowing them to depend on sagebrush for both the majority of their diet, despite its relatively low nutritional value, and protection from predation. It is not fully understood how the species balances the tradeoffs between nutrition and physical protection from sagebrush plants.

Objectives: The authors sought to (1) develop a method using near-infrared spectroscopy to measure nutrient content of sagebrush in the field, (2) determine physical factors of the sagebrush plant that influence nutritional content, and (3) determine the physical and nutritional factors that influence foraging choices made by pygmy rabbits.

Methods: The authors sampled 1,887 sagebrush plants at 48 active burrows at 2 field sites from July 2014 to September 2015. For each sagebrush plant, they recorded size and location of the sagebrush, collected leaf samples, and recorded evidence of herbivory. They developed and tested a near-infrared spectroscopy method to predict crude protein and fiber content in sagebrush. Using the predicted nutritional content values, the authors compared sagebrush nutrient content by season, field site, plant size, and distance from burrow to determine what factors influence pygmy rabbit foraging. 


\title{
Location: Utah
}

Findings: The authors found that sagebrush nutritional content varied with season, field site, and distance from burrows. Sagebrush closest to burrows had higher crude protein levels and lower fiber; smaller plants had higher protein. Sagebrush had the highest fiber during fall and winter and lowest in summer. The authors found that pygmy rabbits preferentially selected sagebrush that was tall, close to burrows, low in fiber, and high in protein.

Implications: The authors developed a portable and affordable method to analyze sagebrush nutritional value. The authors suggest that although the differences in crude protein and fiber content of foraged and non-foraged sagebrush were statistically significant, they may not be biologically significant and that physical sagebrush characteristics such as proximity to burrows and height may be more important factors in pygmy rabbit foraging selection.

Topics: behavior or demographics; site-scale habitat characteristics; effect distances or spatial scale; other: species and population characteristics; sensitive/rare wildlife

\section{Katzner, T.E., Parker, K.L., and Harlow, H.H., 1997, Metabolism and thermal response in winter-acclimatized pygmy rabbits (Brachylagus idahoensis): Journal of Mammalogy, v. 78, no. 4, p. 1053-1062.}

\author{
DOI: https://doi.org/10.2307/1383048
}

Background: Pygmy rabbits occur in regions that experience extended periods of low ambient temperatures, which increases metabolic demands. Unlike species in cold climates, pygmy rabbits are not known to cache food or reduce their metabolic rates. Exploring how individuals tolerate these demands is important to understanding their ecology and addressing declining populations.

Objectives: The authors sought to (1) evaluate energetic costs of thermoregulation, (2) assess how thermal conductance and body temperature correlate, (3) investigate how ambient temperature affects body temperature, and (4) compare results to other lagomorphs.

Methods: The authors captured eight pygmy rabbits and placed them in an outdoor enclosure. They conducted trials four to eight weeks after capture from November 1995 to February 1996. For testing, they placed individuals in a metabolic chamber and conducted trials at 5 degree Celsius $\left({ }^{\circ} \mathrm{C}\right)$ intervals, from -15 to $25^{\circ} \mathrm{C}$, and measured oxygen consumption. They then estimated metabolic rates for each individual, both with access to food and after fasting and at a constant temperature and implanted four pygmy rabbits with transmitters that measured body temperature while rabbits were in the outdoor enclosure.

Location: Wyoming

Findings: The authors found that pygmy rabbits had a thermoneutral zone that spanned 8 to $9{ }^{\circ} \mathrm{C}$, and the lower critical temperature was between -15 and $-20^{\circ} \mathrm{C}$. Food availability was found to have no effect on metabolism. Body heat loss increased at air temperatures above $0{ }^{\circ} \mathrm{C}$ but remained unchanged below this point. Body temperatures remained constant in ambient temperatures between -15 and $15^{\circ} \mathrm{C}$.

Implications: The authors state that because air temperatures during winter are below their lower critical temperature, pygmy rabbits likely experience cold stress most of the winter. The authors believe that rabbits can tolerate these conditions by ingesting sagebrush, a high-energy food source. They also state that pygmy rabbits show no physiological adaptations that differ from other rabbits despite being much smaller. Finally, the authors suggest that behavioral adaptations, such as using microhabitats, allow for pygmy rabbit survival in harsh environments and that alterations to these habitats could contribute to population declines.

Topics: weather and climate patterns; other: species and population characteristics; sensitive/rare wildlife 


\title{
Katzner, T.E., and Parker, K.L., 1997, Vegetative characteristics and size of home ranges used by pygmy rabbits (Brachylagus idahoensis) during winter: Journal of Mammalogy, v. 78, no. 4, p. 1063-1072.
}

\author{
DOI: https://doi.org/10.2307/1383049
}

Background: Determining seasonal characteristics of species home ranges can provide information about vegetation and landscape characteristics needed for survival throughout the year. Pygmy rabbits are sagebrush specialists and may be affected by small changes to their environment. Winter home ranges and habitat characteristics of pygmy rabbits have been largely unstudied.

Objectives: The authors sought to (1) determine patterns in pygmy rabbit home range use, (2) describe winter vegetative characteristics within pygmy rabbit home ranges, and (3) calculate core areas within pygmy rabbit home ranges and identify vegetative characteristics in core areas.

Methods: The authors collected data during January to March of 1993 and 1994. During January and February, they trapped pygmy rabbits, equipped them with radio collars, and located them one to three times a day to identify individual homes ranges and core areas. They also collected various vegetation measurements and measured snow depth along transects in core areas and in areas of high and low use. They used statistics to determine if pygmy rabbit area use differed in response to vegetative characteristics and (or) snow cover.

Location: Wyoming

Findings: The authors quantified home ranges for 10 pygmy rabbits. Pygmy rabbits had variable home range sizes, with significantly smaller home ranges in 1993 than 1994. Most individuals used multiple core areas within their home range. Sagebrush in used areas was more numerous, larger, provided more canopy cover, and had more dead branches than in unused areas. In 1993, a year with very deep snow, pygmy rabbits used areas with greater snow depths more than areas with less snow depth; however, there was no difference in snow depth use in 1994, a year with little snow.

Implications: The authors believe annual differences in snow cover led to variation in home range size between years. They state that pygmy rabbit winter habitat is characterized by dense understories and that livestock grazing could reduce structural complexity of understory vegetation, potentially negatively impacting pygmy rabbits. They state that the below-snow environment provided access to a relatively constant food supply and protection from predators and thermal extremes. The authors suggest that home range size was influenced more by vegetative cover than by forage. Finally, the authors recommend future studies should focus on furthering understanding about relationships between pygmy rabbits and vegetative features.

Topics: behavior or demographics; site-scale habitat characteristics; habitat selection; weather and climate patterns; sensitive/ rare wildlife

\section{Katzner, T.E., and Parker, K.L., 1998, Long-distance movements from established burrow sites by pygmy rabbits (Brachylagus idahoensis) in southwestern Wyoming: Northwestern Naturalist, v. 79, no. 2, p. 72-74.}

DOI: https://doi.org/10.2307/3536706

Background: Pygmy rabbits are sagebrush specialists and are vulnerable to population decline when sagebrush habitat is altered, fragmented, or removed. Prior to this study, pygmy rabbits had not been documented moving across open areas between sagebrush patches, an important factor given extensive fragmentation of sagebrush habitats.

Objectives: The authors sought to (1) describe a long-distance movement by a radio-collared pygmy rabbit, (2) describe the vegetation characteristics at the burrows used by the radio-collared rabbit during its long-distance move, and (3) compare these vegetative characteristics to the burrow sites of other non-moving radio-collared pygmy rabbits.

Methods: The authors conducted monthly pygmy rabbit surveys and tracked 15 radio-collared pygmy rabbits 1 to 3 times per day during December to March 1993 to 1994 as part of a larger study, during which they observed the long-distance moving pygmy rabbit. The authors also collected data on the sagebrush surrounding 10 burrow sites within the study area and at 2 burrows outside of the study site that were used by the long-distance moving rabbit. 


\section{Location: Wyoming}

Findings: The authors documented one male rabbit moving over $3.5 \mathrm{~km}$ in two days and crossing open areas not typically used by pygmy rabbits. The long-distance moving rabbit was observed using abandoned pygmy rabbit burrows and resting and foraging in isolated sagebrush clumps between movements. Vegetative characteristics around the burrows used by the moving pygmy rabbit while in-transit were similar to the vegetative characteristics at the study site where the rabbit originated. Ultimately, this rabbit was killed by a predator before it could settle in a new location. During surveys at the study site, the authors also detected new unmarked adult pygmy rabbits that may have also traveled reasonably long distances though open areas to get to the study area.

Implications: The authors state the long-distance movement described is the longest documented pygmy rabbit movement. The authors suggest that breeding behavior of males could generate long-distance movements. They indicated that pygmy rabbits can travel across unsuitable habitat and that populations may not be as isolated as previously thought. The authors suggest future research into whether long-distance movements are normal pygmy rabbit dispersal behavior or if it is related to their population decline.

Topics: behavior or demographics; dispersal, spread, vectors, and pathways; broad-scale habitat characteristics; site-scale habitat characteristics; habitat selection; sagebrush removal; sensitive/rare wildlife

\section{Kraatz, B., and Sherratt, E., 2016, Evolutionary morphology of the rabbit skull: PeerJ, v. 4, article e2453, $23 \mathrm{p}$.}

DOI: https://doi.org/10.7717/peerj.2453

Background: Past work has found a relationship between vertebrate skeletal morphology and mode of locomotion (hopping, running, etc.), but far fewer studies have examined the relationship between skull shape and locomotion. Work on human ancestors has shown a strong relationship between skull shape and locomotion but this relationship has not been thoroughly explored in other taxa, though there is some evidence of this relationship in leporids.

Objectives: The authors sought to (1) broaden the understanding of skull morphology variation by studying a range of species, (2) explore the variation of skull shape in rabbits, (3) investigate how the rabbit skull evolved in relation to locomotion and size, and (4) quantify the changes associated with facial tilt (or head angle), cranial size, and shape.

Methods: The authors sampled 184 adult skulls of 20 species spanning all 11 living rabbit genera. The authors then obtained 3D computed tomographic (CT) scans of all sampled specimens. They then characterized the shape of each crania based on 3D reconstructed models and compared how skull shape varied between species as well as its relationship to both shape, size, facial tilt, and primary locomotion type.

\section{Location: Not specified}

Findings: The authors found that within their sample of rabbits, species separated out into three groups defined primarily by facial tilt. They found that pygmy rabbits occupy their own group due to enlarged regions of the lower skull relative to facial regions. They found no evidence of evolutionary history strongly influencing skull morphology and that some of the variation in skull shape was predicted by size, though a large portion of this pattern was driven by pygmy rabbits due to their small size. Finally, they found that facial tilt was predictive of skull shape, but mode of locomotion was not.

Implications: The authors state that their results highlight the need to further investigate the differences in morphology across rabbit and hare skeletons. They also state that pygmy rabbits display a good example of heterochrony, or difference in timing of development of the skull, which deserves further research.

Topics: other: species and population characteristics; sensitive/rare wildlife 


\section{Larrucea, E.S., and Brussard, P.F., 2007, A method for capturing pygmy rabbits in summer: Journal of Wildlife Management, v. 71, no. 3, p. 1016-1018.}

DOI: https://doi.org/10.2193/2006-186

Background: Pygmy rabbits are difficult to capture due to living in dense sagebrush and secretive behaviors. Baiting traps has proven to be ineffective in the past and no preferred baits have been identified. Prior methods to capture pygmy rabbits in summer have resulted in very low trap success. Developing effective capture techniques for pygmy rabbits during summer would allow for surveys during months when remote sites are easier to access than in winter.

Objectives: The authors sought to develop a more effective trapping technique for pygmy rabbits during summer months.

Methods: The authors tried five methods of trapping pygmy rabbits during April to November 2005 and one additional method during May to July 2006 in areas where pygmy rabbits were known to occur. These methods consisted of (1) camouflaged box traps with a variety of baits (apples, carrots, alfalfa, sagebrush) as well as unbaited traps placed over burrow entrances,

(2) unbaited box traps with fabric fences to funnel rabbits into the traps, (3) canvas sweep nets, (4) noose poles, (5) camouflaged box traps baited with canned green beans, and (6) uncamouflaged box traps baited with canned green beans.

Location: California, Nevada

Findings: A total of 30 pygmy rabbits were captured across all methods, 5 of which were recaptures. Most captures occurred when using camouflaged traps baited with canned green beans. The same setup without camouflage was also successful but at a lower rate. The use of noose poles was the second most successful method tested. Traps placed over burrows and canvas nets were not successful.

Implications: The authors suggest the use of camouflaged box traps baited with canned green beans in conjunction with noose poles would provide the greatest capture success for pygmy rabbits in summer. They state that the improved trap success with this method would allow for pygmy rabbit trapping in more remote areas, when access to those areas is easier. Finally, they state that summer trapping would require less safeguards against cold weather but require more vigilance against heat.

Topics: behavior or demographics; sensitive/rare wildlife

\section{Larrucea, E.S., and Brussard, P.F., 2008, Efficiency of various methods used to detect presence of pygmy rabbits in summer: Western North American Naturalist, v. 68, no. 3, p. 303-310.}

\section{DOI: https://doi.org/10.3398/1527-0904(2008)68[303:EOVMUT]2.0.CO;2}

Background: Pygmy rabbits are small, elusive animals that prefer dense vegetation and, thus, are difficult to detect. Populations of pygmy rabbits are under increasing threat from human activity that degrades their habitat. Therefore, finding a method to efficiently and accurately detect pygmy rabbits is needed for management efforts.

Objectives: The authors sought to compare the results of (1) pellet surveys, (2) burrow surveys, (3) visual detection, (4) camera surveys, and (5) road transects to determine which method was most accurate and efficient at detecting pygmy rabbits.

Methods: The authors conducted surveys at 20 sites with known pygmy rabbit presence from July to October 2004. At dawn, they surveyed each site visually and checked for fresh pellets and active burrows. They then placed one trail camera at each site and left it in place for one week. The authors conducted road transects for 10 nights from June to July 2004 along a $44.2 \mathrm{~km}$ route. To determine available species composition, camera data were collected at 52 locations within the area where the road surveys were conducted.

Location: California, Nevada

Findings: Fresh pygmy rabbit pellets and active burrows were found at 70 percent and 55 percent of sites, respectively. Pygmy rabbits were visually detected at 30 percent of sites while cameras detected pygmy rabbits at 95 percent of sites. Ten pygmy rabbits were detected during the road surveys, which accounted for 1.8 percent of leporid detections. Camera data indicated that pygmy rabbits comprised 47.7 percent of leporid detections. 
Implications: The authors state that camera surveys were most effective at determining pygmy rabbit presence. They claim that burrow and pellet surveys may not be reliable due to other species using burrows and confusing pellets from other rabbit species. The authors state that visual detection surveys are challenging due to difficulty identifying pygmy rabbits in the field and locating them in dense vegetation. They claim road surveys are not efficient for pygmy rabbits due in part to their hesitance to cross open areas. Finally, the authors state the need for assessing the efficiency of these survey methods in different seasons.

Topics: behavior and demographics: other: species and population characteristics; sensitive/rare wildlife

\section{Larrucea, E.S., and Brussard, P.F., 2008, Habitat selection and current distribution of the pygmy rabbit in Nevada and California, USA: Journal of Mammalogy, v. 89, no. 3, p. 691-699.}

DOI: https://doi.org/10.1644/07-MAMM-A-199R.1

Background: The extent of sagebrush habitat is decreasing, resulting in the decline of sagebrush-dependent wildlife species such as the pygmy rabbit. Accurate data on pygmy rabbit population status and habitat selection are difficult to obtain as pygmy rabbits are difficult to detect and do not occupy all areas of suitable habitat. Improved understanding of site characteristics associated with pygmy rabbit occupancy could improve efficiency of survey efforts.

Objectives: The authors sought to (1) assess environmental characteristics of occupied and unoccupied pygmy rabbit habitat, and (2) provide an updated population status for pygmy rabbits.

Methods: The authors identified potential habitat based on environmental attributes. They surveyed for pygmy rabbit activity at 80 sites focusing on patches of taller sagebrush. The authors recorded vegetation and soils data and placed cameras for one week following surveys. They modeled how microhabitat characteristics related to vegetation and soils related to pygmy rabbit presence. To assess current distribution of pygmy rabbits in the study area, from 2003 to 2006, they placed an additional 1,394 cameras within potential habitat. They modeled current distribution as a function of environmental characteristics and presence of other small mammals.

Location: California, Nevada

Findings: The authors found that pygmy rabbit presence was higher at sagebrush island sites, which have a greater percentage of sagebrush cover and decreased height of surrounding sagebrush. Three distinct regions with extant populations were identified, with one region likely to be disjunct. Across the entire study area, pygmy rabbits were more likely to be found with increasing sagebrush cover, decreasing understory stem density, absence of cottontail rabbits, absence of reddish soils, absence of cheatgrass, and absence of rodent burrows.

Implications: The authors state that within the study area, the current range of pygmy rabbits is similar to the reported historic range, but they were not found at some historically occupied sites. They claim connectivity between populations may be possible when surrounding habitat provides adequate cover from predators. The authors suggest that tall sagebrush clusters might enhance habitat suitability for pygmy rabbits and may be associated with better-watered, deeper soils and greater winter snowpack. Finally, they state that including microhabitat analyses in habitat suitability assessments could improve population survey efficiency.

Topics: population estimates or targets; dispersal, spread, vectors and pathways; broad-scale habitat characteristics; site-scale habitat characteristics; habitat selection; sensitive/rare wildlife

\section{Larrucea, E.S., and Brussard, P.F., 2009, Diel and seasonal activity patterns of pygmy rabbits (Brachylagus idahoensis): Journal of Mammalogy, v. 90, no. 5, p. 1176-1183.}

DOI: https://doi.org/10.1644/08-MAMM-A-272.1

Background: Daily and seasonal activity patterns are critical aspects of a species interaction with its environment. Gathering information about activity patterns in wild pygmy rabbits will help researchers better understand pygmy rabbit ecology, which may optimize survey efforts and improve management. 
Objectives: The authors sought to determine how (1) time of day, (2) seasonality, and (3) site specific conditions affected pygmy rabbit activity levels.

Methods: From June 2004 to July 2005, the authors placed five infrared cameras at five different field sites. The cameras ran for 24 hours a day for one week at two locations per month. Photos were categorized into four periods (day, night, morning, evening) based on time of observation. The authors conducted analyses using 2,670 detections to determine if there were any significant daily or seasonal activity patterns.

Location: California, Nevada

Findings: Pygmy rabbit above-ground activity was highest during the mornings and evenings with peak activity occurring at sunrise. Activity patterns did not vary significantly across seasons, though activity levels were significantly higher during the mornings for all seasons except winter. The study site with the highest elevation had higher levels of activity than the other sites.

Implications: The authors determined that wild pygmy rabbit populations are primarily active above ground during the morning and evening. They suggest that pygmy rabbits may have peak activity levels at dawn and dusk due to an increased predation risk during the day and night. Finally, they propose that pygmy rabbits at the high elevation site may have had increased foraging behavior to offset the harsher weather conditions.

Topics: behavior or demographics; weather and climate patterns; sensitive/rare wildlife

\section{Larrucea, E.S., and Brussard, P.F., 2008, Shift in location of pygmy rabbit (Brachylagus idahoensis) habitat in response to changing environments: Journal of Arid Environments, v. 72 , no. 9, p. 1636-1643.}

DOI: https://doi.org/10.1016/j.jaridenv.2008.04.002

Background: Sagebrush communities are under threat from land use changes, invasive species, fire regime changes, conifer expansion, and climate change. Alterations to this habitat are particularly concerning for sagebrush obligates, such as pygmy rabbits. Understanding how pygmy rabbits respond to these disturbances is important for management efforts.

Objectives: The authors sought to (1) compare historical and current pygmy rabbit occupancy, and (2) determine if land use, climate change, or other disturbances have influenced pygmy rabbit distribution.

Methods: The authors compiled historical pygmy rabbit location data from museum specimens, literature, and state agency records. They then revisited sites and established two-hectare plots centered around prominent sagebrush clusters closest to the historical location. The authors conducted visual surveys of each plot for pygmy rabbit signs and placed a trail camera at each site for one week. They also documented evidence for a suite of disturbance categories including fire, agriculture, and livestock, urbanization, and pinyon-juniper expansion.

Location: California, Nevada

Findings: A total of 105 sites were resurveyed. Pygmy rabbits were present at 36 percent of historic sites, and there was no difference across land ownership categories. Occupied locations tended to be higher in elevation than unoccupied sites, and there was a greater likelihood of local extinction at lower elevations. Conifer encroachment was present at 14 percent of sites, and only one of these sites was currently occupied. Livestock grazing was found at 83 percent of sites, but pygmy rabbits remained at 33 percent of them. Few sites showed evidence of recent fire, urbanization, or agricultural conversion.

Implications: The authors suggest that climate change is driving altitudinal pygmy rabbit habitat shifts by increasing encroachment of conifers at higher elevation sites and increasing temperatures at lower elevation sites. They do state that pygmy rabbit populations naturally fluctuate and thus some local extirpation from historic sites would be expected. The authors claim that climate change also increases risks from wildfires, and that other factors (such as grazing and urbanization) damage pygmy rabbit habitat to a lesser extent.

Topics: population estimates or targets; broad-scale habitat characteristics; site-scale habitat characteristics; fire; conifer expansion; grazing/herbivory; agriculture; climate change; sensitive/rare wildlife 


\title{
Larrucea, E.S., Robinson, M.L., Rippert, J.S., and Matocq, M.D., 2018, Genetically distinct populations of the pygmy rabbit (Brachylagus idahoensis) in the Mono Basin of California: Journal of Mammalogy, v. 99, no. 2, p. 408-415.
}

\author{
DOI: https://doi.org/10.1093/jmammal/gyx187
}

Background: Sagebrush habitat has been reduced and degraded across the West over the past century resulting in declines of sagebrush specialists, such as pygmy rabbits. Fragmentation of pygmy rabbit populations could result in declines of genetic diversity and population persistence. Most genetic research has been conducted on pygmy rabbits in the northern portion of the range, with comparatively little known for southern pygmy rabbit populations.

Objectives: The authors sought to (1) determine the genetic structure, and (2) spatial distribution of genetic diversity across pygmy rabbit populations in the southern portion of the range.

Methods: During winter months, the authors collected fecal pellets at individual burrows across the entire known range in California and Nevada and recorded pellet GPS locations. In the lab, they extracted DNA from frozen pellets and identified genotypes. The authors identified distinct genetic groups across the study area and calculated genetic diversity within and among populations.

Location: California, Nevada

Findings: The authors extracted DNA from 194 fecal pellets collected across 14 sites. They identified two highly differentiated genetic groups; one in Nevada, which could be further sub- divided into four modestly differentiated groups, and one in the Mono Basin of California. The Mono Basin populations had lower genetic diversity than other sampled locations.

Implications: The authors state that while genetically distinct and isolated, the Mono Basin pygmy rabbit population is not as genetically distinct or genetically depauperate as other isolated pygmy rabbit populations in Washington, possibly due to a relatively larger population size. However, the authors suggest continued isolation and loss of genetic diversity could occur if sagebrush habitat continues to be lost or fragmented. They suggest that future management plans should include genetic monitoring of the Mono Basin populations to reduce additional loss of genetic diversity.

Topics: survival; genetics; broad-scale habitat characteristics; sensitive/rare wildlife

\section{Lawes, T.J., Anthony, R.G., Robinson, W.D., Forbes, J.T., and Lorton, G.A., 2012, Homing behavior and survival of pygmy rabbits after experimental translocation: Western North American Naturalist, v. 72, no. 4, 569-581.}

DOI: https://doi.org/10.3398/064.072.0418

Background: Sagebrush degradation, conversion, and fragmentation across the western United States has coincided with pygmy rabbit range contractions. As their habitat becomes more fragmented, pygmy rabbit populations have also become fragmented, leading to concerns about population connectivity. To date, there has been little research on the homing and gap-crossing abilities of pygmy rabbits.

Objectives: The authors sought to determine (1) pygmy rabbits' ability to return to their home ranges post-translocation ("homing ability"), and (2) the impact of homing propensity and landscape features on pygmy rabbit survival.

Methods: The authors trapped and radio-collared 59 pygmy rabbits from June to December 2008. On the same day as capture, the authors released individuals 1 to $2 \mathrm{~km}$ from capture locations. Release locations included sites with contiguous big sagebrush habitat, big sagebrush habitat bisected by a road, and patchy big sagebrush habitat. They recorded individual behavior, vegetation, and coordinates of capture and release sites, calculated landscape features, and then modeled survival. The authors recaptured individuals to remove radio collars, once they returned to within $150 \mathrm{~m}$ of their capture site (individuals "homed") or settled into a new home range, greater than $150 \mathrm{~m}$ from their capture site.

Location: Oregon 
Findings: Nine radio-collared pygmy rabbits homed. Pygmy rabbits crossed areas of little vegetation between big sagebrush patches and used big sagebrush, rabbitbrush, and little sagebrush for shelter while moving across the landscape. Pygmy rabbits homed most frequently when released in the patchy habitat and the least when released in the road-bisected habitat. Of predation-related deaths, 78 percent occurred in the road-bisected habitat. Propensity to home and big sagebrush patch proximity positively impacted survival while proximity to roads negatively impacted survival.

Implications: The authors suggest that familiarity with and access to high-quality habitat in fragmented landscapes can influence pygmy rabbit homing propensity. They state that the influences of big sagebrush patch proximity and road proximity on survival could be informative in selecting future translocation sites. The authors suggest more research on the impacts of habitat quality on survival and on post-translocation survival to better contextualize and understand pygmy rabbit habitat selection.

Topics: survival; behavior and demographics; translocation; site-scale habitat characteristics; sensitive/rare wildlife

\section{Lawes, T.J., Anthony, R.G., Robinson, W.D., Forbes, J.T., and Lorton, G.A., 2013, Movements and settlement site selection of pygmy rabbits after experimental translocation: The Journal of Wildlife Management, v. 77, no. 6, 1170-1181.}

DOI: https://doi.org/10.1002/jwmg.572

Background: The success of wildlife translocation can depend on the location and habitat at release sites. Translocation studies can inform species reintroductions by supplying critical information about habitat in successful translocations. Translocation is a conservation tool with growing consideration for pygmy rabbits across the western United States as sagebrush habitat becomes increasing fragmented.

Objectives: The authors sought to evaluate (1) pygmy rabbit movements and (2) habitat use after short-distance translocations.

Methods: The authors trapped and radio-collared 43 pygmy rabbits from June to December 2008. The authors released captured individuals 1 to $2 \mathrm{~km}$ from capture locations. Release locations included suitable habitat (contiguous areas dominated by big sagebrush), suitable habitat bisected by a road, and marginal habitat (areas lacking continuous big sagebrush). The authors measured the distance between each pygmy rabbit release location and final recorded location and the distance between each pygmy rabbit release location and the farthest recorded location. Finally, the authors modeled the relationships between distance moved and individual activity, vegetation cover, and vegetation configuration at capture and release locations.

Location: Oregon

Findings: Pygmy rabbit settlement distance from release site varied. Individuals released in marginal habitat moved farther from release sites than individuals released in suitable or suitable bisected habitat. There was no difference in distance moved between individuals released in suitable and suitable habitat bisected by roads. The authors recorded a maximum distance from release site of $3.5 \mathrm{~km}$. Larger patches and higher percentage of sagebrush cover were related to shorter distances that pygmy rabbits moved to settlement sites. Pygmy rabbits selected settlement sites with more continuous big sagebrush habitat, lower patch density, and larger patches than at capture sites. Pygmy rabbits all settled in areas with active or inactive pygmy rabbit burrows.

Implications: The authors state that roads did not appear to present a barrier for pygmy rabbits in this study and that pygmy rabbits can move long distances across marginal habitat to access areas of big sagebrush. The authors suggest their findings indicate ground surveys are important for selecting pygmy rabbit release sites for successful translocations. Finally, they state that successful translocations of pygmy rabbits will likely depend on areas of continuous big sagebrush.

Topics: behavior and demographics; translocation; site-scale habitat characteristics; sensitive/rare wildlife 


\title{
Lee, J.E., Larsen, R.T., Flinders, J.T., and Eggett, D.L., 2010, Daily and seasonal patterns of activity at pygmy rabbit burrows in Utah: Western North American Naturalist, v. 70, no. 2, p. 189-197.
}

\author{
DOI: https://doi.org/10.3398/064.070.0205
}

Background: Pygmy rabbits are sagebrush obligates and one of two rabbit species in North America that digs its own burrows. While prior research has examined pygmy rabbit home range, habitat, distribution, and diets, few have documented daily or seasonal activity patterns. A better understanding of pygmy rabbit seasonal and daily activity patterns in relation to burrows can inform other pygmy rabbit studies.

Objectives: The authors sought to (1) document pygmy rabbit activity patterns at burrows, and (2) determine the influence of time of day, season, and site on pygmy rabbit activity.

Methods: In May 2006, the authors installed remote cameras at nine different sites within $3 \mathrm{~m}$ of pygmy rabbit burrow entrances, which had evidence of varying activity levels. The authors left cameras to collect data for 2 to 4 weeks before moving each camera at least $500 \mathrm{~m}$ to another burrow, while maintaining a distance of $100 \mathrm{~m}$ between cameras. They categorized photos into four time blocks: morning, afternoon, evening, and night. Finally, the authors analyzed the impacts of site, season, time of day, and year on activity.

Location: Utah

Findings: The authors analyzed activity at 436 burrow entrances, 302 burrow complexes, and captured 12,603 pygmy rabbit photos. They found time of day, site, season, and the interaction between time of day and season influenced pygmy rabbit activity levels. Pygmy rabbits were most active in the morning during spring, summer, and fall. In the winter, pygmy rabbits were most active in the evening and less active in the morning.

Implications: The authors recommend that remote cameras should be used in future studies, as pygmy rabbits seem unimpacted by their presence. The authors suggest pygmy rabbits may alter their activity patterns to avoid predation or aid in thermoregulation, and that data for movement and home-range studies should be collected during the mornings, when pygmy rabbits are more active.

Topics: behavior or demographics; site-scale habitat characteristics; sensitive/rare wildlife

\section{Lyman, R.L., 1991, Late Quaternary biogeography of the pygmy rabbit (Brachylagus idahoensis) in eastern Washington: Journal of Mammalogy, v. 72, no. 1, 110-117.}

\author{
DOI: https://doi.org/10.2307/1381985
}

Background: Pygmy rabbit populations in eastern Washington are disjunct from neighboring populations and are the only mammal species in the region to exhibit such disjointed distribution. The recently identified range reduction of this separate and declining population is attributed to habitat loss. However, the disjointed distribution seen today could have started forming thousands of years ago, when changing prehistoric climates led to changes in vegetation distribution.

Objective: The author sought to review new data regarding the historic biogeography of eastern Washington pygmy rabbits.

Methods: The author reviewed animal remains from 189 archaeological sites from the Holocene across eastern Washington. The author assumed that the identification of pygmy rabbit remains at a site indicated pygmy rabbit presence at that site and that the remains were not transported through human, animal, or geological (for example, fluvial transport) means.

Location: Washington

Findings: At the reviewed sites, 6 of the 189 sites contained pygmy rabbit remains. While pygmy rabbits were known to occupy the area as early as 100,000 years ago during the Pleistocene, the author identified pygmy rabbit remains at one mid-Holocene site. Of the five late-Holocene records, only one was within the older historic range. No records were identified north or south of the current eastern Washington range during the Holocene. All late-Holocene records contained fewer pygmy rabbit remains than earlier time periods. 
Implications: The author states the distribution of late-Holocene remains indicated a reduction of pygmy rabbits in eastern Washington within the past 3,000 years. They suggest areas to the west, north, and east of the current eastern Washington pygmy rabbit range were likely too moist to support sagebrush habitat during the Pleistocene and early Holocene (circa 10,000 to 8,000 years before present [B.P.]), and thus were likely unable to support pygmy rabbit populations. Finally, the author suggests the pygmy rabbit reduced range and relative abundance in eastern Washington is likely a continuation of a pattern that began in the late Holocene about 4,000 years ago, and that pygmy rabbit abundance was likely greatest in eastern Washington between about 8,000 and 4,500 years ago.

Topics: dispersal, spread, vectors, and pathways; broad-scale habitat characteristics; weather and climate patterns; paleontological resources; sensitive/rare wildlife

\section{Lyman, R.L., 2004, Biogeographic and conservation implications of late Quaternary pygmy rabbits (Brachylagus idahoensis) in eastern Washington: Western North American Naturalist, v. 64, no. 1, p. 1-6.}

Persistent URL: https://jstor.org/stable/41717335

Background: Pygmy rabbit populations in eastern Washington are isolated from other populations in the Great Basin. A biogeographical model was created in 1991 for these populations. New prehistoric records of pygmy rabbits necessitate refinement of the model.

Objectives: The author sought to update a biogeographical model of pygmy rabbit populations in eastern Washington with new prehistoric records.

Methods: The author reviewed all documented occurrences of prehistoric pygmy rabbit remains discovered since 1990. The author recorded the location of all remains, frequency of pygmy rabbit remains relative to other species, and the age of the remains. The author then used this information to refine the original biogeographical model.

Location: Washington

Findings: A total of 11 new pygmy rabbit records were found. The author suggests that pygmy rabbits had not yet reached their maximum range at the end of the Pleistocene, had begun colonizing eastern Washington during this same time, and had their widest distribution in Washington during the middle Holocene. The author also suggests the disjunction between the Washington populations and those in the Great Basin likely existed in the late Holocene.

Implications: The author suggests that if the range of pygmy rabbits was decreasing during the Holocene, then the full prehistoric range of pygmy rabbits in Washington may be larger than previously thought and that historic pygmy rabbit populations could have existed in areas where they have not yet been documented. The author proposes that disturbance from modern grazing activities likely contributed strongly to the decline of pygmy rabbits throughout Washington. Finally, the authors states that management steps must be taken to reduce land-modifications from ranching and other agricultural uses in order to protect the remaining pygmy rabbits in eastern Washington.

Topics: grazing/herbivory; agriculture; paleontological resources; sensitive/rare wildlife

\section{Martin, M.S., and Shepherdson, D.J., 2012, Role of familiarity and preference in reproductive success in ex situ breeding programs: Conservation Biology, v. 26, no. 4. p. 649-656.}

DOI: https://doi.org/10.1111/j.1523-1739.2012.01880.x

Background: Captive breeding may be a useful tool for increasing endangered wildlife populations. However, mates are often paired to minimize inbreeding, and eliminating mate choice has led to reduced reproductive success in some species. Captive breeding of the genetically unique Columbia Basin pygmy rabbit population based solely on genetic criteria has had low success rates, warranting further study of pygmy rabbit mate choice for captive breeding success.

Objectives: The authors sought to investigate the effects of familiar and preferred pygmy rabbit mates on the reproductive success of captive animals. 
Methods: During the spring and summer breeding season in 2006 to 2008, the authors bred genetically pure Columbia Basin pygmy rabbits and genetically mixed Columbia Basin and Idaho pygmy rabbits. They housed individuals in a captive breeding facility. Using separate cages, they placed females next to some males (neighbors) and farther from others (non-neighbors). The authors monitored pygmy rabbit behavior 24 hours/day and further classified neighboring males into "preferred" and "nonpreferred" groups, based on whether females did (preferred) or did not (nonpreferred) display mating behavior when in proximity to these males. Finally, they paired neighboring and non-neighboring preferred and nonpreferred males with females for mating sessions lasting 2 to 3 days and classified sessions as successful based on litter production.

Location: Washington

Findings: Neighboring mate pairs had increased litter production, with more kits emerging from burrows and surviving one year as compared to non-neighboring mate pairs. More females mated with preferred males produced litters than those mated with nonpreferred males. Female mate preference, weight, age, and male weight were associated with larger litter size, and heavier females and older males had more kits emerge from burrows.

Implications: The authors claim a lack of familiarity between mates may negatively impact the reproductive success of captive bred pygmy rabbits, but the factors influencing familiarity are still unknown. They suggest that identifying these factors could help managers maximize captive breeding success. Finally, the authors recommend that, in addition to important genetic factors, managers should also consider behavioral factors when pairing captive pygmy rabbits for breeding.

Topics: behavior or demographics; captive breeding; sensitive/rare wildlife

\title{
McClure, D.E., 2012, Mycobacteriosis in the rabbit and rodent: Veterinary Clinics of North America: Exotic Animal Practice, v. 15, no. 1, p. 85-99.
}

\author{
DOI: https://doi.org/10.1016/j.cvex.2011.11.002
}

Background: Mycobacterial infections are rare in rabbits except for pygmy rabbits, which are particularly susceptible to mycobacteriosis in captivity where it can be a significant cause of mortality. Rabbits and rodents could act as reservoirs between wild populations and captive animals or humans and could help with understanding mycobacterial diseases, including tuberculosis.

Objectives: The author sought to review cases of known mycobacteriosis in rabbits and rodents.

Methods: The author reviewed past studies on spontaneous and induced mycobacteriosis in pygmy rabbits and other rabbit and rodent species.

\section{Location: Washington}

Findings: The literature review determined that infection by Mycobacterium avium was the most common cause of death in captive adult pygmy rabbits from the Columbia Basin population, with 29 percent dying during June 2002 to September 2004, and 37 percent dying during 2008 to 2011 . The onset of symptoms usually occurred between 10.5 to 28.5 months of age and include weight loss, lethargy, soiling, anorexia, and lactation in non-pregnant females. The research also suggested that pygmy rabbits' immune response was not well suited to fighting off mycobacterial infections. Finally, the author reported that efforts to promote hybrid vigor through crossbreeding of Columbia Basin pygmy rabbits with individuals from more genetically diverse populations led to increased immune response to mycobacteriosis.

Implications: The author claims that habitat loss and fragmentation likely led to inbreeding of pygmy rabbits in the Columbia Basin, resulting in low genetic variability and susceptibility to mycobacterial infections. The author states that pygmy rabbits regularly encounter Mycobacterium avium while burrowing and therefore soil used in enclosures should be sterilized or removed. The author highlights the fact that rabbits could act as reservoirs for Mycobacterium species but that this has not been well examined. Finally, the author states that studying mycobacteriosis in rabbits and rodents has provided valuable insights into addressing concerns of other mycobacterial infections in humans, including tuberculosis.

Topics: captive breeding; other: species and population characteristics; sensitive/rare wildlife 


\section{McMahon, L.A., Rachlow, J.L., Shipley, L.A., Forbey, J.S., and Johnson, T.R., 2017, Habitat selection differs across hierarchical behaviors: selection of patches and intensity of patch use: Ecosphere, v. 8, no. 11, article e01993, 14 p.}

DOI: https://doi.org/10.1002/ecs2.1993

Background: Habitat selection is a decision-making process that operates at two scales — at the broader scale, animals should select habitats with resources that reduce the greatest threats to fitness like predation, and at the finer scale animals should select habitats with resources that promote aspects of fitness like accelerating growth or fecundity. For pygmy rabbits, predation is a primary mortality cause and may influence broader habitat selection, but as an obligate sagebrush species, intensity of use may be driven by vegetation characteristics.

Objective: The authors sought to determine how resources influence pygmy rabbit habitat use (1) at the broad behavioral (patch selection) scale and (2) at the fine behavioral (intensity of habitat use) scale.

Methods: During 2015 and 2016, the authors radio collared 29 and 13 pygmy rabbits during winter and summer, respectively. The authors measured habitat characteristics within and around 288 habitat patches in the winter and 170 patches in the summer. They measured characteristics of at least four used and unused available habitat patches per radio-tagged individual. The authors also estimated concealment and counted burrow entrances at each patch. Finally, they modeled the impact of habitat characteristics on selection and intensity of use.

Location: Idaho

Findings: At the coarser scale, pygmy rabbits selected patches with a higher number of burrow entrances and increased security cover during both seasons. At the finer scale, individuals more intensively used patches with more burrow entrances and greater sagebrush canopy during the winter. During the summer, pygmy rabbits patch use intensity was positively associated with increased availability of herbaceous forage, aerial concealment, and the density of nearby burrows.

Implications: The authors suggest that resources providing security from predation were important to both coarse and fine scale habitat selection. They also suggest that understanding the behavioral and spatial scales at which habitat selection operates can help managers understand population distribution and movements.

Topics: behavior or demographics; broad-scale habitat characteristics; site-scale habitat characteristics; habitat selection; sensitive/rare wildlife

\section{McMahon, L.A., Rachlow, J.L., Shipley, L.A., Forbey, J.S., Johnson, T.R., and Olsoy, P.J., 2017, Evaluation of micro-GPS receivers for tracking small-bodied mammals: PLoS ONE, v. 12, no. 3, article e0173185, 19 p.}

DOI: https://doi.org/10.1371/journal.pone.0173185

Background: GPS telemetry enhances the tracking of wildlife movements but is difficult to deploy on small-bodied mammals. New micro-GPS receiver technology has made such efforts increasingly feasible. However, there is limited research that explores how environmental characteristics and animal behaviors that interfere with satellite communication might impact the accuracy of data collected from micro-GPS receivers on small mammals.

Objectives: The researchers sought to determine the effectiveness of two different types of micro-GPS receivers on small mammals using (1) stationary tests and (2) field trials using pygmy rabbits.

Methods: During summer 2015 and 2016, the authors conducted stationary tests on two types of GPS receivers, traditional receivers and "snapshot" receivers (designed to save battery life). They placed both types of receiver at 40 locations, above ground and in burrows. They quantified vegetation cover to study the effect of environmental factors on receivers. The authors calculated two types of error associated with interrupted satellite communication to determine receiver accuracy. During winter and summer 2015 and 2016, the authors trapped pygmy rabbits and fitted them with either traditional or "snapshot" receivers to compare the accuracy of on-animal use with stationary tests.

Location: Idaho 
Findings: In stationary and field trials, "snapshot" receivers had a high overall failure rate and were less reliable than traditional receivers. Traditional receivers produced more accurate locations both below and above ground than "snapshot" receivers. The placement of a receiver in a burrow and the presence of shrub cover both interfered with satellite communication and led to data collection errors. Field trials suggested burrow use, not behavior above ground, influenced successful data collection. When rabbits were above ground the success rate of data collection was comparable to stationary tests.

Implications: The authors state that their field trials indicate burrow and vegetation cover had the biggest impact on GPS error and that above-ground behavior did not impact accuracy. They propose micro-GPS receivers can be used in small mammal studies, but suggest that traditional receivers were more appropriate for field use than "snapshot" receivers. They also suggest that extra measures may be needed to collect accurate data for animals that use burrows or similar types of structures.

Topics: behavior or demographics; site-scale habitat characteristics; sensitive/rare wildlife

\section{Milling, C.R., Rachlow, J.L., Johnson, T.R., Forbey, J.S., and Shipley, L.A., 2017, Seasonal variation in behavioral thermoregulation and predator avoidance in a small mammal: Behavioral Ecology, v. 28, no. 5, p. 1236-1247.}

\section{DOI: https://doi.org/10.1093/beheco/arx084}

Background: Mammals that live in areas with climatic extremes may use behavioral thermoregulation, such as temporal activity patterns and rest site selection, to maintain body temperature. However, at certain times of year, small mammals like the pygmy rabbit may make trade-offs between maintaining body temperature and avoiding predation risk.

Objectives: The authors sought to identify how small mammals regulate body temperature and avoid predation across different seasons by (1) characterizing microclimate at pygmy rabbit rest sites and (2) quantifying activity patterns and linking them to environmental factors and individual condition.

Methods: The authors radio collared, tracked, and recorded rest site locations for 11, 25, and 26 pygmy rabbits during summer 2014, winter 2015, and summer 2015, respectively. They collected data on microhabitat conditions, concealment from predators, and distance to burrows at rest sites and at nearby random locations. To measure activity, they attached accelerometers to 6 pygmy rabbits in summer 2014 and 12 pygmy rabbits in both summer and winter 2015, and quantified activity levels during dawn, dusk, day and night. They compared activity levels to predictor variables to determine drivers of pygmy rabbit behavior.

Location: Idaho

Findings: During summer, rest site selection was influenced by cooler temperatures, lower amounts of sunlight, and higher concealment from predators. During winter, rest site selection was influenced by burrow distance and aerial concealment. Throughout the year, pygmy rabbit activity peaks centered around dawn and dusk. During summer, reproduction predicted activity, with reproductive pygmy rabbits more active during day and night than non-reproductive rabbits. During winter, pygmy rabbit activity increased at night, dawn, and dusk as temperature increased. Pygmy rabbits were also significantly more active at night during new and partial moon phases.

Implications: The authors state that this research shows pygmy rabbits can respond to several different variables related to activity, thermoregulation, and predation risk, demonstrating behavioral plasticity. The authors propose some species may initially tolerate warming trends until a threshold level is reached. The authors suggest understanding the limits of behavioral plasticity is essential for predicting species responses to climate change.

Topics: behavior or demographics; site-scale habitat characteristics; habitat selection; predators or predator control; weather and climate patterns; climate change; sensitive/rare wildlife 


\title{
Milling, C.R., Rachlow, J.L., Chappell, M.A., Camp, M.J., Johnson, T.R., Shipley, L.A., Paul, D.R., and Forbey, J.S., 2018, Seasonal temperature acclimatization in a semi-fossorial mammal and the role of burrows as thermal refuges: PeerJ, article 6:e4511, $22 \mathrm{p}$.
}

\author{
DOI: https://doi.org/10.7717/peerj.4511
}

Background: Animals that live in areas with seasonal climate extremes use adaptations to survive harsh conditions. Pygmy rabbits use burrows as a type of behavioral thermoregulation to reduce the energy costs of maintaining a constant body temperature in extremely hot or cold weather. However, pygmy rabbit burrow use is variable, and more understanding is needed about how burrows are used for thermoregulatory purposes.

Objectives: The authors sought to quantify the energetic consequences of thermoregulating in a burrow during summer and winter by (1) measuring the correlation between temperature and oxygen use, (2) measuring temperature within burrows and at above-ground rest sites, and (3) estimating and comparing the thermoregulatory costs of resting in burrows versus above-ground sites.

Methods: During January-March and June-July 2016, the authors measured oxygen consumption rates of captive wild-caught pygmy rabbits at temperatures ranging from -5 to $25^{\circ} \mathrm{C}$ in the winter and 5 to $30^{\circ} \mathrm{C}$ in the summer. During January to February and July to August 2015, the authors collected field data and used temperature loggers to measure environmental temperature at 10 above-ground rest sites and within 10 active pygmy rabbit burrows. They regressed oxygen consumption against temperature to generate a model by which the energetic costs associated with resting in different microenvironments could be estimated.

Location: Idaho, Montana

Findings: Six pygmy rabbits were sampled in the summer and winter for a total of 39 winter trials and 35 summer trials. Pygmy rabbits displayed seasonal acclimation to cold temperatures, expending more energy on thermoregulation in the summer than winter when the temperature was $0{ }^{\circ} \mathrm{C}$. In winter, burrows were more thermally stable than above-ground rest sites, and winter use of burrows could reduce thermoregulatory costs. During summer, availability of thermally diverse above-ground rest sites reduced the value of burrows for energy savings during that season.

Implications: The authors suggest that pygmy rabbits possess physiological adaptations that allow them to live in extreme winter climates, but burrows also help mitigate energy costs. The authors state climate and land-use change may increase thermoregulatory costs associated with burrow use and future research should explore the impacts of these changes.

Topics: behavior or demographics; site-scale habitat characteristics; weather and climate patterns; climate change; sensitive/ rare wildlife

\section{Murray, L.K., Bell, C.J., Dolan, M.T., and Mead, J.I., 2005, Late Pleistocene fauna from the southern Colorado Plateau, Navajo County, Arizona: Southwestern Naturalist, v. 50, no. 3, p. 363-374.}

DOI: https://doi.org/10.1894/0038-4909(2005)050[0363:LPFFTS]2.0.CO;2

Background: Identifying fossils helps scientists better understand historical species occurrence, observe changes over time, and allows for conclusions about the landscape during the time they were deposited.

Objectives: The authors sought to (1) identify and describe several fossils discovered in a quarry and (2) draw conclusions about the time period of the fossils and vegetation in that region.

Methods: In November and December of 1989, researchers unearthed several animal fossils from the wall of a quarry. They prepared and reconstructed the fossils in a laboratory, identified them by species, described them in detail, and used species information and published paleoecological data to make inferences about historical vegetation.

Location: Arizona 
Findings: The authors identified fossils from seven animal taxa and describe four of them in detail: a mole salamander, pygmy rabbit, sagebrush vole, and flat-headed peccary. Based on the presence of the flat-headed peccary, the authors determined the fossils dated to the late Pleistocene. The authors also conclude that the presence of pygmy rabbits and sagebrush vole likely indicates the presence of sagebrush during that time.

Implications: The authors state that this research describes the first record of a mole salamander on the Colorado Plateau during the Pleistocene and adds a second record of pygmy rabbits occurring in Arizona. The authors note that these findings may be combined with other fossil findings, including those of pollen, to help draw conclusions about the landscape of this region during earlier time periods. They suggest this region may have supported a sagebrush-grassland steppe during the late Pleistocene, and that the Grand Canyon and tributary drainages of the southern Colorado Plateau acted as a geographic connection during the Pleistocene, allowing for a continuous distribution of sagebrush vole and pygmy rabbit between the Great Basin and fossil localities in the Rio Grande and San Juan valleys in New Mexico.

Topics: paleontological resources; sensitive/rare wildlife

\title{
Neves, F., Abrantes, J., Almeida, T., Costa, P.P., and Esteves, P.J., 2015, Evolutionary insights into IL17A in lagomorphs: Mediators of Inflammation, v. 2015, article 367670, 7 p.
}

\author{
DOI: https://doi.org/10.1155/2015/367670
}

Background: Tularemia is a zoonotic disease that can cause serious illness in humans and is usually passed to humans by lagomorphs, rodents, or some arthropods. The IL17A gene is important in defending against infections, including tularemia, but has not been closely studied in lagomorphs.

Objectives: The authors sought to characterize the genetics of the IL17A gene in four species of rabbits and hares, including the pygmy rabbit.

Methods: The authors obtained tissue samples of the pygmy rabbit, European rabbit, brush rabbit, and European brown hare, and extracted DNA from each sample and RNA from one European rabbit and one European brown hare. They estimated phylogenetic relationships between the IL17A nucleotide sequences based on the number of nucleotide differences. Finally, they amplified, sequenced, and compared the IL17A gene sequences of all four species, and also compared results to American pikas and representatives of other major mammalian groups.

Location: Not specified

Findings: The authors successfully amplified and sequenced the IL17A gene in all four leproid species. They found that the structure of IL17A was highly conserved across all species but did discover a mutation in the interaction site between IL17A and another gene, IL17RA, in European rabbits and European brown hares. Nucleotide differences for IL17A were the least divergent between European rabbit and European brown hare and the most divergent between European rabbit and pygmy rabbit. They also found that human IL17A sequences were more similar to those of European rabbits than those of mice or rat sequences.

Implications: The authors state that the single mutation within the interaction site between IL17A and IL17RA could cause changes in structure, function, stability, signaling, or conformation. The authors suggest that the European rabbit may be a more suitable animal model for studying immunity given the similarity of the IL17A sequence between humans and European rabbit.

Topics: genetics; sensitive/rare wildlife 


\title{
Neves, F., Abrantes, J., and Esteves, P.J., 2016, Evolution of CCL11-Genetic characterization in lagomorphs and evidence of positive and purifying selection in mammals: Innate Immunity, v. 22, no. 5, p. 336-343.
}

\author{
DOI: https://doi.org/10.1177/1753425916647471
}

Background: The CCL11 gene plays an important role in allergic and parasitic inflammation and is known to exist in several mammalian species. Past work with similar genes in lagomorphs revealed evidence of purifying selection, which is the selective removal of deleterious versions of a gene, though no research has investigated the evolutionary history of the CCL11 gene.

Objectives: The authors sought to (1) characterize the CCL11 gene in several lagomorph species and (2) investigate the selection pressures driving the evolution of this gene in mammals.

Methods: The authors extracted genomic DNA from pygmy rabbit, both European rabbit subspecies, European brown hare, brush rabbit, volcano rabbit, and American pika tissue samples. They then amplified and sequenced the CCL11 gene for all species and compared the results between lagomorph species as well as other mammal species. To investigate different types of selection acting on this gene, the authors compared the ratio of different types of substitutions within the gene for each species.

\section{Location: Not specified}

Findings: The authors found that pygmy rabbits differed from the other leporid species examined in that there was a mutation in the CCL11 gene leading to an extension in the stop codon. The authors found 21 codons that showed evidence of purifying selection and 3 codons that showed evidence of positive selection. Finally, the authors found that the CCL11 gene in all leporid species tested differed from humans.

Implications: The authors state that the implications of pygmy rabbits having a longer CCL11 protein than other rabbit species is unknown and should be investigated further, but could potentially affect protein function. The authors state that the portions of the gene showing evidence of purifying selection are close to regions important for receptor binding confirming the importance of maintaining these sections of the CCL11 gene.

Topics: genetics; sensitive/rare wildlife

\section{Neves, F., Abrantes, J., Lopes, A.M., Fusinatto, L.A., Magalhaes, M.J., Loo, W. van der, and Esteves, P.J., 2019, Evolution of CCL16 in Glires (Rodentia and Lagomorpha) shows an unusual random pseudogenization pattern: BMC Evolutionary Biology, v. 19, article 59, $10 \mathrm{p}$.}

DOI: https://doi.org/10.1186/s12862-019-1390-7

Background: Rodents and lagomorphs are part of the superorder Glires. Within this superorder, the gene CCL16, which has important inflammatory, homeostatic and immune response functions, is functional in some species and not functional in others. The superorder Glires is a useful model system to study evolution of the CCL16 gene.

Objectives: The authors objective was to investigate the evolution of CCL16 in the superorder Glires.

Methods: The authors collected tissue samples from 11 species from the family Leporidae and 7 species from the family Ochotonidae. They sequenced the CCL16 gene in these 18 lagomorph species and compared the sequences to 12 rodent species. They performed a statistical analysis to determine the statistical significance of the evolutionary rate of CCL16 in Glires.

Location: Not specified

Findings: The authors found that CCL16 is non-functional in lagomorphs, and that the same mutation leading to non-functionality is present in both Leporidae and Ochotonidae families. The statistical analysis suggests that non-functional CCL16 genes are evolving faster than the functional version of this gene that persists in some members of the superorder Glires.

Implications: The authors state their results suggest that species within the superorder Glires may have evolved mutations related to non-functional CCL16 independently. The authors suggest that the evolution of non-functional CCL16 is ongoing, and that these mutations may be beneficial to lagomorphs - perhaps relating to pathogen resistance or other biological functions.

Topics: genetics; sensitive/rare wildlife 


\section{Nobler, J.D., Camp, M.J., Crowell, M.M., Shipley, L.A., Dadabay, C., Rachlow, J.L., James, L., and Forbey, J.S., 2019, Preferences of specialist and generalist mammalian herbivores for mixtures versus individual plant secondary metabolites: Journal of Chemical Ecology, v. 45, no. 1, p. 74-85.}

DOI: https://doi.org/10.1007/s10886-018-1030-5

Background: Plant secondary metabolites are chemicals that have physiological effects on animals that consume them and may therefore influence foraging behavior of both dietary specialists, such as pygmy rabbits, and dietary generalists, such as mountain cottontail rabbits. Because plant secondary metabolites occur in varying complexities and different species have a variable capacity to detoxify them, the specific compounds, concentrations, and combinations that influence foraging behavior are poorly understood.

Objectives: The authors sought to (1) determine the preferences of pygmy rabbits and mountain cottontails for individual and combined plant secondary metabolites in sagebrush, and (2) determine the rate of detoxification of the same metabolites from pygmy rabbits and mountain cottontails.

Methods: The authors captured wild adult rabbits from three locations. In spring of 2014, they determined relative concentrations of the 5 most prevalent plant secondary metabolites from 420 Wyoming big sagebrush plants that showed evidence of prior rabbit browsing. The authors added the top five plant secondary metabolites to rabbit food individually and as combinations in their naturally occurring proportions. They then conducted five feeding trials to determine foraging preferences of pygmy rabbits and mountain cottontails. They also added plant secondary metabolites to in vitro enzymatic assays using rabbit livers to determine detoxification rates.

Location: Idaho, Montana, Washington

Findings: Pygmy rabbits consumed more individual plant secondary metabolites and showed less preference between individual and mixed plant secondary metabolites than cottontail rabbits did. Pygmy rabbit enzymatic assays showed faster rates of detoxification than mountain cottontail rabbits for all plant secondary metabolites, though detoxification rates varied among individual metabolites. Pygmy rabbits preferred camphor, the plant secondary metabolite with the slowest detoxification rate, while cottontails avoided it. Both rabbit species avoided $\beta$-pinene, despite it having a fast detoxification rate.

Implications: The authors found that pygmy rabbits have a higher detoxification capacity than mountain cottontail rabbits, but that it did not always correspond with dietary preference. They therefore suggest that alternative mechanisms also influence dietary preference of plant secondary metabolites. Finally, the authors suggest that their methods can help determine which plant secondary metabolites influence diet selection for specialist and generalist herbivores.

Topics: behavior or demographics; grazing/herbivory; sensitive/rare wildlife

\section{Olsoy, P.J., Shipley, L.A., Rachlow, J.L., Forbey, J.S., Glenn, N.F., Burgess, M.A., and Thornton, D.H., 2018, Unmanned aerial systems measure structural habitat features for wildlife across multiple scales: Methods in Ecology and Evolution, v. 9, no. 3, p. 594-604.}

DOI: https://doi.org/10.1111/2041-210X.12919

Background: Broad-scale ecological research is increasing, yet current field-based methods of assessing habitat quality do not always scale to larger spatial extents. Fine-scale variability in habitat quality is important for many terrestrial wildlife species, like pygmy rabbits, which are strongly influenced by the structure of sagebrush habitat. Unmanned aerial systems may provide a method for creating high-resolution maps that depict variability at a scale relevant to management of pygmy rabbit and other species.

Objectives: The authors sought to determine if unmanned aerial systems could be used to (1) measure fine-scale habitat features and (2) estimate habitat quality for pygmy rabbits at a landscape scale. 
Methods: In June of 2013 the authors used an unmanned aerial system to collect 1,600 photographs at the first field site, and in June of 2015 they took 1,300 photographs at a second field site. The authors also measured vegetation height, volume, and canopy cover using ground-based terrestrial laser scanning and field-based measurements at several plots within each field site. Photographs from unmanned aerial systems were processed and compared to data from ground-based surveys at plant, patch, and landscape scales.

Location: Idaho

Findings: At the plant scale, unmanned aerial systems predicted structural measurements from terrestrial laser scanning better than field-based measurements. At the patch scale, variables estimated by unmanned aerial systems were more related to field-based measurements than at the plant scale. Landscape-scale maps depicted patterns of structural heterogeneity between different patch types that were relevant to pygmy rabbits.

Implications: The authors state that unmanned aerial systems are capable of estimating sagebrush steppe habitat characteristics at fine spatial scales and may be more accurate at large spatial extents than field-based measurements. The authors suggest that this approach can accurately depict structural habitat quality and highlight areas of functional heterogeneity, which are important in understanding animal space use. They suggest that unmanned aerial systems provide a rapid and low-cost method to measure habitat structure that can aid conservation and management of wildlife species.

Topics: broad-scale habitat characteristics; site-scale habitat characteristics; sensitive/rare wildlife

\section{Olsoy, P.J., Forbey, J.S., Shipley, L.A., Rachlow, J.L., Robb, B.C., Nobler, J.D., and Thornton, D.H., 2020, Mapping foodscapes and sagebrush morphotypes with unmanned aerial systems for multiple herbivores: Landscape Ecology, v. 35, p. 921-936.}

DOI: https://doi.org/10.1007/s10980-020-00990-1

Background: Herbivores choose where to forage based on forage quality, which changes seasonally. Scientists struggle to map forage quality at finer resolutions due to time and cost constraints, however, new technology with unmanned aerial systems may allow scientists to map forage quality at smaller scales. Sagebrush ecosystems are important to some key herbivores and a greater understanding of forage quality may benefit management of these species.

Objectives: The authors sought to (1) determine spatial patterns of plant chemicals that alter forage quality at a fine scale, (2) compare differences in plant chemicals across landscapes during summer and winter, and (3) evaluate how the physical structure and different species of sagebrush impact the ability to map plant chemicals.

Methods: The authors established two study sites within sagebrush ecosystems. They classified sagebrush into three physical structure types, randomly selected sampling patches, and quantified plant chemicals by clipping samples and analyzing their amount of protein and plant chemicals. During June 2013 and 2015, they took photos of the landscape using unmanned aerial systems and used models to classify sagebrush type, map plant chemicals, and analyze forage quality across the landscape.

Location: Idaho

Findings: The authors found chemistry of sagebrush to be variable, with plant chemicals differing between sites, seasons, and sagebrush types. During the summer, protein content was higher and patches with higher protein were more connected. The authors had high accuracy in classifying sagebrush type at both sites. They found forage quality extremely variable depending on site, season, and type, and discovered use of models to classify plant chemical content depended on chemical type, with coumarins predicted more accurately than others.

Implications: The authors suggest their methods could be used to map various types of diverse environmental structures. They state that when mapping plant chemicals, there is higher accuracy when chemical concentrations are distinct between structure types. Because forage quality and connectedness varied seasonally, they suggest smaller herbivores, such as pygmy rabbits, may be more at risk of isolation from small-scale fragmentation. Finally, the authors state that landscape wide mapping of forage quality will help managers prioritize functional habitat features.

Topics: broad-scale habitat characteristics; site-scale habitat characteristics; habitat selection; sensitive/rare wildlife 


\title{
Parsons, M.A., Barkley, T.C., Rachlow, J.L., Johnson-Maynard, J.L., Johnson, T.R., Milling, C.R., Hammel, J.E., and Leslie, I., 2016, Cumulative effects of an herbivorous ecosystem engineer in a heterogeneous landscape: Ecosphere, v. 7, no. 3, article e01334, 17 p.
}

\author{
DOI: https://doi.org/10.1002/ecs2.1334
}

Background: Some herbivores are considered ecosystem engineers, as they exhibit activities that can directly or indirectly alter vegetation communities such as digging, foraging, and depositing waste. Because patchy landscapes can concentrate animal activity, herbivores may have greater localized impacts on these communities over time. However, the influence of pygmy rabbit activities within patchy landscapes is poorly understood.

Objectives: The authors sought to (1) quantify the effects of pygmy rabbit browsing on sagebrush, (2) determine if pygmy rabbit burrowing and waste deposition alters soil characteristics, and (3) evaluate the impacts of pygmy rabbit activities on vegetation reproduction and landscape heterogeneity over time.

Methods: The authors conducted annual surveys to map pygmy rabbit burrows on domelike natural mounds at two study sites during September or October of each year from 2002 to 2014. They categorized burrows based on how recently they appeared used and tracked the duration of pygmy rabbit occupancy at surrounding mounds. The authors collected and analyzed soil, measured vegetation cover and sagebrush reproductive output, and counted fecal pellets from occupied and unoccupied mounds. They sampled vegetation at 104 mounds and analyzed soil from 52 mounds.

Location: Idaho

Findings: The authors found that percentage of browsed sagebrush was positively correlated with duration of occupancy, and that browsing reduced the amount of sagebrush available for forage and cover from predators. Density of fecal pellets and localized soil disturbance also increased with duration of occupancy. Pygmy rabbit occupancy on mounds had a significant correlation with decreased ammonium and increased nitrate within soils. Indirect effects from pygmy rabbits significantly increased sagebrush reproduction at both sites and seedling density at one site.

Implications: While pygmy rabbits directly reduced sagebrush through foraging, the authors suggest that they had a net positive impact overall by indirectly increasing sagebrush reproduction via fecal pellet deposition and ground disturbance on mounds. They note that rabbits may degrade habitat quicker than it can recover, and that population persistence may require an excess of suitable patches for rabbits to move between. The authors propose that pygmy rabbits are an important ecosystem engineer and help to maintain heterogeneity in sagebrush dominated landscapes.

Topics: behavior or demographics; broad-scale habitat characteristics; site-scale habitat characteristics; grazing/herbivory; soils or geology; sensitive/rare wildlife

\section{Pierce, J.E., Larsen, R.T., Flinders, J.T., and Whiting, J.C., 2011, Fragmentation of sagebrush communities-Does an increase in habitat edge impact pygmy rabbits?: Animal Conservation, v. 14, no. 3, p. 314-321.}

\author{
DOI: https://doi.org/10.1111/j.1469-1795.2010.00430.x
}

Background: Sagebrush communities across the western United States are experiencing fragmentation and reduction, leading to an increase in edge habitat. Pygmy rabbits are reliant on sagebrush communities for survival, and more research is needed to determine how an increased amount of edge habitat may impact them, their competitors, and their predators.

Objectives: The authors sought to (1) quantify pygmy rabbit activity in edge habitat and non-edge habitat, and (2) understand predator and competitor activity within edge habitat and non-edge habitat.

Methods: From November 2004 to August 2009, the authors surveyed for occupied and unoccupied pygmy rabbit burrows in a landscape that had been fragmented to restore understory grasses and forbs. Beginning in May 2006, they set up camera traps at 313 randomly selected burrows and left them out for up to 4 weeks to monitor pygmy rabbits, other rabbit species, and predators. From 2005 to 2007, they sampled for fecal pellets to determine burrow use by pygmy rabbits, cottontails, and black-tailed jack rabbits. They recorded the distance between each burrow and the nearest habitat edge. 


\title{
Location: Utah
}

Findings: The authors found that the proportion of active pygmy rabbit burrows decreased as the distance from edge habitat decreased. They also observed fewer camera trap images of pygmy rabbits near edge habitat, while images of predators and competitors in edge habitat increased. Finally, they found that pygmy rabbit fecal pellets decreased near edge habitat, while fecal pellets from cottontails and jackrabbits were more abundant.

Implications: The authors suggest that a decrease in abundance of pygmy rabbits near edge habitat may be due to a higher number of predators and competitors in those areas. They propose fragmentation may limit pygmy rabbit population sizes, impede movement between habitat patches, and facilitate the spread of disease. The authors therefore note that edge habitat is an important consideration when planning for pygmy habitat conservation. They recommend that if mechanical reduction of sagebrush is necessary, buffers should be maintained around burrow systems and corridors should be maintained between habitat patches to facilitate dispersal.

Topics: behavior or demographics; broad-scale habitat characteristics; habitat selection; effect distances or spatial scale; predators or predator control; sensitive/rare wildlife

\section{Price, A.J., Estes-Zumpf, W., and Rachlow, J., 2010, Survival of juvenile pygmy rabbits: Journal of Wildlife Management, v. 74, no. 1, p. 43-47.}

\author{
DOI: https://doi.org/10.2193/2008-578
}

Background: Juvenile survival is one of the most important demographic parameters influencing population growth for many short-lived and highly reproductive species such as pygmy rabbits. However, natal behavior of pygmy rabbits is cryptic, and therefore little is known about the survival of juvenile pygmy rabbits in the wild.

Objectives: The authors sought to (1) estimate survival rates of wild juvenile pygmy rabbits and (2) determine factors affecting survival rates.

Methods: From May to July of 2004 and 2005, the authors captured 50 juvenile pygmy rabbits outside their natal burrows at 2 study sites. They measured and weighed rabbits, determined their age and sex, and fitted them with small glue-on radio transmitters. Once rabbits were six weeks old, the authors recaptured them and fitted them with radio collars. They tracked rabbits every three to four days until August, and then biweekly until April. The authors determined age and cause of death when possible for rabbits that did not survive. Finally, they used modeling to determine the influence of several variables on survival.

Location: Idaho

Findings: Of the juvenile rabbits that the authors collected data on, 24 survived until 18 weeks and 11 survived until April of the following year. Juvenile pygmy rabbit survival up to 18 weeks varied between study sites and years. Overall, survival decreased over time and was not impacted by dispersal. The authors also found that individuals born later in the season were less likely to survive.

Implications: The authors suggest that juvenile pygmy rabbit survival is variable and that this may lead to fluctuations in population size, or cause extirpation in isolated populations. As such, they note that further research into the connectivity of populations and assessing population trends at a larger spatial scale are imperative for understanding conservation needs.

Topics: survival; behavior or demographics; population estimates or targets; sensitive/rare wildlife 


\title{
Price, A.J., and Rachlow, J.L., 2011, Development of an index of abundance for pygmy rabbit populations: Journal of Wildlife Management, v. 75, no. 4, p. 929-937.
}

\author{
DOI: https://doi.org/10.1002/jwmg.103
}

Background: Obtaining population estimates for patchily distributed species, such as the pygmy rabbit, is often resource intensive and logistically difficult. Counts of burrow entrances have been used to estimate abundance for burrowing species, and a calibrated index of burrow density and activity could provide key data on pygmy rabbit abundance and distribution that can inform conservation planning.

Objectives: The authors sought to evaluate pygmy rabbit burrows as an index of abundance by (1) determining the relationship between burrow densities and population densities, (2) examining the use of burrows by individual rabbits, and (3) determining the relationship between pygmy rabbit densities and vegetation cover.

\begin{abstract}
Methods: At 7 sites from September to November of 2007 and 2008, the authors measured vegetation, censused burrow systems, ranked burrow activity status using fecal pellet condition, and trapped and collared 80 pygmy rabbits. They used a combination of mark-resight and snow track surveys to estimate population size. The authors used a subset of standardized telemetry data to determine spatial distribution of burrows and evaluate patterns of burrow use. Finally, they employed several statistical modeling techniques to analyze their data.
\end{abstract}

Location: Idaho

Findings: The density estimates of burrows, abundance of rabbits, and density of rabbits varied by site. There was a positive correlation between burrow density and pygmy rabbit density, though increases in rabbit pygmy rabbit density slowed as burrow density increased. Individual rabbits used between one and six different burrow systems, and the number of burrows used by an individual increased with the density of active burrows available. Pygmy rabbit density was also positively correlated with visual obstruction caused by shrub cover.

Implications: The authors suggest that the density of pygmy rabbit burrows may serve as a useful index to estimate population abundance or monitor change in abundance over time. Furthermore, they state these surveys are cost-effective and noninvasive, making them pragmatic for most applications. The authors note that site-level covariates should be assessed and incorporated for this index to be used at different spatial extents or within different geographic regions.

Topics: behavior or demographics; population estimates or targets; site-scale habitat characteristics; habitat selection; sensitive/ rare wildlife

\section{Pu, X., Lam, L., Gehlken, K., Ulappa, A.C., Rachlow, J.L., and Forbey, J.S., 2015, Antioxidant capacity of Wyoming big sagebrush (Artemisia tridentata ssp. wyomingensis) varies spatially and is not related to the presence of a sagebrush dietary specialist: Western North American Naturalist, v. 75, no. 1, p. 78-87.}

DOI: https://doi.org/10.3398/064.075.0109

Background: Some plants minimize oxidative stress caused by environmental factors such as extreme temperatures, herbivory, and pathogens by producing polyphenols, a type of antioxidant. Sagebrush occurs across a wide range of environmental conditions and has therefore evolved a diverse array of antioxidants. However, antioxidant capacity in North American sagebrush species has not been investigated.

Objectives: The authors sought to (1) examine the relationship between polyphenols and antioxidant capacity in sagebrush, (2) determine if antioxidant capacity in sagebrush species varies spatially, (3) determine differences in antioxidants in sagebrush based on leaf type, and (4) establish if there are interactions between antioxidant capacity and herbivory by a sagebrush specialist, the pygmy rabbit. 
Methods: In the winter of 2009 and spring of 2010 and 2012, the authors collected sagebrush leaves at one or two field sites. They collected sagebrush leaves from heavily and lightly browsed plants, plants with varying degrees and duration of occupancy by pygmy rabbits, and plants located on and off of mima mounds, a natural domelike area of raised sediment. They also compared ephemeral and persistent leaves within individual plants on unoccupied mima mounds. The authors extracted polyphenols from all leaf samples, determined antioxidant capacity, and investigated interactions between variables.

Location: Idaho

Findings: The authors found a positive correlation between polyphenol content and antioxidant capacity at both sites, however, polyphenol content varied by site. Polyphenol content was higher in plants located off of mima mounds, and both polyphenol content and antioxidant capacity were higher in persistent leaves. They did not find a difference in antioxidant capacity or polyphenol content between plants with high or low levels of pygmy rabbit browsing, or between pygmy rabbit occupied and unoccupied mounds.

Implications: The authors state that herbivory from pygmy rabbits did not illicit an increase in polyphenol content or antioxidant capacity. They suggest that the observed increases in antioxidant capacity may have resulted from abiotic factors such as spatial variation, colder temperatures, water stress, or sunlight, and that changing environmental conditions may impact sagebrush stress ecology. Additionally, they suggest that antioxidants in sagebrush plants could provide a biomarker of environmental stress, and aid managers in assessing sagebrush health.

Topics: grazing/herbivory; sensitive/rare wildlife

\section{Rachlow, J.L., Sanchez, D.M., and Estes-Zumpf, W.A., 2005, Natal burrows and nests of free-ranging pygmy rabbits (Brachylagus idahoensis): Western North American Naturalist, v. 65, no. 1, p. 136-139.}

Persistent URL: https://jstor.org/stable/41717435

Background: Pygmy rabbits are a species of conservation concern, but several aspects of their natural history are not well understood. While captive populations have provided some insights on reproductive behaviors, little is known about natal burrows in wild populations.

Objectives: The authors sought to identify and describe nesting behaviors and natal burrows of free-ranging pygmy rabbits.

Methods: From April to July 2003, the authors located a total of seven vacant natal burrows of pygmy rabbits at two sites, six of which were complete. They observed pygmy rabbit behavior, took measurements of the burrows, examined nesting materials, and measured nearby vegetation. They also searched for nearby residential burrow systems and evaluated their spatial relationships with natal burrows.

Location: Idaho

Findings: The authors observed females digging and backfilling natal burrows, as well as the creation of dead-end tunnels in the vicinity of true natal burrows. They found size, construction, and nesting material to be similar among the six completed natal burrows, while the unfinished natal burrow had structural differences. Rabbits primarily used their fur, grass, and sagebrush bark as nesting material. Pygmy rabbits built natal burrows with only one entrance and tended to place them under dense shrub cover and away from residential burrows.

Implications: The authors state that this study provides the first documentation of free-ranging pygmy rabbit natal burrows. The authors observed behaviors in wild rabbits that had previously been seen in captive populations and documented the use of a new nesting material, sagebrush bark. They suggest that pygmy rabbits build natal burrows away from residential burrows to reduce predation on juveniles. Due to the difficulty of finding natal burrows, they suggest that researchers focus on observations of nest-building in order to locate them.

Topics: behavior or demographics; site-scale habitat characteristics; habitat selection; effects distances or spatial scale; sensitive/ rare wildlife 


\title{
Rachlow, J.L., and Svancara, L.K., 2006, Prioritizing habitat for surveys of an uncommon mammal-A modeling approach applied to pygmy rabbits: Journal of Mammalogy, v. 87, no. 5, p. 827-833.
}

\author{
DOI: https://doi.org/10.1644/05-MAMM-A-387R2.1
}

Background: Determining occurrence for rare species is challenging, but models that predict habitat suitability can increase survey success and aid in conservation planning. A better understanding of pygmy rabbit habitat use is needed to develop quantitative models for the species.

Objectives: The authors sought to (1) create a habitat model for pygmy rabbits, and (2) validate their model by conducting field surveys.

Methods: The authors created a base map of potential pygmy rabbit habitat using spatial vegetation and soil depth data. They conducted a literature search to determine important habitat variables and then used 164 documented pygmy rabbit occurrences to evaluate the importance of slope, elevation, percent clay content of soil, and fire history at those points. They used these results to rank potential habitat from high to low survey priority. From June to September of 2003, they measured habitat variables and conducted surveys for pygmy rabbit presence or absence at 141 sites across all habitat rankings to evaluate the performance of their model.

Location: Idaho

Findings: The authors' base map classified 5.7 million hectares of land in Idaho as possible pygmy rabbit habitat, and their habitat model ranked 3.4 million hectares as high priority. They determined model accuracy to be 65 percent and found that most new pygmy rabbit occurrences happened in the top two priority ranks of four final ranks. Vegetation type and fire history were useful in categorizing priority areas, while elevation was not.

Implications: While the authors found their habitat model to be accurate, they note that other factors impact species occurrence and therefore their model likely overpredicts suitable habitat. They also note that their cutoff for soil depth may have been too stringent and increasing this may improve model performance. They suggest that their model may aid researchers by identifying high priority regions for pygmy rabbits on a broad scale, and that researchers should use local knowledge to focus survey efforts at a site-scale. The authors also stress the importance of using the correct spatial and temporal scales when developing habitat models.

Topics: broad-scale habitat characteristics; site-scale habitat characteristics; habitat selection; fire; soils or geology; sensitive/ rare wildlife

\section{Rachlow, J.L., Peter, R.M., Shipley, L.A., and Johnson, T.R., 2014, Sub-lethal effects of capture and collaring on wildlife-Experimental and field evidence: Wildlife Society Bulletin, v. 38, no. 3, p. 458-465.}

DOI: https://doi.org/10.1002/wsb.444

Background: Telemetry is commonly used to study behaviors of elusive or wide-ranging species. However, fitting animals with telemetry devices may incur negative effects by causing injury or death, or by altering their behavior and physiology. A better understanding of the sub-lethal effects of telemetry devices and how these effects might change over time is needed to more accurately estimate the impacts of this research technique on pygmy rabbits.

Objectives: The authors sought to (1) evaluate whether radio collars increase pygmy rabbit vulnerability to predation by increasing their grooming activity, and (2) determine if individuals alter their space use due to the disturbance caused by being captured and collared.

Methods: In September 2006, the authors observed nine captive pygmy rabbit males to investigate grooming behaviors. They monitored rabbit behavior without radio collars for one week, then attached radio collars and used motion-activated cameras to record and quantify above-ground behaviors for an additional week. The authors weighed rabbits before, during, and after observations, and modeled grooming behaviors. Next, they trapped 99 wild adult rabbits and fitted them with radio collars to investigate space use from 2004 to 2008. The authors located rabbits two to three times a week and quantified movement patterns. 
Location: Idaho, Washington

Findings: Grooming frequency increased immediately after radio collars were placed on captive rabbits but decreased over time and was similar to pre-collaring levels after the first week. Body weights of captive rabbits fluctuated, and most lost weight but remained within normal range. The movements of wild rabbits increased following collaring but subsequently decreased over time. Wild rabbits also avoided areas where they were captured, and some individuals continued to avoid these areas for 2 to 4 weeks.

Implications: The authors suggest that increased grooming may decrease vigilance and increase predation risk, which may impact survival. They propose that shifts in space use due to collaring may represent a shift of use within home range, which may introduce biases in studies on pygmy rabbit movements. The authors suggest these results may help future researchers mitigate impacts on pygmy rabbits and better understand biases that may exist.

Topics: survival; behavior or demographics; habitat selection; effect distances or spatial scale; sensitive/rare wildlife

\section{Ramos, C.N., 1999, An Irvingtonian species of Brachylagus (Mammalia: Lagomorpha) from Porcupine Cave, Park County, Colorado: Great Basin Naturalist, v. 59, no. 2, p. 151-159.}

DOI: https://doi.org/10.5962/bhl.part.15819

Background: The pygmy rabbit is the only living species of the genus Brachylagus, and although a lack of fossil evidence makes its origins uncertain, the species is thought to have existed in the Great Basin for much of its evolutionary history. However, new fossil material was discovered that may provide more insight on the origins of the pygmy rabbit.

Objectives: The author sought to (1) determine whether fossil remains belong to a known or newly discovered species and (2) hypothesize its evolutionary relationship to modern day pygmy rabbits.

Methods: Researchers screened, washed, and collected fossil materials from Porcupine Cave. They took collected materials to a lab for further processing, where the author measured several areas of the jaw and teeth on adult specimens. The author took the same measurements on 85 skulls of adult pygmy rabbits for comparison during statistical analysis.

Location: Colorado

Findings: Comparisons of measurements from the teeth and jaws suggest that the fossil remains are a newly discovered species, which the author named Brachylagus coloradoensis. The author suggests that this new species may have a closer evolutionary relationship to extant pygmy rabbits than other known species.

Implications: The author states that while the newly discovered species provides insight into the evolution of the current day pygmy rabbit, there is still not enough information to determine the origins of the genus itself. They note that new findings from this cave are ongoing and will continue to clarify the evolutionary history of the pygmy rabbit.

Topics: paleontological resources; sensitive/rare wildlife

\section{Rowland, M.M., Wisdom, M.J., Suring, L.H., and Meinke, C.W., 2006, Greater sage-grouse as an umbrella species for sagebrush-associated vertebrates: Biological Conservation, v. 129 , no. 3, p. 323-335.}

DOI: https://doi.org/10.1016/j.biocon.2005.10.048

Background: Greater sage-grouse garner high levels of conservation interest and priority, and are considered an umbrella species in the Great Basin region. Management efforts to support umbrella species may benefit several species with overlapping ranges if they share similar resource requirements. It is unknown how much sagebrush-dependent species like pygmy rabbits may benefit under the greater sage-grouse management umbrella.

Objectives: The authors studied the potential for sage-grouse management actions to impact other sagebrush-associated species with overlapping ranges by measuring their (1) habitat type overlap, (2) spatial range overlap, (3) overlap in habitat at risk of cheatgrass displacement, and (4) considering the implications of their findings to management planning. 
Methods: The authors selected 39 sagebrush-associated vertebrates of conservation concern within the historic range of greater sage-grouse in the Great Basin. They classified 47 habitat types in the region and associated each species with one or more habitat types for comparison to sage-grouse data. The authors also gathered information about the geographic ranges of each species to assess spatial overlap with greater sage-grouse. They then used a previously developed model to compare the amount of overlap in habitat at-risk from cheatgrass displacement between greater sage-grouse and the other species. Finally, they used these three overlap measurements to calculate the potential benefit of sage-grouse habitat improvements for each species of concern.

\section{Location: California, Nevada, Utah}

Findings: The authors found a positive correlation between sagebrush obligate species, especially pygmy rabbits, and greater sage-grouse in the degree of overlap in habitat type, spatial range, and high-risk habitat. Mammals had the highest level of habitat type overlap with sage-grouse and reptiles had the lowest. Using greater sage-grouse as an umbrella species for this ecosystem was not significantly better than using randomly selected sites for about half the species of conservation concern evaluated.

Implications: The authors determined that greater sage-grouse is not an effective umbrella species for the region, except for sagebrush-obligate species. The authors advise against using a single species management approach and instead recommend using a small group of umbrella species to target management actions that could more effectively benefit the entire sagebrush ecosystem.

Topics: broad-scale habitat characteristics; habitat selection; nonnative invasive plants; sensitive/rare wildlife

\section{Sanchez, D.M., and Rachlow, J.L., 2008, Spatio temporal factors shaping diurnal space use by pygmy rabbits: Journal of Wildlife Management, v. 72, no. 6, p. 1304-1310.}

DOI: https://doi.org/10.2193/2007-225

Background: Pygmy rabbits are a sagebrush specialist that are of management concern as a result of widespread habitat conversion. To improve management planning for pygmy rabbits, it is important to understand the factors that influence their spatial use patterns.

Objectives: The authors wanted to determine (1) if the sex of pygmy rabbits affects home range size and movements, (2) whether there are seasonal changes in space use patterns, and (3) the influence of site-specific resource distribution on space use patterns

Methods: The researchers trapped and radio-collared pygmy rabbits between 2004 and 2005 at three sites with variable distributions of food and cover resources. They maintained a sample size of 36 to 48 collared rabbits. They recorded spatial location data regularly during the day and estimated seasonal and annual home ranges. The authors surveyed two sites for pygmy rabbit sign in Fall 2003 and 2005 to identify the number and spatial arrangement of burrow systems.

\section{Location: Idaho}

Findings: The authors found that male pygmy rabbits had annual and seasonal home ranges that were larger than those for females. The data indicated that male home ranges were largest during the breeding season and that female home ranges remained stable across seasons. Pygmy rabbit home ranges varied between years, but often overlapped the previous extent. Additionally, pygmy rabbits at the site with higher sagebrush cover had larger annual home ranges than pygmy rabbits at the site with lower and more patchily distributed cover.

Implications: The authors suggest that pygmy rabbits have larger home ranges than expected by body size due to the high energy requirements of the species. They recommend that wildlife managers consider both the large, fluctuating home ranges of pygmy rabbits as well as the amount and distribution of cover and other resources at the site-level when making long-term conservation plans.

Topics: behavior or demographics; site-scale habitat characteristics; predators or predator control; effect distances or spatial scale; sensitive/rare wildlife 


\title{
Sanchez, D.M., Rachlow, J.L., Robinson, A.P., and Johnson, T.R., 2009, Survey indicators for pygmy rabbits-Temporal trends of burrow systems and pellets: Western North American Naturalist, v. 69, no. 4, p. 426-436.
}

DOI: https://doi.org/10.3398/064.069.0402

Background: Pygmy rabbits are a rare and cryptic species, so researchers rely on indirect indicators like fecal pellets and burrows to estimate relative and absolute abundance. Both fecal pellets and burrow systems change over time making it difficult to determine if a burrow is active. An evaluation of these indirect abundance estimation techniques is needed.

Objectives: The authors aimed to (1) evaluate impacts of environment and time on fecal pellet persistence and appearance and (2) observe whether complexity and activity in burrow systems changes temporally, seasonally, or between sites.

Methods: To study fecal pellet persistence, the researchers collected 38 fresh fecal pellets during breeding and nonbreeding seasons and kept them refrigerated until deployment. They set the pellets outside active burrows at two study sites during the 2005 breeding season. Some pellets were placed beneath sagebrush and others were placed in more exposed areas and were monitored for at least 34 months. The researchers also recorded changes in color and appearance for one year. Additionally, they mapped burrow systems in October 2003, recorded the number of burrow entrances, and classified activity levels using 2 established systems used in Idaho and Washington for 60 burrow systems. The researchers monitored the burrows quarterly from March 2004 to September 2005 and documented any changes in activity or number of entrances at the burrow systems. They used statistical models to relate complexity and activity to season and other explanatory variables.

Location: Idaho

Findings: The authors found that pellet persistence was higher in shrub-protected fecal pellets than exposed pellets. Exposed pellets lasted 24 months maximum, and sheltered pellets lasted a maximum of 34 months. The authors found that burrow system activity did not change seasonally or annually.

Implications: The authors suggest that researchers continue to use both fecal pellets and burrow activity to estimate pygmy rabbit abundance. They recommend that other researchers consider pellet persistence when determining the activity level of burrow systems, since the pellet freshness can be difficult to determine accurately. They recommend using the Washington pellet classification system in areas with low population density and the Idaho system for studying changes in population activity.

Topics: population estimates or targets; sensitive/rare wildlife

\section{Scarlata, C.D., Elias, B.A., Godwin, J.R., Powell, R.A., Shepherdson, D., Shipley, L.A., and Brown, J.L., 2011, Characterizing gonadal and adrenal activity by fecal steroid analyses in pygmy rabbits (Brachylagus idahoensis): General and Comparative Endocrinology, v. 171 no. 3, p. 373-380.}

\author{
DOI: https://doi.org/10.1016/j.ygcen.2011.03.002
}

Background: Pygmy rabbits are declining throughout their range and the Columbia Basin population was listed as endangered following population collapse, prompting captive breeding efforts to reintroduce the population into the wild. Captive breeding programs have seen low reproductive success. Information on pygmy rabbit endocrinology is needed to monitor stress and increase reproductivity of captive pygmy rabbits.

Objectives: The authors sought to (1) develop methods for noninvasive monitoring of stress and reproductive hormones in pygmy rabbits, (2) study hormone changes during pregnancy and lactation, and (3) study seasonal changes in stress and reproductive hormones.

Methods: The authors studied the hormone levels of 27 captive-born adult female pygmy rabbits over 3 breeding and nonbreeding seasons between October 2005 and December 2009. They documented pregnancies using observations of nest-building behaviors and collected fecal samples two to seven times a week from which they extracted stress and reproductive hormones. The authors calculated mean and baseline hormone levels for each rabbit. They then analyzed each rabbit's hormone levels by season, month, gestation period, and lactation period. 


\section{Location: Not specified}

Findings: After establishing noninvasive methods to measure hormones, the authors found a significant increase in reproductive hormone levels the day following copulation. They discovered that reproductive and stress hormones slowly rise during gestation, typically peak zero to three days pre-partum, and then decrease post partum. In over half of the pregnancies, the authors found that both stress hormones and reproductive hormones doubled zero to three days pre-partum. During lactation, they found that reproductive hormone levels remained near baseline and stress hormone levels varied between individuals. The authors found that stress hormones were highest in the winter and lowest in the spring, and that conception rates were highest in April and May.

Implications: The authors recommend continued monitoring of hormone levels in captive breeding facilities to provide information on improving reproductive output. They suggest using the spike in reproductive hormones immediately after copulation as a pregnancy indicator. The authors suggest that the pre-partum spike in reproductive hormones may influence nest-building behavior.

Topics: behavior or demographics; captive breeding; sensitive/rare wildlife

\section{Scarlata, C.D., Elias, B.A., Godwin, J.R., Powell, R.A., Shepherdson, D., Shipley, L.A., and Brown, J.L., 2012, Relationship between fecal hormone concentrations and reproductive success in captive pygmy rabbits (Brachylagus idahoensis): Journal of Mammalogy, v. 93, no. 3, p.759-770.}

DOI: https://doi.org/10.1644/11-MAMM-A-223.1

Background: Captive breeding programs can aid in the recovery of declining species, but the efficacy of these programs is variable. Stress is known to hinder reproduction by influencing behaviors and suppressing reproductive hormones. Captive breeding is being used to increase the population of the endangered Columbia Basin pygmy rabbit, so a study on stress in captive pygmy rabbits is a conservation priority.

Objectives: The authors sought to (1) compare average hormone levels between pregnant and non-pregnant females throughout the breeding season, (2) study hormone levels during the mating period to identify an indicator of successful breeding, and (3) determine the effect of stress hormones during gestation on offspring survival and litter size.

Methods: The authors studied 48 captive-born adult female pygmy rabbits from January 2006 to December 2008. Researchers collected fecal samples several times per week during the breeding season and calculated baseline hormone levels for each rabbit. The authors analyzed changes to stress and reproductive hormone concentrations across the breeding season. They also studied stress and reproductive hormone levels during the mating period to look for hormonal indicators of successful mating and compared stress hormone levels during gestation and lactation to offspring survival and litter size.

Location: Idaho, Washington

Findings: The authors sampled 123 pregnancies in 41 individual females and found stress and reproductive hormones fluctuated across the breeding season. Stress and reproductive hormone concentrations increased during gestation and decreased after birth. The authors found that lower stress hormone concentrations and higher reproductive hormone concentrations significantly improved the likelihood of breeding success. The authors found that a significant increase in reproductive hormones the day after copulation was an indicator of successful mating. They also found that high stress hormone concentration during late gestation negatively impacted offspring survival.

Implications: The authors suggest that high stress negatively impacted conception, conception rates, and litter survival in pygmy rabbits and recommend future studies focus on what causes this stress. The authors also recommend testing reproductive hormone concentrations to identify successful pairings and suggest that high stress hormone concentrations towards the end of gestation may be the best indicator of litter survival.

Topics: behavior or demographics; survival; captive breeding; sensitive/rare wildlife 


\title{
Scarlata, C.D., Elias, B.A., Godwin, J.R., Powell, R.A., Shepherdson, D., Shipley, L.A., and Brown, J.L., 2013, Influence of environmental conditions and facility on faecal glucocorticoid concentrations in captive pygmy rabbits (Brachylagus idahoensis): Animal Welfare, v. 22, no. 3, p. 357-368.
}

\author{
DOI: https://doi.org/10.7120/09627286.22.3.357
}

Background: Captive breeding is being used to increase the population of the endangered pygmy rabbit, but reproductive rates are low. Low reproduction may be caused by chronically high stress hormone levels that suppress fecundity. Captive breeding programs would benefit from understanding what environmental conditions increase pygmy rabbit stress.

Objectives: The authors sought to determine if captive pygmy rabbit stress hormone levels are influenced by (1) pen size and (2) soil availability.

Methods: The authors studied 55 adult female pygmy rabbits at two captive breeding facilities. Pen sizes at the breeding facilities ranged from crates at $0.37 \mathrm{~m}^{2}$ to carports at $75 \mathrm{~m}^{2}$, and soil treatments ranged from no soil to full soil. They collected fresh pygmy rabbit fecal pellets regularly during breeding and nonbreeding seasons from January 2006 to December 2008 . The authors measured glucocorticoid concentration of fecal pellets to establish baseline stress levels and compare levels between 35 rabbits with different pen sizes and 24 rabbits with varying soil enrichment. The authors also studied rabbits that were moved between pen sizes.

Location: Not specified

Findings: The authors found that pygmy rabbits in crates had the highest stress hormone levels. Pygmy rabbits living in all other pen sizes did not show significant differences in baseline glucocorticoid levels. Rabbits with soil enrichment had lower glucocorticoid levels than rabbits without soil enrichment. Baseline glucocorticoid levels varied between facilities. Rabbits that moved from crates to pens had higher stress hormone levels in the crates than in the larger pens.

Implications: The authors claim that decreasing stress of pygmy rabbits in captive breeding facilities may lead to higher reproductive rates. The authors note that stress hormone levels may be influenced by specific husbandry practices or environmental factors at captive facilities. To decrease stress of captive pygmy rabbits, the authors advise against keeping rabbits in crates, and instead suggest dividing large pens and creating hiding spots to eliminate the need for crates. The authors suggest that the presence of soil also reduces stress and recommend filling at least half of the pen with soil for enrichment.

Topics: captive breeding; soils or geology; sensitive/rare wildlife

\section{Schmalz, J.M., Wachocki, B., Wright, M., Zeveloff, S.I., and Skopec, M.M., 2014, Habitat selection by the pygmy rabbit (Brachylagus idahoensis) in northeastern Utah: Western North American Naturalist, v. 74, no. 4, p. 456-466.}

DOI: https://doi.org/10.3398/064.074.0411

Background: Pygmy rabbits are sagebrush dependent and considered a keystone species in sagebrush steppe ecosystems. Pygmy rabbit populations are declining because of habitat loss due to fragmentation, agricultural conversion, and other land use changes. Understanding habitat selection of pygmy rabbits can help inform management planning to support pygmy rabbit conservation.

Objectives: The authors sought to study pygmy rabbit (1) habitat use, (2) selection of burrow sites, and (3) seasonal sagebrush consumption.

Methods: Researchers surveyed the study site in spring and summer of 2010 along nine transects to record active, recently active, and very old burrow sites. They identified active and recently active burrow sites by observing fecal pellets. They took sagebrush measurements at 40 active and 40 unoccupied sites $50 \mathrm{~m}$ south of active burrows. In spring, summer, and fall of 2011 , they took understory vegetation and soil measurements at active, recently abandoned, and potential burrow sites. They also analyzed fecal pellets collected in spring through winter 2011 for vegetation preferences. In December 2010, they took samples of foraged and non-foraged sagebrush to measure herbivore-deterring compounds and perform other nutrient analyses. 


\section{Location: Utah}

Findings: The authors found that sagebrush at active burrow sites was generally taller with wider crowns than sagebrush at potential burrow sites. They found that grass biomass was higher at active burrows than potential burrows in the spring. They found no differences in soil at active, recently abandoned, or potential burrow sites with the soil at all sites being predominantly sand (70 to 73 percent). The researchers found sagebrush was important in pygmy rabbit diets, varying seasonally from a low of 53.6 percent of their diet during the summer to a high of 99.1 percent of their diet in winter. Forbs made up the smallest part of pygmy rabbit diets. They found there was no difference in the concentration of herbivore-deterring compounds between foraged and non-foraged sagebrush, but foraged sagebrush had higher crude protein and lower fiber levels.

Implications: The authors suggest that maintaining large and mature sagebrush is important for pygmy rabbit survival due to their heavy dependence on sagebrush for diet and cover. They also recommend maintaining grass near pygmy rabbit burrows during the summer because low understory biomass may lead to burrow abandonment.

Topics: site-scale habitat characteristics; habitat selection; sensitive/rare wildlife

\section{Schmitt, D.N., Madsen, D.B., and Lupo, K.D., 2002, Small-mammal data on early and middle Holocene climates and biotic communities in the Bonneville Basin, USA: Quaternary Research, v. 58, no. 3, p. 255-260.}

DOI: https://doi.org/10.1006/qres.2002.2373

Background: A recent excavation of Homestead Cave in the northern Great Basin provided evidence that the early Holocene in that region was cooler and moister than it is today, and that a climactic shift in the mid-Holocene led to the extinction or extirpation of several small mammal species. Excavating Camels Back Cave to compare findings to the Homestead Cave excavation will provide additional information about the paleoecology of the Great Basin.

Objectives: The authors sought to (1) identify the small mammal remains in a cave dating from the end of the Pleistocene to the mid-Holocene and (2) compare their findings to those from another excavation in the northern Great Basin.

Methods: The authors excavated faunal deposits from Camels Back Cave between 1996 to 1998 and then used a mesh sieve to isolate small mammal remains. The authors assigned remains to nine radiocarbon age groups and attempted to identify specimens to the genus or species level when possible.

Location: Utah

Findings: The authors found small mammal deposits dating back 12,000 to 5,000 years B.P. The authors found signs indicating that most of the specimens were collected by non-human predators and observed many specimens that showed signs of being digested. They identified most of the more recent remains as small-mammal species currently associated with the dry, low-elevation areas of the Great Basin. The authors also identified older remains of species that are currently associated with boreal habitats and species associated with mesic, low-elevation grassland or sagebrush habitat including pygmy rabbits, Great Basin pocket mice, sagebrush voles, and western harvest mice. They observed a decline in species richness between 8,600 to 8,100 years B.P., except for kangaroo rats and ground squirrels whose remains became more common. The authors state that their findings were similar to the excavation in the northern part of the Great Basin.

Implications: The authors indicate that the presence of pygmy rabbit remains are evidence that the area once had more vegetative cover including sagebrush stands. The authors state that their findings support other studies showing evidence of a mid-Holocene desertification of the area.

Topics: other: species and population characteristics; weather and climate patterns; sensitive/rare wildlife 


\section{Shipley, L.A., Davila, T.B., Thines, N.J., and Elias, B.A., 2006, Nutritional requirements and diet choices of the pygmy rabbit (Brachylagus idahoensis)—A sagebrush specialist: Journal of Chemical Ecology, v. 32, no. 11, p. 2455-2474.}

DOI: https://doi.org/10.1007/s10886-006-9156-2

Background: Because many plant species contain low nutrient levels and toxic chemicals, most herbivores have adapted as dietary generalists to meet their nutritional needs. Pygmy rabbits are considered sagebrush obligates, but more information is needed about the nutritional requirements and diet choices of pygmy rabbits.

Objectives: To study the level of pygmy rabbit dependence on sagebrush, the authors sought to (1) determine their nutritional requirements, (2) determine how they process sagebrush toxins, and (3) compare pygmy rabbit and eastern cottontail nutritional requirements.

Methods: The authors studied two to five adult captive-born pygmy rabbits and three to four wild-caught adult cottontails between January and March 2003 to 2005. They conducted single diet digestion trials for seven different types of food pellets, greenhouse-grown sagebrush, and outdoor-grown sagebrush. During digestion trials, the authors recorded rabbit weight and collected all food scraps, urine, and feces. The authors measured daily food intake and urine $\mathrm{pH}$. They conducted nutrient analyses from the diets, feces, urine, and scraps to measure the amount of nitrogen, crude protein, and gross energy content to estimate energy requirements for pygmy rabbits. They also analyzed terpene content in the sagebrush diets. Additionally, the authors measured the voluntary consumption of both types of sagebrush and the food pellets to compare between species.

Location: Idaho, Washington

Findings: The authors found that after adjusting for body mass, pygmy rabbits have a higher digestible energy requirement than cottontails, presumably because of higher metabolic rates. Both species had relatively low dietary requirements for crude protein. Pygmy rabbits were able to meet their daily dietary requirements whereas cottontails could not. Pygmy rabbits voluntarily ate more sagebrush than cottontails. When offered higher quality food pellets, both species ate less sagebrush.

Implications: The authors claim that although pygmy rabbits are considered sagebrush obligates, sagebrush is not essential to meeting their dietary needs and consuming sagebrush is energetically costly. They suggest that the small body size of pygmy rabbits likely aids in the elimination of toxins in sagebrush. The authors speculate that there are also other behavioral or environmental conditions that resulted in pygmy rabbits becoming sagebrush obligates.

Topics: behavior or demographics; grazing/herbivory; sensitive/rare wildlife

\section{Shipley, L.A., Davis, E.M., Felicetti, L.A., McLean, S., and Forbey, J.S., 2012, Mechanisms for eliminating monoterpenes of sagebrush by specialist and generalist rabbits: Journal of Chemical Ecology, v. 38, no. 9, p. 1178-1189.}

DOI: https://doi.org/10.1007/s10886-012-0192-9

Background: Sagebrush is the primary food source for pygmy rabbits despite containing compounds that are toxic to mammals. Mammals can cope with toxic plants by avoidance, blocking absorption of toxins, and excreting toxins. The specific mechanisms that allow pygmy rabbits to consume sagebrush are unknown.

Objectives: The authors sought to determine how sagebrush specialists like pygmy rabbits and generalist species like mountain cottontails either process or block the absorption of toxic compounds found in sagebrush.

Methods: The authors trapped four pygmy rabbits and six cottontails and fed them pellets containing four levels of cineole (one of the toxic compounds in sagebrush). The authors recorded the levels of cineole in the food that was consumed or refused. They measured each rabbit's cineole intake and excretion of cineole metabolites through chemical analysis of urine and feces. They measured glucuronic acid production and energy content from urine samples. The authors compared pygmy rabbit and cottontail cineole consumption and excretion.

Location: Idaho, Washington 
Findings: Two rabbits were removed from the study due to excessive weight loss. After adjusting for body mass, the authors found that pygmy rabbits voluntarily consumed two to four times more cineole than cottontails. The amount of cineole metabolites excreted in the urine increased with consumption for both species. The authors observed that pygmy rabbits had higher cineole metabolite levels in their urine than cottontails that consumed the same amount of cineole. The authors found high concentrations of cineole metabolites in pygmy rabbit feces and detected no cineole in cottontail feces.

Implications: The authors identified several strategies used by pygmy rabbits that allow them to consume sagebrush toxins, which include quickly detoxifying them in the liver and eliminating them in the urine. The authors suggest that pygmy rabbits can specialize on sagebrush because they are able to eliminate toxins more rapidly and with less energy costs than a similar generalist, the mountain cottontail. The authors hypothesize that the benefits of specializing on sagebrush somehow outweigh the energetic cost of consuming toxins for pygmy rabbits.

Topics: behavior or demographics; habitat selection; grazing/herbivory; sensitive/rare wildlife

\section{Simons, E.M., and Laundré, J.W., 2004, A large-scale regional assessment of suitable habitat for pygmy rabbits in southwestern Idaho: Northwest Science, v. 78, no. 1, p. 33-41.}

Background: Pygmy rabbit distribution is thought to be influenced by the presence of big sagebrush and the texture and depth of soil. Recent reductions of sagebrush habitat due to fires and agricultural conversion are correlated with population declines of pygmy rabbits. Large-scale spatial models can be a useful tool to predict the distribution of suitable habitat for pygmy rabbits.

Objectives: The authors sought to test the accuracy of an existing spatial model at predicting (1) habitat suitability and (2) use and non-use areas for the pygmy rabbit at a regional spatial scale.

Methods: The authors updated an existing spatial model with vegetation, soil, slope, and aspect data relevant to their area of analysis. They defined suitable pygmy rabbit habitat by the presence of big sagebrush, soil with a clay content of less than 12.5 percent, slope below 15 percent, and aspects between 0 to $120^{\circ}$ or 300 to $360^{\circ}$, and predicted the distribution of suitable and unsuitable habitat across a study area of $15,000 \mathrm{~km}^{2}$. To explore the accuracy of their modeling approach, the authors measured vegetation type, soil content, and pygmy rabbit presence or absence at 137 randomly selected sites.

Location: Idaho

Findings: The model predicted that 21 percent of the study area was suitable pygmy rabbit habitat. The authors found that the model predicted suitable habitat and unsuitable habitat with similar accuracy. The authors reported that the vegetation data was the most likely source of error in the model, and that some sites predicted to be suitable habitat were dominated by cheatgrass. The model was better at predicting areas of pygmy rabbit non-use than use.

Implications: The authors suggest that the model's lower prediction success of use areas could be caused by the overall low population density of pygmy rabbits. The authors believe that errors in their vegetation data could be from grazing effects, species interactions, and fire and recommend more research in these areas. The authors suggest that spatial models are a useful tool for identifying potential pygmy rabbit habitat but warn that the amount of suitable habitat may be overestimated.

Topics: site-scale habitat characteristics; habitat selection; soils or geology; sensitive/rare wildlife

\section{Smith, I.T., Rachlow, J.L., Svancara, L.K., McMahon, L.A., and Knetter, S.J., 2019, Habitat specialists as conservation umbrellas-Do areas managed for greater sage grouse also protect pygmy rabbits?: Ecosphere, v. 10, no. 8, article e02827, 23 p.}

DOI: https://doi.org/10.1002/ecs2.2827

Background: Sagebrush habitat is decreasing throughout the West and establishing Habitat Management Areas (HMAs) has been a primary mechanism for managing greater sage-grouse habitat. The umbrella species strategy suggests that protecting habitat for one high-profile species will also protect other species within the same habitat, such as pygmy rabbits in sage-grouse HMAs, but an evaluation of this concept is warranted. 
Objectives: The authors sought to (1) compile a comprehensive map of pygmy rabbit minimum occupied area, (2) create a range-wide species distribution model to determine indicators of suitable and primary habitat, and (3) compare pygmy rabbit occurrence and predicted habitat to sage-grouse HMAs.

Methods: The authors assembled 10,420 records of pygmy rabbit occurrence collected during 2000 or later from existing datasets. Next, the authors created a set of environmental variables (topography, soils, vegetation, climate, and fire regime) related to pygmy rabbit occupancy using existing spatial datasets and combined these variables with the mapped records of rabbit occurrence to create a species distribution model of suitable and primary habitat. Overlap between the model was compared with three sage-grouse HMAs.

Location: California, Colorado, Idaho, Montana, Nevada, Oregon, Utah, Wyoming

Findings: Records of pygmy rabbit occurrence showed that most rabbits are in the northern and eastern parts of their range. In the species distribution model, big sagebrush, slope, and elevation were the most important variables in predicting suitable and primary pygmy rabbit habitat. The authors identified four core areas of pygmy rabbit primary habitat in Wyoming, Idaho, and Nevada. Most occurrences of pygmy rabbits overlapped with the range of sage-grouse and the vast majority of predicted habitat for pygmy rabbits fell within the sage-grouse HMAs.

Implications: The authors state that this study presents the first range-wide catalog of pygmy rabbit occurrence and the first distribution model for the species, which can be used as baseline for future changes in the species' distribution. The authors conclude that greater sage-grouse may be an effective umbrella species for pygmy rabbit conservation. The authors suggest that the species distribution model can be used to target areas for future studies and to identify potential connectivity corridors.

Topics: broad-scale habitat characteristics; site-scale habitat characteristics; sensitive/rare wildlife

\section{Thimmayya, A.C., and Buskirk, S.W., 2012, Genetic connectivity and diversity of pygmy rabbits (Brachylagus idahoensis) in southern Wyoming: Journal of Mammalogy, v. 93, no. 1, p. $29-37$.}

DOI: https://doi.org/10.1644/11-MAMM-A-045.1

Background: Habitat connectivity can impact genetic connectivity, especially in habitat specialist species, such as the pygmy rabbit. Genetic diversity of pygmy rabbits tends to be lower in areas where physical barriers or distance lead to increased population isolation. The genetic diversity and connectivity of Wyoming pygmy rabbit populations has not been described.

Objectives: The authors sought to examine the degree of gene flow between groups of pygmy rabbits in order to (1) make inferences about whether the seemingly patchy nature of suitable habitat for this sagebrush specialist led to genetic differences in geographically isolated populations and (2) compare genetic variability between geographic groups of pygmy rabbits and sympatric generalist cottontail species.

Methods: The authors trapped and took tissue samples from the ears of 52 pygmy rabbits and 40 cottontails at a total of 9 sites. Using standard genetic techniques, the authors analyzed genetic diversity and assessed the relationship between diversity estimates and the degree of isolation due to distance and barriers.

Location: Wyoming

Findings: Genetic connectivity of pygmy rabbits and cottontails was similar, but pygmy rabbits showed a stronger isolation-by-distance effect than cottontails. Pygmy rabbits in Wyoming were less genetically diverse than populations in other parts of their range, but overall, the results suggest that gene flow is occurring among the populations in the state. The separation of two populations by a major highway caused slight genetic differentiation.

Implications: The authors state the observed genetic connectivity of pygmy rabbit populations in Wyoming could be the result of historic habitat connectivity and does not necessarily mean gene flow is still occurring. They also suggest that pygmy rabbits in Wyoming may be more adapted to dispersal across patchy habitats, which could promote connectivity. The authors suggest that there is some evidence that pygmy rabbits in Wyoming have become isolated from populations outside of the state, and that managers should ensure pygmy rabbit habitat remains connected.

Topics: genetics; effect distances or spatial scale; infrastructure; sensitive/rare wildlife 


\title{
Thines, N.J.S., Shipley, L.A., and Sayler, R.D., 2004, Effects of cattle grazing on ecology and habitat of Columbia Basin pygmy rabbits (Brachylagus idahoensis): Biological Conservation, v. 119, p. 525-534.
}

\author{
DOI: https://doi.org/10.1016/j.biocon.2004.01.014
}

Background: Degradation and loss of sagebrush habitat has caused decline of the endangered Columbia Basin pygmy rabbit population. While the effects are not fully understood, cattle grazing is common in pygmy rabbit sagebrush habitat and has the potential to influence sagebrush and cover of forbs and grasses.

Objectives: The authors sought to investigate the effects of grazing on pygmy rabbit (1) burrow use, (2) diet makeup, (3) food quality, and (4) habitat characteristics.

Methods: The authors performed biweekly surveys within two grazed and two ungrazed units to locate pygmy rabbit burrows and record activity from July to September 2000. To determine diet, they collected and dissected pygmy rabbit pellets from August to December 2000. In June and December 2000 and March 2001, they collected vegetation samples from 10 plots to determine crude protein and fiber content. To compare habitat between grazed and ungrazed units, they sampled vegetation at 103 plots during June 1996 and 2000. Finally, the authors used spatial tools to determine aspect, slope, and soil characteristics within units.

\section{Location: Washington}

Findings: Pygmy rabbits constructed and used burrows in ungrazed units more than grazed units. Pygmy rabbits primarily ate grasses and forbs in the summer and sagebrush in winter. Diet was similar across all units. Protein content was highest in the spring and summer for grasses and sagebrush, respectively. Forage quality was similar across all units in the summer before grazing. After grazing, grasses decreased in availability within grazed units and remaining grasses had more fiber and less protein. Mature sagebrush increased throughout the study in all units but was the densest in grazed units. Spatial analysis showed grazed and ungrazed areas differed in soil types and indicated pygmy rabbits used southwest aspects disproportionate to availability.

Implications: The authors state that their study area did not appear permanently altered by cattle, despite 100 years of grazing. However, they suggest livestock grazing may not be compatible with pygmy rabbit conservation due to decreased quality and quantity of grasses in units after grazing and pygmy rabbit preference for ungrazed sites. They conclude by stating maintaining healthy sagebrush habitat is essential for pygmy rabbit conservation.

Topics: site-scale habitat characteristics; habitat selection; grazing/herbivory; sensitive/rare wildlife

\section{Thines, N.J., Shipley, L.A., Bassman, J.H., Fellman, J.K., Mattison, D.S., Slusser, J.R., and Gao, W., 2007, Effects of enhanced UV-B radiation on plant chemistry-Nutritional consequences for a specialist and generalist lagomorph: Journal of Chemical Ecology,} v. 33, p. 1025-1039.

DOI: https://doi.org/10.1007/s10886-007-9280-7

Background: Ozone depletion causes higher amounts of solar radiation on earth, which may change the chemical and molecular makeup of plants. These changes can impact herbivores, because plants may become less nutritious and more toxic. Specialist species, such as pygmy rabbits, and generalist species, such as eastern cottontails, may react to these changes differently; however, mammalian response to changes in plant chemical makeup due to increased radiation had not previously been studied.

Objectives: The authors sought to examine how increased solar radiation affects the (1) chemical makeup, (2) nutritional quality of three plant species, and (3) quantify how a specialist and generalist mammal respond these changes in both preference and digestibility. 
Methods: The researchers grew big sagebrush, yarrow, and bluebunch wheatgrass from winter to summer 2004. The authors exposed plants to two different 12-week long solar radiation treatments, normal radiation levels and higher radiation levels that simulated ozone depletion. They took samples from both treatments and analyzed their chemical makeup and nutritional quality. Next, they fed plants from both treatments to six pygmy rabbits and four eastern cottontails and analyzed diet preference by measuring how much of each treatment was eaten. They also measured digestibility by feeding plants from both treatments separately and testing urine and fecal samples.

Location: Idaho, Washington

Findings: Solar radiation caused two chemical compound types to decrease in yarrow, while increasing one of these compound types in sagebrush and slightly increasing the same compound type in bluebunch wheatgrass. Radiation changed the nutritional quality of sagebrush, slightly decreasing two different quality measures. There was no difference in preference or digestibility between treatments in either rabbit species, although cottontails digested yarrow and wheatgrass better than pygmy rabbits

Implications: The authors found that increased solar radiation influenced one plant compound type. They suggest that increases in this compound can lower plant protein, although this was not observed in this study. The authors suggest that the chemical changes to plants may have been too slight and inconsistent for rabbits to notice. The authors state the chemical variation caused by increased radiation may be comparable to chemical changes that occur seasonally in nature.

Topics: behavior and demographics; grazing/herbivory; sensitive/rare wildlife

\section{Torstrom, S.H., Adams, J.R., and Waits L.P., 2013, Detecting pygmy rabbits (Brachylagus idahoensis) using DNA extracted from fecal pellets of mixed-species groups: Wildlife Society Bulletin, v. 37, no. 3, p. 603-607.}

DOI: https://doi.org/10.1002/wsb.294

Background: Noninvasive genetic sampling can aid researchers when studying endangered wildlife. Genetic sampling through fecal pellets can be used to survey pygmy rabbits, however, it can be difficult to differentiate their pellets from other rabbit species and it can be expensive to run large numbers of samples. Pooling samples can decrease costs, but may increase the risk of combining multiple species' pellets into one sample, creating the need to differentiate and identify species within samples.

Objectives: The authors sought to (1) evaluate an established genetic method in its ability to detect pygmy rabbit pellets when mixed with eastern cottontail pellets at different proportions, (2) evaluate if the ability to detect pygmy rabbits differs when pellets are mixed with eastern cottontails versus mountain cottontails, and (3) evaluate alternative genetic protocols to determine if pygmy rabbit detection rates can be increased in mixed samples.

Methods: The authors collected pellets from captive pygmy, eastern cottontail, and mountain cottontail rabbits during February, March, and November 2011. To test the accuracy of the established genetic protocol, the authors mixed pygmy rabbit pellets with eastern cottontail pellets at 3 different ratios with 20 samples each. To test 2 alternative genetic protocols, the authors mixed pygmy rabbit pellets with eastern and mountain cottontail pellets at an equal 1:1 ratio with 20 samples each.

Location: Washington

Findings: The established genetic method was more likely to amplify eastern cottontail DNA and detected pygmy rabbits in only a small number of samples. In contrast, both alternative genetic protocols were significantly more likely to detect pygmy rabbits, with pygmy rabbits being detected in 80 to 95 percent of samples. The ability to detect pygmy rabbits was the same whether they were mixed with eastern or mountain cottontail pellets.

Implications: When pooling samples, the authors recommend using at least four pellets from each pellet pile, including at least eight pellets in each sample, and using their alternative pygmy rabbit specific genetic protocol. The authors state that although the method is not perfect, pooling samples can be effective at detecting and differentiating rabbit species, while also cutting costs.

Topics: population estimates or targets; genetics; sensitive/rare wildlife 


\title{
Ulappa, A.C., Kelsey, R.G., Frye, G.G., Rachlow, J.L., Shipley, L.A., Bond, L., Pu, X., and Foreby, J.S., 2014, Plant protein and secondary metabolites influence diet selection in a mammalian specialist herbivore: Journal of Mammalogy, v. 95, no. 4, p. 834-842.
}

\author{
DOI: https://doi.org/10.1644/14-MAMM-A-025
}

Background: Herbivores forage based on how they can maximize nutrition and minimize energy and selecting plants low in toxicity or high in protein may increase efficiency. When herbivores forage in one area continuously, plants may respond by increasing their toxicity. While they are tolerant of the toxins in sagebrush, it is unclear how sagebrush toxins impact pygmy rabbit foraging patterns or selection.

Objectives: The authors sought to (1) determine if protein content and toxins in sagebrush influence pygmy rabbit foraging, and (2) examine if long term foraging from pygmy rabbits alters sagebrush chemistry.

Methods: From October to November 2009, the authors identified occupied pygmy rabbit burrows at two different sites and recorded length of occupancy at one of the sites. The authors collected samples of browsed and unbrowsed sagebrush at both sites and measured protein content and toxin type and amount. The authors determined whether protein or toxicity affected browse status and analyzed whether length of occupancy at burrow systems affected plant toxicity or protein content using statistical models.

Location: Idaho

Findings: Pygmy rabbits responded positively to protein and were more likely to consume sagebrush with higher protein content at both sites. Pygmy rabbits had a negative response to plant toxins and avoided higher toxicity sagebrush at one of the sites, while at the other site, pygmy rabbits did not respond to plant toxicity. The duration of occupation at burrow systems did not affect sagebrush protein content or toxicity.

Implications: The authors suggest protein content and plant toxicity influence pygmy rabbit browsing and state that this study provides information about how forage quality influences the diet of specialist herbivores. The authors recommend land managers consider forage quality when making determinations about habitat use and land conservation for specialist herbivores. They also suggest that scaling up forage selection to the landscape, rather than individual plant, scale is important for habitat conservation and restoration.

Topics: behavior or demographics; site-scale habitat characteristics; habitat selection; grazing/herbivory; sensitive/rare wildlife

\section{Utz, J.L., Shipley, L.A., Rachlow, J.L., Johnstone-Yellin, T., Camp, M., and Forbey, J.S., 2016, Understanding tradeoffs between food and predation risks in a specialist mammalian herbivore: Wildlife Biology, v. 22, no. 4, p. 167-173.}

DOI: https://doi.org/10.2981/wlb.00121

Background: Herbivores make trade-offs when choosing where to forage, considering factors that include perceived predation risk and potential exposure to toxic plants. Species with diets specialized towards toxic plants, such as the sagebrush specialist pygmy rabbit, may make these trade-offs differently than generalist species. In addition to varying levels of toxicity, cover from predation risk provided by sagebrush also varies from plant to plant. However, research into trade-offs between toxicity and predation risk have primarily focused on generalist species and have not been studied in a dietary specialist.

Objectives: The authors objectives were to determine how pygmy rabbits respond to (1) risk of plant toxicity, (2) risk of predation, and (3) how they make trade-offs between the two.

Methods: The authors conducted 3 experiments on 10 pygmy rabbits captured during summer and fall 2010. During December 2010 and February 2011, the authors studied food risk by providing pygmy rabbits with two identical feeding stations, one with toxin-free food and the other containing 5 percent sagebrush toxin. From October to November 2010, the authors performed a predation risk experiment by placing toxin-free food under dark or transparent shelters to simulate low and high predation risk. From November 2010 to January 2011, the authors conducted a risk trade-off experiment by placing toxin-free food under the transparent shelters and food containing toxins under the darkened shelters. 
Location: Idaho

Findings: Pygmy rabbits ate more non-toxic food than toxic. Pygmy rabbits ate more food out of dark shelters than transparent shelters. The results for the risk trade-off trial were inconclusive, with individual pygmy rabbits taking starkly different approaches to perceived risks.

Implications: The authors propose that the sample of pygmy rabbits perceived the threat of dietary toxicity and the threat of predation similarly during the control trials. However, they suggest the inconclusive tradeoff results highlight the importance of preserving pygmy rabbit habitat that accommodates a breadth of individual risk thresholds. They suggest that integrating these risks at different spatial scales and population sizes may support the conservation and management of the species. The authors also state their research shows that concentrations of toxic plant compounds and shrub cover can be used to determine habitat suitability for pygmy rabbits.

Topics: behavior or demographics; site-scale habitat characteristics; habitat selection; predators or predator control; sensitive/ rare wildlife

\title{
Wilson, T.L., Odei, J.B., Hooten, M.B., and Edwards, T.C., Jr., 2010, Hierarchical spatial models for predicting pygmy rabbit distribution and relative abundance: Journal of Applied Ecology, v. 47, p. 401-409.
}

\author{
DOI: https://doi.org/10.1111/j.1365-2664.2009.01766.x
}

Background: Spatial models that predict species distribution can be an important tool when managing wildlife. However, biases in distribution data and flawed detection can lead to inaccurate models, especially when modeling secretive species like pygmy rabbits. Combining different indirect measures of presence, such as burrows and fecal pellets, may be used to create more accurate spatial models.

Objectives: The authors sought to create hierarchical spatial models that use indirect measures of presence to determine (1) pygmy rabbit distribution and (2) relative abundance.

Methods: The authors conducted distance sampling at 38 sites within pygmy rabbit habitat. They walked transects and counted the number of burrows that could be seen from the transect line. When a burrow was detected, the authors documented presence or absence of pygmy rabbit pellets at the burrow entrance. The authors then measured slope, aspect, distance to water, and vegetation characteristics using spatial data, and included these variables in a spatially explicit model with two levels of interest: (1) all burrows expected to be on the landscape (burrow intensity) and (2) burrows expected to be used by pygmy rabbits (burrow utilization). The authors then used their models to predict maps of pygmy rabbit burrow intensity and utilization.

\section{Location: Utah}

Findings: Higher pygmy rabbit burrow abundance was predicted on slopes and within valleys at the center of the study area while lower abundance was predicted near agricultural areas. Burrow intensity was predicted to be positively associated with slope and an aspect measurement suggestive of higher soil moisture. Burrow utilization was predicted to be positively associated with an aspect measurement suggestive of higher soil and snow deposition and satellite imagery depicting a visual signature of sagebrush. Both burrow intensity and utilization were negatively associated with riparian areas and agriculture fields.

Implications: The authors believe that accounting for hierarchical indirect measures of presence creates more accurate spatial models, especially when modelling distribution and relative abundance of secretive species. The authors suggest that this framework could help improve ecological analyses and might provide important information for conservation and management.

Topics: population estimates or targets; site-scale habitat characteristics; habitat selection; effect distances or spatial scale; agriculture; soils or geology; wetlands/riparian; sensitive/rare wildlife 


\section{Wilson, T.L., Howe, F.P., and Edwards, T.C., Jr., 2011, Effects of sagebrush treatments on multi-scale resource selection by pygmy rabbits: Journal of Wildlife Management, v. 75,} no. 2, p. 393-398.

DOI: https://doi.org/10.1002/jwmg.51

Background: Treatments on sagebrush rangelands often reduce shrub cover and promote herbaceous vegetation that is thought to be beneficial for cattle and big game species. However, these treatments may negatively impact sagebrush-dependent species like the pygmy rabbit that rely on sagebrush for year-round forage and cover.

Objectives: The authors sought to (1) examine the effects of sagebrush treatments on pygmy rabbit habitat selection and (2) evaluate the movement behavior of pygmy rabbits at treatment edges.

Methods: The authors captured eight pygmy rabbits in spring 2008, fitted them with radio transmitters, and tracked them from May 2008 to April 2009. They estimated home ranges and recorded weekly telemetry point locations of collared rabbits. The authors then used null models to evaluate these data for behavior suggesting avoidance of sagebrush treatments at two different scales. During winter 2006 and 2007 they used fresh tracks in the snow to explore pygmy rabbit response to treatment edges.

Location: Utah

Findings: Sagebrush treatments did not appear to impact the location of pygmy rabbit home ranges. Of the eight collared pygmy rabbits, two that occurred closest to the sagebrush treatments appeared to avoid these areas when compared to random null locations. Winter track surveys also suggested that pygmy rabbits avoided entering treatment areas.

Implications: The authors suggest that modern sagebrush management techniques that avoid systematic conversion over a large area may have less impact on pygmy rabbit populations. To reduce potential impacts on pygmy rabbits, the authors recommend using islands of small, narrow, and widely spaced treatment areas within larger swaths of intact sagebrush.

Topics: behavior or demographics; habitat selection; habitat restoration or reclamation; sagebrush removal; sensitive/ rare wildlife

\section{Wilson, T.L., Rayburn, A.P., and Edwards, T.C., Jr., 2012, Spatial ecology of refuge selection by an herbivore under risk of predation: Ecosphere, v. 3, no. 1, p. 1-18.}

DOI: https://doi.org/10.1890/ES11-00247.1

Background: Many prey species use burrows to escape from predators, the spatial arrangement of which may result in trade-offs between safety and dietary needs. Pygmy rabbits dig their own burrows and use them to escape from predators. Past studies have documented associations with burrows and vegetation; however, pygmy rabbit burrow selection is poorly understood.

Objectives: The authors sought to examine burrow selection and the arrangement of refuges used by prey by (1) examining pygmy rabbit burrow use in relation to burrow availability, and (2) determining if vegetation cover impacted pygmy rabbit burrow use.

Methods: The authors searched for and recorded the location and use of all pygmy rabbit burrows within four sites with known pygmy rabbit occupancy. They used a model to measure the density and clustering of burrows with and without pygmy rabbit use as determined by fecal pellets. They measured vegetation and burrow density factors at a random selection of the burrows. The authors used the measured factors to determine burrow distribution, burrow use versus availability, and determined how vegetation and distribution impacted burrow use.

Location: Utah 
Findings: The authors found a clustered burrow pattern at small spatial scales and randomly or regularly distributed pattern at larger scales. At three sites, burrow use was higher in areas where burrows were clustered. The top models exploring the probability of use as a function of burrow intensity and plant cover broken into overstory (cover) and understory (forage) suggested that burrow density and overstory cover were important for predicting pygmy rabbit use of burrows. Three sites showed significant interaction effects that suggested rabbits would use sites with low burrow intensity or overstory cover if the cover of understory forage plants was high.

Implications: The authors suggest that clustered spatial arrangements of burrows may reduce predation risk but, in some instances, pygmy rabbits may make trade-offs between the safety of high burrow density in favor of greater amounts of understory forage availability. The authors' research quantifies the spatial scale where trade-offs between predator avoidance and foraging ability occurs. However, they suggest further research is needed to determine how prey use their environment at different spatial scales in relation to potential trade-offs between refuge structures and food availability.

Topics: site-scale habitat characteristic; habitat selection; effect distances or spatial scale; predators or predator control; sensitive/rare wildlife

\section{Woods, B.A., Rachlow, J.L., Bunting, S.C., Johnson, T.R., and Bocking, K., 2013, Managing high-elevation sagebrush steppe-Do conifer encroachment and prescribed fire affect habitat for pygmy rabbits?: Rangeland Ecology and Management, v. 66, no. 4, p. 462-471.}

DOI: https://doi.org/10.2111/REM-D-12-00144.1

Background: Disruption of historic fire regimes in sagebrush steppe has reduced the frequency of fire and caused conifer encroachment at high elevations. Prescribed burns are used by managers to reduce conifer growth. However, both increasing conifer levels and prescribed burns may affect pygmy rabbits by impacting food supply and their ability to detect and avoid predators.

Objectives: The authors sought to determine how increasing conifer cover and prescribed burns affect pygmy rabbit (1) concealment, (2) visibility, and (3) food supply.

Methods: The authors selected 10 historic prescribed burns ranging from 6 to 32 years post-fire. During May to August 2011, they placed five $30 \times 30 \mathrm{~m}$ plots at each burn — one plot inside the burn perimeter, three plots within progressively denser conifer cover, and one reference plot in unburned sagebrush steppe with no conifer cover. The authors quantified concealment and visibility from aerial and terrestrial predators and measured canopy cover of sagebrush and conifers. They assessed vegetation composition and collected samples to quantify forage biomass. Finally, they performed laboratory analyses on fecal pellets to assess diet composition.

Location: Idaho, Montana

Findings: Sites with the highest conifer cover provided less concealment from terrestrial predators, while providing increased visibility of the surrounding area. Concealment from terrestrial predators increased, while visibility of surrounding habitat decreased with post-burn time. The highest conifer cover sites also had reduced availability of forage including sagebrush, grasses, and forbs. Sagebrush cover was lower in plots of more recent burns, while grass cover was higher. It took 13 to 27 years after the prescribed burn for plots to yield cover and forage levels like those found in reference plots.

Implications: The authors state that while encroaching conifers will cause areas to become unsuitable for pygmy rabbits in the long term, loss of sagebrush from prescribed burns used to control conifer growth would cause areas to become unsuitable in the short term. The authors suggest that managers investigate other methods and consider several different variables when deciding how to control conifer encroachment.

Topics: site-scale habitat characteristics; habitat restoration or reclamation; fire; sagebrush removal; conifer expansion; sensitive/rare wildlife 


\section{Zeoli, L.F., Sayler, R.D., and Wielgus, R., 2008, Population viability analysis for captive breeding and reintroduction of the endangered Columbia basin pygmy rabbit: Animal Conservation, v. 11, p. 504-512.}

DOI: https://doi.org/10.1111/j.1469-1795.2008.00208.x

Background: Captive breeding can help conserve endangered species, such as the Columbia Basin pygmy rabbit, a distinct population which has been extirpated from the wild. However, captive breeding is difficult and for species with short life spans, it can be challenging to sustain a captive population that can sufficiently maintain wild populations.

Objectives: The authors sought to examine the growth and stability of the captive breeding population to support reintroduction efforts using two different types of population modeling.

Methods: The authors created two models using data collected from captive pygmy rabbit populations housed in three facilities from 2003 to 2007. In both models, the authors started with a population of 75 rabbits. Examining rabbit population growth in the captive breeding model, they established 4 different age classes and ran a 10-year model where extinction was considered inevitable if the population dropped below 30 rabbits. Examining the stability of the rabbit population in the harvest model, they removed 30 rabbits each year for 6 years and used these data in model manipulations to investigate the effects of survival, maternity, and population size on risk of extinction and ability to sustain a breeding population.

\section{Location: Washington}

Findings: The modeled growth rate of the captive pygmy rabbit population was positive, but highly variable. The population was largely made up of juveniles, with both adults and juveniles having low survival rates. In the authors' model simulations, removing 30 rabbits each year from the captive population for reintroduction efforts led to probable extinction of the captive colony, while harvesting only surplus rabbits would have been insufficient in sustaining wild populations. In models of survival, maternity, and population size, the only scenarios that supported a sufficiently large captive population were an increase in juvenile survival, increase in maternity, or an increased juvenile survival while doubling the population size.

Implications: The authors recommend focusing on several factors to stabilize captive pygmy rabbit populations including increasing maternity, adult survival, and juvenile survival. The authors suggest that for captive pygmy rabbit populations to remain sustainable and allow for supplementation of wild populations, captive populations must quickly and efficiently increase in size.

Topics: survival; population estimates or targets; captive breeding; sensitive/rare wildlife 

Publishing support provided by the Science Publishing Network Denver Publishing Service Center

For more information concerning the research in this report, contact the

Center Director, USGS Fort Collins Science Center

2150 Centre Ave., Bldg. C

Fort Collins, CO 80526-8118

(970) 226-9100

Or visit the Fort Collins Science Center website at: https://www.usgs.gov/centers/fort 


\section{$\frac{\mathbb{2}}{3}$}

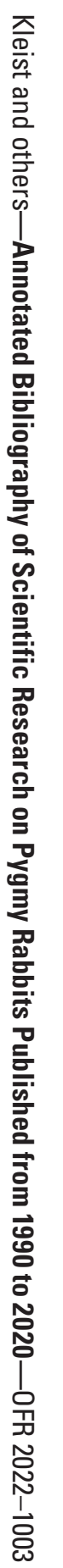

